UCRL-ID-131007

\title{
Thermal-Hydrological Models
}

\author{
Thomas A. Buscheck
}

April 29, 1998

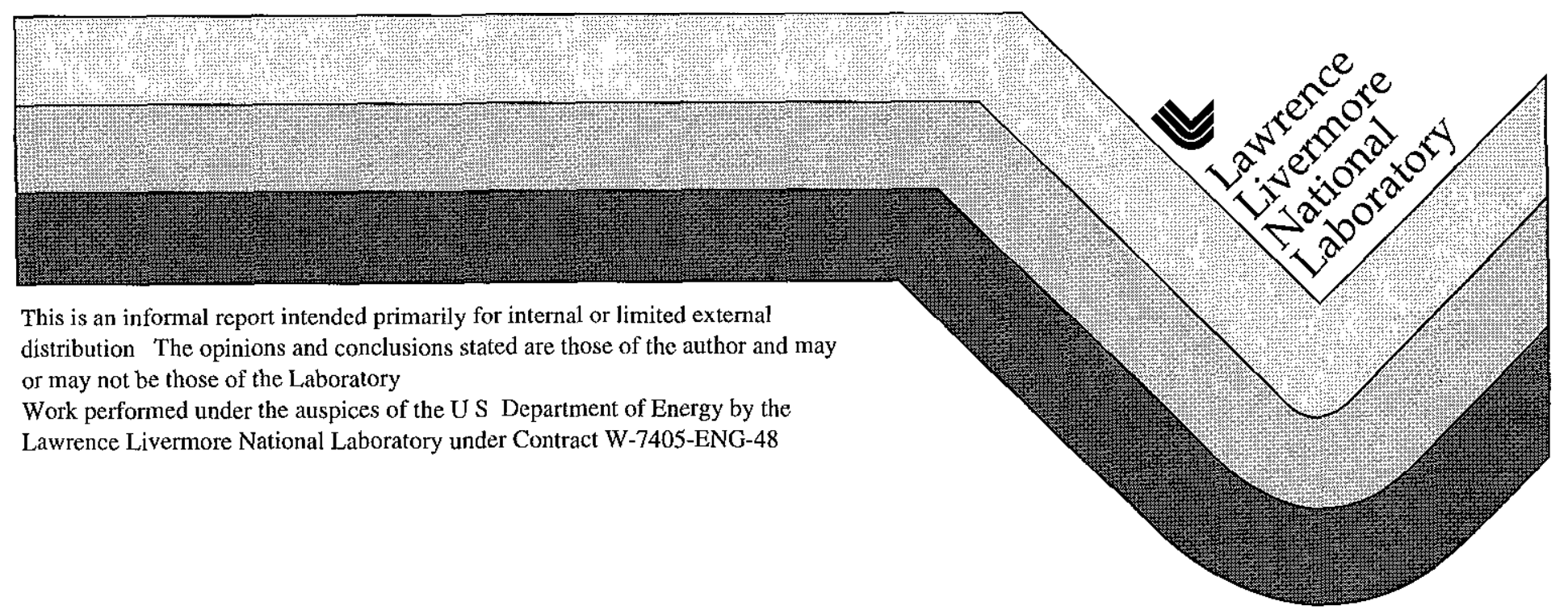




\section{DISCLAMER}

This document was prepared as an account of work sponsored by an agency of the United States Govermment Neither the United States Government nor the University of California nor any of their employees, makes any warranty, express or implied, or assumes any legal liability or responsibility for the accuracy, completeness, or usefulness of any information, apparatus, product, or process disclosed, or represents that its use would not infringe privately owned rights Reference herein to any specific commercial product, process, or service by trade name, trademark, manufacturer, or otherwise, does not necessarily constitute or imply its endorsement, recommendation, or favoring by the United States Government or the University of Califorria The views and opinions of authors expressed herein do not necessarily state or reflect those of the United States Government or the University of Califomia, and shall not be used for advertising or product endorsement purposes

This report has been reproduced directly from the best available copy

Available to DOE and DOE contractors from the Office of Scientific and Technical Information PO Box 62, Oak Ridge, TN 37831

Prices available from (423) 576-8401

Available to the public from the National Technical Information Service

US Department of Commerce 5285 Port Roval Rd. Springfield VA 22161 


\title{
Thermal-Hydrological Models
}

\author{
by Thomas A. Buscheck
}

April 29, 1998

Milestone SPLX5AM4 


\section{Thermal-Hydrological (T-H) Models}

\section{Significance of Thermal Hydrology at Yucca Mountain}

This chapter describes the physical processes and natural and engineered system conditions that affect thermal-hydrological $(\mathrm{T}-\mathrm{H})$ behavior in the unsaturated zone (UZ) at Yucca Mountain and how these effects are represented in mathematical and numerical models that are used to predict $\mathrm{T}-\mathrm{H}$ conditions in the near field, altered zone, engineered barrier system (EBS), and on waste package (WP) surfaces. Before considering the details of these processes and models, it is useful to review, in a broad sense, the principal reasons why thermal hydrology must be adequately understood and modeled to assess the adequacy of engineered nuclear waste containment and isolation at Yucca Mountain. The key concerns are:

- Seepage into emplacement drifts. The radioactive heat of decay from WPs mobilizes vapor and condensate flow, causing the liquid-phase flux to be much greater than the ambient percolation flux for 100-1000 yr and greater than ambient for at least 5000 yr. Thus, decay-heat-mobilized liquid-phase flux will play a dominant role on seepage into drifts and radionuclide transport (if any) in the EBS and natural system for at least $5000 \mathrm{yr}$.

- Rock dryout and relative humidity reduction on WPs. Decay heat causes dryout and reduces relative humidity $R H$ in the near field, EBS, and on WPs. Ambient conditions in the UZ are extremely humid $(R H \approx 99 \%)$. Depending on WP and drift spacing, decay heat reduces $R H$ on WPs for thousands of years; for tens of thousands of years if an engineered backfill is used.

- Near-field, EBS, and WP temperatures. Depending on what is learned from in situ thermal tests, $\mathrm{T}-\mathrm{H}$ processes may either increase or decrease the efficiency of heat flow away from emplacement drifts. If advective heat-flow processes, such as heat pipes and gas-phase buoyancy, are found to be important, nearfield and WP temperatures would be much lower than if thermal conduction were the dominant mode of heat flow. On the other hand, rock dryout will reduce the thermal conductivity of the near-field rock, causing near-field and WP temperatures to be much higher than if dryout did not occur.

- Alteration of hydrological properties. T-H flow processes can cause thermalchemical (T-C) and thermal-mechanical (T-M) effects that will permanently alter the hydrological properties of the natural system that may significantly influence seepage into drifts and radionuclide transport in the EBS and natural system both during and long after the period of decay-heat-dominated T-H flow behavior.

These key concerns will strongly influence the ability of the EBS to safely contain radionuclides, as well as the transport of any radionuclides released from the EBS. In particular, the integrity of WPs, dissolution of the waste form, and the release and transport of radionuclides are all strongly dependent on these key concerns. 


\section{Key Processes and Conditions Affecting T-H Behavior}

\subsection{Overview of Important Processes and Conditions}

The potential repository is located in the unsaturated zone (UZ), approximately midway between the ground surface and the water table. The UZ consists of fractured, porous rock with the pores of the rock matrix being partially filled with liquid water and partially filled with a mixture of air and water vapor. At the potential repository horizon, the matrix rock pores are approximately $90 \%$ filled by liquid water. Fractures at Yucca Mountain play a key role in the movement of water, air, and water vapor. Because the rock matrix generally has a low permeability, particularly in the repository host-rock units (Tptpmn, Tptpll, and Tptplnl in Table 1), fractures are the primary conduits for large-scale transport of water, air, and water vapor. Under ambient conditions, liquid-phase fracture flow arises as a result of the percolation of rainfall and snowmelt. The in situ pore fluids (air, water, and water vapor) will respond significantly to decay heat generated by the emplacement of WPs in the repository; this response is called thermal-hydrological (T-H) behavior. The decay-heat-driven transport of water and water vapor away from the heat source causes a redistribution of the pore fluids, including:

- Dryout zones, which are the regions of decreased liquid-phase saturation $S_{\text {liq }}$ (relative to ambient) that occur around the emplacement drifts. The relative humidity $R H$ in the dryout zone is less than ambient; correspondingly, the magnitude of suction potential is much greater than ambient. The vertical extent of the dryout zone increases with (1) local decay-heat flux, (2) distance from the repository edge, and (3) decreasing percolation flux $q_{\text {perc. }}$ For locations away from the repository edge and for low $q_{\text {perc }}(<5 \mathrm{~mm} / \mathrm{yr})$, the vertical extent of dryout increases with repository depth below the ground surface.

- Condensation zones, which are the regions of increased $S_{\text {liq }}$ that generally surround the dryout zones.

- Reduced gas-phase, air-mass-fraction zone. The generation of steam will displace air away from the boiling zone, causing a large reduction in the gasphase air-mass fraction $X_{\text {airgas }}$ (to near zero). This process will occur regardless of whether rock dryout out occurs.

Decay heat flows away from the drifts by conductive and advective (also called convective) heat-transfer processes. For heat convection, latent-heat transport is much more important than sensible-heat transport; consequently the flow of water vapor results in much greater heat transport than does liquid-phase flow. The primary mechanisms for gas-phase, advective heat transfer are:

- Heat pipes that result from countercurrent vapor (away from the heat source) and condensate flow (back towards the heat source). Because this mechanism requires gravity-driven condensate flow, it will primarily occur in fracture pathways that are well connected vertically. Heat-pipe development is 
strongly affected by ambient percolation flux $q_{\text {perci }}$ high $q_{\text {perc }}(>10 \mathrm{~mm} / \mathrm{yr}$ ) suppresses rock dryout and increases the tendency for heat pipes to form in the vicinity of drifts, while low $q_{\text {perc }}(<5 \mathrm{~mm} / \mathrm{yr})$ favors rock dryout and suppresses heat-pipe development near the drifts.

- Buoyant gas-phase convection that results from mass-density gradients that arise from temperature gradients in the rock mass. This mechanism is significant if the rock-mass bulk permeability $k_{\mathrm{b}}>1-10$ darcy and the fractures are ubiquitous and connected enough. This mechanism, which may occur at both the drift and mountain scales, can increase the buildup of condensate above the repository.

Decay-heat-driven heat flow in the rock causes a temperature buildup in the near field and altered zone, as well as in the EBS. The temperature buildup depends strongly on the thermal-loading conditions imposed by the emplacement of WPs. The overall repository thermal-loading conditions are best quantified using the areal mass loading (AML, expressed in metric tons of uranium per acre, MTU/acre). Details of the heat output from individual WPs strongly influences near-field T-H behavior; in particular, the T-H conditions immediately adjacent to and within emplacement drifts, including the conditions on the WP surfaces.

Gas-phase advective heat-transfer mechanisms increase the overall efficiency of heat transfer away from the drift; consequently, these mechanisms decrease nearfield temperature buildup. If heat pipes extend from the boiling front all the way back to the repository horizon, near-field temperatures cannot increase much above the nominal boiling point $\left(\approx 96^{\circ} \mathrm{C}\right)$. If buoyant gas-phase convection is significant, near-field temperatures will be decreased, particularly at the edges of the repository. A key issue (or hypothesis) to be resolved through field-scale thermal testing and analysis is whether conduction dominates heat flow or whether heat pipes and buoyant gas-phase convection significantly influence heat flow around emplacement drifts and the repository as a whole.

Decay-heat-driven T-H behavior will also generate thermal-chemical (T-C) and thermal-mechanical (T-M) processes that will alter hydrological properties (the fracture properties in particular) in the UZ, as well as in the saturated zone (SZ). Some changes, such as fracture closure that results from T-M effects, may be temporary, while others, such as the filling of fractures that results from $T-C$ effects, may be permanent.

\subsection{Ambient Hydrology}

Fluid flow in the UZ at Yucca Mountain involves liquid- and gas-phase flow through the fractures and through the rock matrix. Under ambient conditions, the pores in the rock matrix at the repository horizon are approximately $90 \%$ filled by liquid water and $10 \%$ filled by the gas phase with the gas phase containing about $98.5 \%$ air and $1.5 \%$ water vapor (by mass). An important feature of the UZ at Yucca Mountain is its high fracture density. Moreover, the repository host-rock units (Tptpmn, Tptpll, and Tptplnl in Table 1) are among the most densely fractured 
hydrostratigraphic units in the UZ at Yucca Mountain and consequently, have relatively large values of bulk permeability $k_{\mathrm{b}}$. This is significant because, without fractures, the rock throughout most of the UZ (including the repository horizon) would be impermeable.

Modeling and analytical studies of high-level radioactive waste isolation have demonstrated the importance of nonequilibrium flow processes between the fractures and the matrix in the UZ [Buscheck et al., 1991; Nitao et al., 1993]. Except for regions with a perched water table or during transient percolation episodes, capillary forces cause most fractures to be drained of liquid water in the UZ. The permeability of the rock matrix is extremely low, particularly in the repository host rock, so matrix flow is much less likely (than fracture flow) to seep into emplacement drifts and contact WPs or to result in large-scale radionuclide transport. The shallow infiltration of rainfall and snowmelt not removed from the evapotranspiration zone by gas-phase advection and diffusion to the atmosphere determines the netinfiltration flux, which is also called percolation or recharge flux. Liquid-phase flow occurs in fractures when the net-infiltration (or percolation) flux results in a combination of the following conditions:

- Steady-state percolation for which the liquid-phase drainage flux exceeds the hydraulic conductivity of the rock matrix.

- Episodic percolation events during which liquid-phase flow in the fracture is not in capillary-pressure equilibrium with the adjoining rock matrix.

- Lateral flow in perched water bodies. This condition probably results when either steady-state or episodic percolation in fractures intersects a flow barrier such as might occur if the fracture pathways are not vertically continuous.

The first two conditions may occur within fault zones as well as within the fracture networks between fault zones. It is likely that the distribution of percolation flux in fractures is spatially heterogeneous as well as temporally variable.

The distribution of capillary pressure (also called matric or suction potential) in the UZ at Yucca Mountain is the result of the conditions at the ground surface and the location of the water table and the influence of these conditions on gas- and liquid-phase flux in the UZ. Under static gravity-capillary equilibrium (i.e., zero moisture flux through the UZ), the suction potential at a particular location is determined by its height above the water table. Therefore, the magnitude of suction potential increases with height above the water table and for a given rock type, the liquid-phase saturation $S_{\text {liq }}$ will decrease with height above the water table.

Gas- and liquid-phase flux through the UZ can cause the suction potential distribution in the UZ to deviate from gravity-capillary equilibrium. In the absence of incoming liquid-phase flux, the net transport of water vapor out of the UZ (by gas-phase advection and diffusion) can reduce $S_{\text {liq }}$ in the rock matrix and thereby increase the magnitude of suction potential. Under ambient conditions, advective drying may occur as a result of barometric pumping. Advective drying can also occur when decay heat from WPs drives a sufficiently large buoyant gas-phase 
convective flux (see Section 2.3). Incoming liquid-phase flux will decrease the magnitude of suction potential as a result of a combination of the following conditions:

- Steady-state percolation that causes an increase in $S_{\text {liq }}$ and a corresponding decrease in the magnitude of suction potential. Because liquid-phase relative permeability increases with $S_{\text {liq, }}$ it is necessary for $S_{\text {liq }}$ to increase with increasing liquid-phase percolation flux.

- Episodic nonequilibrium fracture-flow percolation events that, as a result of imbibition by the adjoining rock matrix, cause a net increase in $S_{\text {liq }}$ and a corresponding decrease in the magnitude of suction potential. The water in the matrix that is in excess of the gravity-capillary saturation level must eventually drain to the water table or be removed from the mountain by gasphase advection and diffusion.

- Perched water bodies which, for overlying locations in the UZ, decrease the effective height above of the water table.

Recent measurements indicate higher values of $S_{\text {liq }}$ in the repository host rock than previously estimated. Samples from the Single Heater Test (SHT) in the ESF indicate a $S_{\text {liq }}$ range of 80.5 to $99.0 \%$, which compare with values of $85 \pm 12 \%$ for the same interval from surface boreholes (CRWMS M\&O, 1996). LLNL's version (Buscheck et al., 1997) of the LBNL site-scale model (Bodvarsson and Bandurraga, 1996) yields $S_{\text {liq }}$ ranging from 88 to $96 \%$, with an average of $90.5 \%$. Consistent with these recent measurements of higher $S_{\text {liq }}$ are measurements of suction potential in the UZ that are less (in some locations, much less) than previously anticipated (Bodvarsson and Bandurraga, 1996).

Figure 1a shows the depth of the repository horizon below the ground surface. The summit of Yucca Mountain is parallel to (and approximately one-fourth of the way from) the western edge of the repository. Because the repository is close to being horizontal (with a northward dip of about 1.6\%), the repository depth contours correspond to the surface topography. The ground surface slopes steeply downward to the west of the summit and less steeply to the east of the summit. The depression in the northeast corner of the repository corresponds to drill-hole wash. The repository depth plays an important role in determining the duration of boiling conditions in the near field and EBS.

Figure $1 \mathrm{~b}$ is a contour map of the infiltration-flux $q_{\text {inf }}$ distribution over the repository area at Yucca Mountain on the basis of the infiltration map of Flint and Hevesi (1997). The repository area shown in Fig. 1b is the slightly idealized representation of the repository area that is utilized by the mountain-scale $T$ model and the multi-scale T-H modeling approach for predicting near-field and EBS T-H conditions. The actual repository area differs slightly from this idealized representation along the northern, western, and southern edges of the repository (Fig. 1c). 
Infiltration flux varies from 0 to $26 \mathrm{~mm} / \mathrm{yr}$ over the repository area (Fig. 1b). There is a strong correlation between repository depth (which closely corresponds to ground-surface elevation) and $q_{\text {inf }}$ with $q_{\text {inf }}$ increasing with ground-surface elevation (or repository depth). Accordingly, areas of the repository beneath the summit of Yucca Mountain experience the highest $q_{\text {inf }}$ and areas beneath the flanks of the mountain experience lower $q_{\text {inf. }}$. This correlation results from the role that alluvium

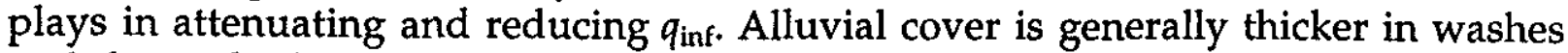
and down the lower flanks of the mountain, while alluvial cover generally decreases with proximity to the summit. Areas of thicker alluvium, such as drillhole wash, experience lower $q_{\text {inf., }}$ while areas with minimal alluvial cover, such as the summit, experience greater $q_{\text {inf }}$.

Figure $1 \mathrm{~d}$ is a histogram of the $q_{\mathrm{inf}}$ distribution over the repository area. The $q_{\mathrm{inf}}$ distribution plays an important role in determining the spatial and temporal extent of rock dryout. Nearly $25 \%$ of the repository area has $q_{\text {inf }}<2 \mathrm{~mm} / \mathrm{yr}$, while $25 \%$ of the area has a $q_{\text {inf }}>14 \mathrm{~mm} / \mathrm{yr}$ (Fig. 1d). For the repository area, the mean infiltration flux is $7.8 \mathrm{~mm} / \mathrm{yr}$. Note that this flux distribution is considered to pertain to presentday conditions; infiltration fluxes estimated for the long-term average conditions $(t$ $>1000 \mathrm{yr}$ ) are considerably greater.

\subsection{Decay-Heat-Driven T-H Flow Processes and Mechanisms}

As mentioned in the previous sub-section, a key feature of the UZ at Yucca Mountain is its high fracture density and resulting high bulk permeability $k_{\mathrm{b}}$. In general, radioactive decay heat mobilizes moisture by (1) vaporization, (2) driving water vapor from high to low gas-phase pressure, (3) condensation, and (4) gravityor capillary-driven flow of condensate. Without fractures, the rock would be too impermeable to allow significant vaporization and advective movement of water vapor. The flow of condensate would also be very slow. A system of connected fractures facilitates significant decay-heat-driven gas-phase flow of water vapor and air and liquid-phase flow of condensate as well as ambient percolation. Binary gasphase diffusion of air and water vapor may significantly contribute to vaporization and vapor transport in less permeable rock in the UZ.

Radioactive decay heat causes a temperature buildup in the near field and altered zone and mobilizes vapor and condensate flow by the following mechanisms and processes:

1. Thermal radiation in emplacement drifts. Decay heat is transferred from the WPs to the drift surfaces primarily by thermal radiation with gas-phase buoyancy and thermal conduction playing minor roles. As long as the drift remains open, thermal radiation provides an efficient means of distributing heat to all of the drift surfaces. If WPs are placed very close together (i.e., end to end) WP-to-WP thermal-radiative heat transfer will be very efficient, thereby allowing decay-heat generation to be more uniformly shared among the WPs. 
2. Thermal conduction in the near-field rock. Heat is conducted radially away from the emplacement drifts or, at very early time, spherically away from very hot or widely spaced WPs.

3. Thermal conduction in WPs. If WPs are placed very close enough together so that WP-to-WP thermal-radiative heat transfer is very efficient, thermal conduction along the axis of WPs will be an important mechanism that allows decay-heat generation to be more uniformly shared among WPs.

4. Boiling in the rock matrix and matrix-to-fracture vapor transport. As boiling temperatures are attained in the matrix, liquid water in the pores of the matrix begins to boil, starting with locations near the fracture surfaces and proceeding into the interior of the matrix block (Fig. 2). The increase in gas-phase pressure $P_{\text {gas }}$ in the matrix caused by the generation of steam leads to an advective gasphase flux that transports steam from within the matrix blocks to the nearest fracture. The $P_{\text {gas }}$ buildup in the matrix raises the boiling point of water, so that temperatures in the boiling zone can be above the ambient boiling point $\left(\approx 96^{\circ} \mathrm{C}\right)$, with some liquid water remaining in the pores in the interior of the matrix blocks. Because matrix permeability in the host-rock units (Tptpmn, Tptpll, and Tptplnl in Table 1) is extremely low, large $P_{\text {gas }}$ gradients can initially develop in the matrix, particularly if the matrix block is large. As boiling proceeds into the matrix, the $P_{\text {gas }}$ gradients will dissipate and thermodynamic conditions in the matrix block and adjoining fractures will be similar. Microfractures (if present) in matrix blocks will tend to enhance the matrix-to-fracture advection of water vapor. If the matrix permeability is very low or the matrix blocks are very large, enhanced binary gas-phase diffusion may contribute to matrix-to-fracture vapor transport.

5. Gas-phase advection and diffusion of vapor in fractures. Advective vapor fluxes are driven by $P_{\text {gas }}$ gradients and gas-density (buoyancy) gradients. Generally, water vapor is driven away from the repository (Fig. 3). If $k_{b}$ of the rock mass is high enough and the fractures are well connected, $P_{\text {gas }}$ in the fracture cannot build up much above atmospheric pressure in the boiling region; under these conditions, density gradients dominate the advective gas-phase flux at the repository, and buoyant convection cells may develop. The size of these cells depends on the scale over which the fracture network is well connected and the geometry and magnitude of the heat source. These cells can carry steam from the boiling zone both below and above the repository to a condensation region above the upper boiling zone. For sub-boiling conditions, gas-phase buoyant convection can carry vapor from below the repository to a condensation zone above the repository. Sub-boiling, buoyant gas-phase convection can reduce the liquid-phase saturation $S_{\text {liq }}$ below the repository, increase $S_{\text {liq }}$ above the repository, and reduce temperature buildup in the near field and EBS, particularly at the repository edge.

If $k_{\mathrm{b}}$ is not high enough for buoyant gas-phase convection to dominate vapor transport, then the advective gas-phase flux is dominated by the boiling-driven $P_{\text {gas }}$ gradients, which drive steam from the boiling zone away from the 
repository, where it condenses. If $k_{\mathrm{b}}$ is low enough ( $k_{\mathrm{b}}<1-10$ millidarcy), dryout due to boiling will be substantially suppressed (i.e., throttled). This throttling can arise in two ways. Throttling can arise because the gas-phase conductivity in the fracture network is low enough ( $k_{\mathrm{b}}<1-10$ millidarcy) to restrict fracture flow and cause a buildup in $P_{\text {gas }}$ that results in an increase in the saturation temperature $T_{\text {sat }}$ (i.e., the boiling point) in the fractures themselves. Throttling can also result from restricted matrix-to-fracture flow that causes a $P_{\text {gas }}$ buildup within matrix blocks. Thus, throttling may be more pronounced in sparsely fractured regions (with large matrix blocks) and may be less pronounced in intensely fractured regions (with small matrix blocks).

6. Displacement of air from the boiling zone. As boiling continues, the generation of steam causes the displacement of air away from the boiling zone (and away from WPs). This process can reduce the gas-phase air-mass fraction $X_{\text {air,gas }}$ to nearly zero for up to several thousand years. This process will occur regardless of whether rock dryout out occurs. The spatial and temporal extent of $X_{\text {air,gas }}$ reduction increases with the duration of boiling; therefore, it increases with the repository depth below the ground surface and with distance away from the repository edge. Advective and diffusive mechanisms that promote the mixing of air and water vapor decrease the spatial and temporal extent of $X_{\text {air,gas }}$ reduction. The two most significant mixing mechanisms are (1) buoyant gasphase convection (in particular, mountain-scale convection) and (2) binary gasphase diffusion of air and water vapor, particularly if it is substantially enhanced [Buscheck and Nitao, 1994]. The $X_{\text {air,gas }}$ history in emplacement drifts plays an important role in WP corrosion and waste-form dissolution.

7. Condensation and condensate drainage in fractures. As liquid water forms in the condensate zone, it will condense within the matrix pores or within the fractures. If water condenses within the fractures, it will imbibe into the matrix. or flow downward by gravity. Much of this condensate flow will return to the boiling zone and be reboiled and some will shed around the boiling zone and through the rock pillar between the emplacement drifts, possibly draining below the repository horizon. If the local liquid-phase flux is high enough, condensate flow may penetrate through the boiling zone above the drift and possibly seep into the drift. The theory of fracture-matrix interaction [Nitao and Buscheck, 1991; Nitao et al., 1993] indicates that if the rate of boiling, and hence the rate of condensate generation, is high enough, then condensate flow is fracturedominated, and downward flow by gravity can be very fast as long as there is a sufficiently connected fracture network, even if the matrix is not completely saturated.

8. Heat-pipe effect. The cyclic boiling, vapor transport away from the heat source, condensation of water, and condensate drainage can set up a gravity-driven heat pipe. Pruess and others [1984, 1990] were the first to model the heat-pipe effect in the context of T-H behavior at Yucca Mountain. Their calculations pertained to a capillary-driven heat pipe. The possible influence of gravity-driven heat pipes has been shown in mountain- and drift-scale model calculations [Buscheck and Nitao, 1993a; Buscheck and Nitao, 1993b]. Under most conditions, the heat-pipe 
mechanism is more efficient than thermal conduction in transporting heat away from the repository. Various calculations show the vertical extent of the heatpipe zone above the repository exceeding $100 \mathrm{~m}$ [Buscheck et al., 1997].

Because heat pipes at Yucca Mountain require gravity-driven condensate flow, they will primarily occur in fracture pathways that are well connected vertically. Heat-pipe development is strongly influenced by ambient percolation flux $q_{\text {perci }}$ high $q_{\text {perc }}(>10 \mathrm{~mm} / \mathrm{yr})$ suppresses rock dryout and increases the tendency for heat pipes to form in the vicinity of drifts, while low $q_{\text {perc }}(<5$ $\mathrm{mm} / \mathrm{yr}$ ) favors rock dryout and suppresses the tendency for heat-pipe development near the drifts.

Model calculations have indicated that T-H behavior of the repository can be divided into three sequential periods: drying, quasi-steady, and rewetting [Buscheck and Nitao, 1993a, 1993b]. The concept of these three periods is applicable over dynamically changing spatial regimes. Therefore, at a given time, certain locations in a repository (such as repository-edge locations or regions of high $q_{\text {perc }}$ ) may have already progressed to the rewetting regime while other locations (such as the repository-center locations or regions of low $q_{\text {perc }}$ ) remain in the drying regime.

During the initial drying period, the rate of evaporation is greater than the rate of condensation. Note that the durations of these sequential periods, including the initial drying period, depend on the location in the repository and the local $q_{\text {perc }}$. Depending on the thermal loading of the repository, the location within the repository (e.g., center versus edge locations), and the local $q_{\text {perc, }}$ the drying period can last from tens of years to up to thousand years and can extend several to hundreds of meters vertically [Buscheck and Nitao, 1993a, 1993b]. The important thermal-loading parameters include:

- Areal mass loading (AML, expressed in metric tons of uranium per acre, MTU/acre). This is the most useful measure of the time-integrated heat-flux density that drives the spatial and temporal extent of boiling and dryout for the overall repository system.

- Lineal mass loading (LML). This is a useful measure of the local thermal power density along the emplacement drift. Note that for a given AML, drift spacing increases linearly with LML. For a given AML, the magnitude of temperature buildup and dryout around an emplacement drift increases strongly with LML. Because the line-load design has twice the LML of the point-load design, the line load causes more intense, persistent dryout (and lower $R H$ ) around drifts (and on WPs) than the point load.

- Age of spent nuclear fuel (SNF). Younger SNF has a higher thermal power output than older SNF. Consequently, younger SNF WPs can have much higher local drift-wall and WP temperatures than older-age SNF WPs. Differences between younger and older SNF WPs is more pronounced for the point-load design than the line-load design. Differences between young and old SNF WP locations diminish with time. 
- Depth of the repository below the ground surface. This determines how much rock insulates the repository from the ground surface. The duration of boiling conditions increases with repository depth.

During the drying period, the cumulative volume of water removed from the dryout zone increases monotonically. As the repository heating rate decreases and the volume of the boiling region increases, conditions stabilize to a quasi-steady state in which the rate of evaporation is equal, or nearly equal, to the rate of condensation. Temperature $T$, liquid-phase saturation $S_{\text {liq, }}$ and relative humidity $R H$ in the repository change very little during this period. Depending on the AML and SNF age, this quasi-steady period may last up to several thousand years, and the drying/rewetting front may be located well away from the repository. As the repository heating rate further decreases, the rewetting period begins as $T, S_{\text {liq }}$ and $R H$ begin to slowly return to ambient values. During the rewetting period, the net volume of water removed from the dryout zone decreases monotonically.

Rock dryout is the result of the balance between (a) the rate of vaporization and vapor transport away from emplacement drifts and (b) the rate of return liquidphase flow to the dryout zone. Two mechanisms influence the rate of rewetting:

- Gravity-driven percolation and condensate flux in fractures.

- Capillary-driven matrix imbibition and wicking in fractures.

Superheated conditions, resulting in rock dryout and a reduction in $R H$ in the repository rock will occur if the local heat flux $q_{\mathrm{H}}$ is enough to evaporate the local incoming liquid-phase mass flux $q_{\text {liq }}$ as expressed by the following relation:

$$
q_{\mathrm{H}}>q_{\mathrm{liq}} \rho_{\mathrm{liq}} h_{\mathrm{fg}},
$$

where $\rho_{\text {liq }}$ is the mass density of water and $h_{\mathrm{fg}}$ is the specific latent heat of vaporization. if $q_{\mathrm{ll}}$ is too large, $q_{\mathrm{H}}$ is insufficient to generate superheated conditions. If the right and left hand sides of eq. 1 are equal, heat-pipe conditions will occur.

Near the drift, $q_{\mathrm{H}}$ is proportional to LML; further out in the rock it is proportional to AML after the thermal fields have coalesced. Spatial variability in either $q_{\mathrm{H}}$ or $q_{\text {liq }}$ can result in local regions where $q_{\text {liq }}$ will prevail. Because $q_{\mathrm{H}}$ increases with proximity to the drift, it is more likely for $q_{\text {liq }}$ to prevail in the rock away from the drift (e.g., at the pillar centerline), rather than near the drift; conversely, it is more likely for $q_{\mathrm{H}}$ to prevail near the drift than at the pillar centerline. Near the drifts, $q_{\mathrm{H}}$ is twice as large for the line-load design than it is for the point-load design, causing more intense, persistent rock dryout around line-load drifts. Moreover, $q_{\mathrm{H}}$ at the pillar centerline is less for the line-load design than it is for the point load, which allows more effective condensate shedding between line-load drifts. The point-load design results in much greater variability in both $q_{\mathrm{H}}$ and $q_{\mathrm{liq}}$ along drifts than the line load. Cooler intervals of point-load drifts are more likely to be overwhelmed by $q_{\text {liq }}$ as a result of:

- Less effective condensate shedding around point-load drifts than around lineload drifts. 
- Condensate being displaced from hotter to cooler locations along drifts. This situation is further aggravated by the larger contrast between hotter and cooler locations along point-load drifts than for line-load drifts.

- The local $q_{\mathrm{H}}$ at cooler locations of point-load drifts being much lower than it is for line-load drifts, thus making it more likely for $q_{\text {liq }}$ to locally prevail.

- The greater tendency for heat pipes to form above the cooler intervals of point-load drifts, which increases the local cooling rate, thereby making it even more difficult for the development of local superheated conditions.

The net result is higher $R H$ and a greater tendency for water to seep into the cooler intervals of point-load emplacement drifts. The large difference in near-field dryout around point- and line-load drifts has been thoroughly demonstrated in various modeling studies [Buscheck, 1996; Buscheck et al., 1996].

\subsection{Modeling and Analysis Approach}

The following steps articulate the methodology that has been used over a number of years for the development, refinement, and validation of conceptual and numerical models used to support TSPA-VA and will be used to support TSPA-LA. The steps are not necessarily taken in order; the method is a process of iterative refinement as knowledge of the site-repository system increases. The method relies on a combination of mathematical models and laboratory and field data to develop conceptual models and parameter regimes and to test hypotheses.

1. Conceptual and Mathematical Model Development.

- Identify processes and conditions that are important to T-H behavior in the near field and altered zone.

- Develop conceptual models and related mathematical models of T-H behavior in the near field and altered zone.

- Verify the mathematical models.

2. Process Analysis and Parameter-Sensitivity Studies.

- Develop an understanding of the important T-H processes and their intercoupling with geochemical and geomechanical processes through the use of detailed process models.

- Identify parameter regimes that govern decay-heat-driven T-H behavior.

- Quantify the parameter sensitivity of T-H behavior to ambient conditions and repository design (i.e., thermal loading distribution).

- Refine conceptual and mathematical models on the basis of results from detailed process models and parameter-sensitivity analyses.

3. Numerical Model Development.

- Develop a complementary suite of drift- and mountain-scale T and T-H models (see Section 3 ) that are required by the multi-scale T-H modeling 
approach for predicting near-field and EBS T-H conditions. This approach has also been called the hybrid-scale T-H model-abstraction methodology.

- Analyze spatial variability of natural system parameters and conditions (such as infiltration flux) to determine the necessary number of drift-scale model locations for the multi-scale $\mathrm{T}-\mathrm{H}$ modeling approach to adequately capture this variability.

4. Integration with Thermal Tests.

- Conduct scoping calculations to help design laboratory- and field-scale thermal tests [Buscheck et al., 1997] to quantify important parameters and properties.

- Refine conceptual, mathematical, and numerical models on the basis of results from laboratory- and field-scale thermal tests [Nitao and Buscheck, 1995].

- Analyze the adequacy of hydrological property values used to model fieldscale thermal tests and make any necessary refinements to the property values used in the $\mathrm{T}-\mathrm{H}$ models of the thermal tests as well as in corresponding models supporting TSPA-VA [Buscheck et al., 1997].

5. Hypothesis Testing and Model Validation.

- Establish hypotheses critical to the prediction of T-H behavior.

- Establish hypotheses critical to EBS performance.

- Conduct scoping calculations [Buscheck and Nitao, 1995] to help design laboratory- and field-scale thermal tests that critically test these hypotheses.

- Test the critical hypotheses on the basis of testing, at the laboratory and field scale, and related analyses, including bounding analyses.

- Validate conceptual and mathematical models on the basis of results from laboratory- and field-scale thermal tests and hypothesis testing.

6. Subsystem and Total System Performance Assessment.

- Determine the parameter sensitivity of EBS performance to natural-system parameters and repository design (and thermal loading) parameters [Buscheck, 1996].

- Develop a multi-scale T-H modeling approach for predicting near-field and EBS T-H conditions to support total systems performance assessment.

- Using the reference repository-design, thermal-loading assumptions, thermal-property set, hydrological-property set, boundary conditions, and infiltration-flux map, conduct the mountain- and drift-scale T-H model calculations required by the multi-scale T-H modeling approach for predicting EBS T-H conditions. Repeat this modeling procedure for 
alternative conceptual models, property sets, and infiltration maps, as well as for alternative repository designs and thermal loading conditions, such as the line-load design and backfill.

- Analyze the infiltration-flux $q_{\text {inf }}$ distribution over the repository area and subdivide the repository area into major $q_{\text {inf }}$ subdomains. The $q_{\text {inf }}$ subdomain boundaries are chosen to minimize the spatial variability of $q_{\text {inf }}$ within any given subdomain.

- Determine probability density functions of temperature $T$ and relative humidity $R H$ conditions for commercial spent nuclear fuel (CSNF) WPs and defense high-level waste (DHLW) WPs. The probability density functions are expressed as $R H$ and $T$ histograms. The environmental conditions on WPs are categorized or "binned" according to the time required by WPs rewet to $R H=85 \%$ and $T$ on the WP surface at $5000 \mathrm{yr}$. In each of the $q_{\text {inf }}$ subdomains, the CSNF and DHLW WPs are each divided into $10 \mathrm{RH}$ bins and each $R H$ bin is then subdivided into $3 \mathrm{~T}$ bins, resulting in a total of $30 \mathrm{WP}$ bins for CSNF WPs and 30 WP bins for DHLW WPs. The $T$ and $R H$ history for a typical WP within each WP bin is provided to TSPA-VA along with the probability density functions of $T$ and $R H$ conditions.

- Conduct model-abstraction testing of the multi-scale T-H modeling approach, investigating the influence of alternative assumptions and conceptual models.

Most of these six categories of modeling and analysis activities have been underway for a number of years, in particular, categories 1, 2, and 5. Categories 3, 4, and 6 have received increased emphasis in fiscal years 1997 and 1998.

\section{Numerical Models and Assumptions}

\subsection{Background}

A multi-scale T-H modeling approach has been developed that integrates the results from 1-, 2-, and 3-D drift-scale models and a 3-D mountain-scale model (Fig. 4) to provide a full description of the T-H variables (Table 2) affecting the performance of the engineered barrier system (EBS). This information is required by Total Systems Performance Assessment for the Viability Assessment (TSPA-VA) to assess waste-package (WP) corrosion, waste-form dissolution, and radionuclide transport in the EBS. The T-H variables (Table 2) are provided to TSPA-VA as a function of the following:

- Location in the repository area, including the influence of the local hydrostratigraphy and percolation flux.

- WP type, such as commercial spent nuclear fuel (CSNF) versus defense highlevel waste (DHLW), WP age and burnup, WP spacing, and WP sequencing. 
- Design options such as the line-load design or backfill.

The influence of the following model assumptions and boundary conditions can be assessed:

- Alternative thermal-property sets.

- Alternative hydrological-property sets.

- Infiltration-flux distributions, including the influence of climate change.

- Conceptual models of fracture-matrix interaction, such as the effectivecontinuum model (ECM) and dual-permeability model (DKM).

- Heat-flow assumptions at the water table, such as a fixed-temperature assumption versus explicitly representing heat flow in the SZ.

This multi-scale modeling approach uses complementary thermal-hydrological (T-H) and thermal-conduction (T) models at various scales and conceptualizations, including:

1. Smeared-heat-source, mountain-scale $\underline{T}$ (SMT) model (Fig. 4d) that can incorporate the following:

- Geometry, hydrostratigraphy, and boundary conditions of the site-scale UZ model (Bodvarsson and Bandurraga, 1996; Bodvarsson et al., 1997). The hydrological-model units at the repository horizon are shown in Fig. 5a.

- Geometry of the reference 85-MTU/acre repository design (Fig. 1c).

- Heat flow in the SZ, including the influence of regional groundwater flow.

2. Drift-scale T and T-H models (Fig. $4 a, b, c$ ) that can incorporate the following:

- Local hydrostratigraphy and boundary conditions of the site-scale UZ model.

- Local infiltration flux from an infiltration map (Fig. 1b), including the TSPAVA base-case map [Flint and Hevesi, 1996] and the long-term-average (LTA) map and multiples of those two maps. For the TSPA-VA T-H calculations, infiltration flux is assumed to be equal to percolation flux because calculations with the site-scale UZ model indicates that lateral diversion above the repository is relatively minor $(\mathrm{Wu}, 1997)$.

- DKM approximation (with the ECM as an alternative conceptual model).

- Complementary 1-D smeared-heat-source drift-scale I (SDT) models, 2-D lineaveraged-heat-source drift-scale T-H (LDTH) models, and 3-D discrete-heatsource drift-scale I (DDT) models (Figs. $4 a, b, c)$ that are regularly spaced throughout the repository area in either a $3 \times 5$ or a $5 \times 7$ grid (Fig. 1c). For each grid location, parallel SDT- and LDTH-model calculations are conducted for AMLs of 85, 56.67, and 42.5 MTU/acre (the lower 2 AMLs are required to represent cooler areas in the repository such as edge locations), resulting in 6 
model calculations per grid location; thus, 90 drift-scale model salculations are required for the $3 \times 5$ grid, while 210 calculations for the $5 \times 7$ grid. For TSPAVA, the $5 \times 7$ grid (with 35 locations) is used to provide a more finely resolved representation of the influence of the infiltration-flux distribution in the repository area (Fig. 1c). Besides the SDT and LDTH models, at least 1 DDTmodel calculation is required by the multi-scale $\mathrm{T}-\mathrm{H}$ modeling approach; additional DDT-model calculations can be included to capture the wide range of potential WP-type/sequence scenarios that may arise during emplacement. Using the $5 \times 7$ grid, a single TSPA-VA EBS T-H scenario requires 424 model runs, including 211 drift-scale calculations and 1 mountain-scale calculation, as well as an additional 212 model-initialization runs.

- Alternative hydrological-parameter sets, including (1) the TSPA-VA 7/97 base-case set, (2) the 11/97 "T-H" set calibrated to temperatures measured in the Single-Heater Test [Buscheck et al., 1997; Birkholzer, 1997], and (3) an imbibition-test set that is calibrated on the basis of laboratory measurements of matrix-imbibition sorptivity (Flint et al., 1996).

- Reference point-load design, as well as alternatives such as the line-load design and backfill.

A complementary suite of model types and scales is required to capture mountain-scale heat flow driven by the overall repository thermal-loading conditions and drift-scale T-H behavior driven by spatially variable decay-heat flux from individual WPs, each having distinctively different (and sometimes widely varying) heat-output histories. To explicitly account for these effects in a monolithic multi-scale T-H model would require approximately 60 million gridblocks, which is computationally beyond the capability of the current generation of T-H numericalsimulation codes. With the use of the NUFT numerical-simulation code, a complete set of 424 model runs, which is required by the multi-scale T-H modeling approach to predict EBS T-H conditions for a single TSPA-VA scenario, usually requires 12-16 hours to run on 9 Sun Ultra2 Sparc workstation processors.

In addition to the family of models used to support TSPA-VA, various T-H models have been developed to analyze field-scale thermal tests at various scales, including:

3. G-Tunnel Heater Test [Buscheck and Nitao, 1988; Nitao and Buscheck, 1995].

4. Large-Block Test (LBT) [Lee, 1995; 1996; Wilder, 1997].

5. Single-Heater Test (SHT) [Buscheck et al., 1997; Tsang and Birkholzer, 1997].

6. Drift-Scale Thermal Test (DST) [Buscheck et al., 1993; Buscheck and Nitao, 1995; Buscheck et al., 1997].

The scale of the first three tests is smaller than the scale of the repository drifts. The scale of the DST is comparable to that of the scale of the repository drifts; consequently, the models used to model the DST are similar in scale and resolution to that of the drift-scale T-H models used to support TSPA-VA. 


\subsection{Mathematical Models}

The behavior of T-H processes, which are described in Section 1, is predicted with the use of mathematical models. These models consist of partial differential equations describing the balance of energy and the balance of mass of each important chemical species, with the primary species being air and water. A species such as water can occur in both a gas and a liquid (or aqueous) phase. As is usually the case, the mathematical models of $\mathrm{T}-\mathrm{H}$ processes are defined at the macroscopic level-that is, they are derived from microscopic balance laws through volume-averaging [Bear and Bachmat, 1990] over a representative elementary volume (REV) of the porous medium. Predicted quantities, such as temperature or liquid-phase saturation, are therefore averages over the REV, and any variations in these quantities are lost over distances less than the size of the REV.

The following fundamental assumptions, which are typical of macroscopic mathematical models for flow and transport in porous media, are applied in all of the T-H models of the near field and altered zone as well as those of the field-scale thermal tests:

- Darcy's law is assumed to hold for advective fluxes.

- Fick's law is assumed to hold for diffusive and dispersive fluxes.

- Thermodynamic equilibrium is assumed over the REV.

For these models, the following two classes of the mathematical treatment of heat and fluid flow are used:

I. Thermal-conduction (T) models. This model class only predicts heat flow and does not predict the flow and transport of chemical species such as air and water. This model class is used in three of the model-geometry/scale types (see Section 3.4), including: (1) smeared-heat-source, mountain-scale thermal-conduction (SMT) models, (2) smeared-head-source, drift-scale, thermal-conduction (SDT) models, and (3) discrete-heat-source, drift-scale, thermal-conduction (DDT) models. This model class has also been used in highly detailed models of the Drift-Scale Thermal (DST) Test [Buscheck et al., 1997]. The following are the mechanisms of heat flow that can be represented:

- Thermal conduction in the bulk rock and in the EBS materials. Thermal conduction can occur in both the unsaturated zone (UZ) and saturated zone (SZ) domains of the model. The dependence of rock thermal conductivity $K_{\text {th }}$ on liquid-phase saturation $S_{\text {liq, }}$ which is discussed below, is approximated by correlating temperature in the $\mathrm{T}$ model to $S_{\mathrm{liq}}$ in a corresponding T-H model and developing a corresponding functional relationship between $K_{\text {th }}$ and temperature in the T model. This $K_{\text {th }}$ versus $T$ relationship in the T model mimics the $K_{\text {th }}$ versus $S_{\text {liq }}$ in the T-H model.

- Liquid-phase convection in the SZ that arises from regional groundwater flow. This heat-flow mechanism, which is only applicable to mountain-scale models, results from an assumed, specified, regional groundwater flux in the $\mathrm{SZ}$ domain of the model. 
- Thermal radiation between all surfaces in the emplacement drift. The primary component of thermal radiation occurs between the waste package (WP) and the neighboring surfaces, including drift-wall, drift-floor, and neighboring WP surfaces. Cross-drift thermal radiation between all surfaces in the drift is also represented because it plays an important role in smoothing out temperature variations (in both the axial and circumferential direction) along emplacement drifts that are not backfilled. For situations where backfill partially fills the drift, thermal radiation is represented in the cavity between the backfill and drift wall. Thermal radiation is represented in model-geometry/scale types that do not areally smear out WP decay heat, including the discrete-heat-source, drift-scale thermal-conduction (DDT) model.

- Storage of thermal energy in the bulk rock and in the EBS materials such as the invert and backfill. The heat capacity of each hydrological-model unit is treated as being temperature dependent to approximate latent-heat effects that occur as a result of liquid water being evaporated and water vapor being condensed. The temperature dependence of the heat capacity for a given model unit reflects the initial bulk water content, which is equal to the product of the porosity and initial $S_{\mathrm{liq}}$ of that model unit.

II. Thermal-hydrological (T-H) models. This model class represents both heat flow and the multiphase (gas- and aqueous-phase) flow and transport of chemical species, including air and water. This model class is used in all of the modelgeometry/scale types (see Section 2.4), including: (1) line-averaged-heat-source, drift-scale, T-H (LDTH) models, (2) discrete-heat-source, drift-scale T-H (DDTH) models, and (3) smeared-heat-source, drift-scale T-H (SDTH) models, as well as various models of the field-scale thermal tests. The following are the mechanisms of heat flow that can be represented:

- Thermal conduction in the bulk rock and in the EBS materials. Thermal conduction can occur in both the UZ and SZ domains of the model. The dependence of rock thermal conductivity $K_{\text {th }}$ on liquid-phase saturation $S_{\text {liq }}$ is explicitly represented in the model. The large difference in wet and dry $K_{\mathrm{th}}$ (with $K_{\text {th }}$ decreasing with $S_{\text {liq }}$ ) plays an important role in the near-field and EBS temperature distributions, particularly in the lower lithophysal Tptpll unit (which is model unit tsw35). Rock dryout around the drift causes a large decrease in $K_{\text {th }}$ that results in a further increase in the temperature buildup around the emplacement drift.

- Liquid-phase convection in the $\mathbf{S Z}$, including that arising from regional groundwater flow and decay-heat-driven, buoyant, liquid-phase convection. This mechanism is only applicable to mountain-scale models.

- Thermal radiation between all surfaces in the emplacement drift. Thermal radiation is represented in the T-H models in the same fashion as in the thermal-conduction $(\mathrm{T})$ models. Thermal radiation is represented in modelgeometry/scale types that do not areally smear out the WP decay heat, 
including the line-averaged-heat-source, drift-scale T-H (LDTH, model and the discrete-heat-source, drift-scale T-H (DDTH) model.

- Liquid-phase convection in the UZ that arises from percolation flux and condensate drainage.

- Gas-phase convection in the UZ, including that arising from barometric pumping, decay-heat-driven, buoyant, gas-phase convection, and decay-heatdriven boiling.

- Liquid-phase species diffusion in the UZ and SZ. Although this effect is included in the mathematical and numerical models, it is not considered to be significant.

- Binary gas-phase diffusion of air and water vapor in the UZ, including the possibility of enhanced vapor diffusion. The most significant impact of this mechanism is its influence on the gas-phase air-mass fraction in the boiling zone and within the EBS.

- Latent-heat effects that arise from the changes in thermal energy from the condensation of water vapor and the evaporation of liquid water. These effects contribute to the extremely high heat-transfer efficiency of heat pipes.

- Storage of thermal energy in the bulk rock and in the EBS materials. The temperature-dependent heat-capacity approach, which is used to approximate latent-heat effects in thermal-conduction $(T)$ models, is not required because the influence of evaporation, latent-heat transport, and condensation are already accounted for in T-H models.

Three principal classes of the mathematical treatment of fracture-matrix interaction are used in the T-H models, including:

A. Effective-Continuum Model (ECM). The ECM assumes the equality of capillary pressure (also called matric or suction potentials) between the fractures and matrix block. Thermodynamic equilibrium is also assumed between the fractures and matrix. Composite characteristic curves are used to define the unsaturated hydraulic conductivity and matric potential versus $S_{\text {liq }}$ relationships. The ECM is computationally simple because it uses a single continuum for both fractures and matrix. The assumption of capillary-pressure and thermodynamic equilibrium between fractures and matrix is adequate only if the liquid-phase flux in the fractures is low enough [Nitao et al., 1993; Buscheck et al., 1991]. This assumption is adequate for modeling condensate drainage during the quasi-steady and rewetting periods of decay-heat-driven moisture movement, but may be inadequate during the early stages of the dryout period when high specific heat flux in the boiling region leads to high condensate drainage fluxes. The ECM assumptions are not adequate for modeling episodic infiltration events. The ECM does not treat fractures as discrete features; rather, fracture-flow effects are averaged over the whole spatial domain. In effect, fractures are treated as a porous medium. This approach is used in the following studies:

- Pre-test analysis of the DST [Buscheck et al., 1997]. 
- Pre- and post-test analyses of the SHT, which are described in Section 3 [Lee, 1996; Buscheck et al., 1997].

- Pre- and post-test analyses of the LBT, which are described in Section 3 [Lee, 1996; Wilder et al., 1997].

B. Dual-Permeability Model (DKM). The DKM treats the matrix and the fractures as two distinct porous continua with transfer terms to represent the mass and heat flux between the two continua. Because the DKM does not assume capillarypressure equilibrium between fracture and matrix, it can handle much larger liquid-phase fluxes (than the ECM) without producing conditions near $100 \%$ liquid-phase saturation in the matrix. The DKM also allows thermodynamic disequilibrium between the matrix blocks and adjoining fractures because its ability to represent heat flow between these two continua. Because the DKM allows for gas-phase pressure $P_{\text {gas }}$ disequilibrium between the matrix blocks and adjoining fractures, it can account for how $P_{\text {gas }}$ buildup in matrix blocks throttles the rate of rock dryout. This throttling occurs during the early stages of the dryout period (see Section 2.3) and will persist (at least locally) if the matrix permeability $k_{\mathrm{m}}$ is extremely small $\left(k_{\mathrm{m}}<1-10\right.$ microdarcy) and the matrix blocks are large $(>3 \mathrm{~m} \times 3 \mathrm{~m})$. Compared to the Discrete Fracture-Matrix Model (DFM), which is described below, the DKM tends to overpredict the $P_{\text {gas }}$ buildup during the early stages of dryout in the matrix and thereby overpredicts the throttling of rock dryout during this early period. For large matrix blocks ( $>3 \mathrm{~m} \times 3 \mathrm{~m}$ ), the throttling of rock dryout would continue to be overpredicted after the early dryout period.

The DKM is more computationally intensive than the ECM, but less intensive than the DFM, which is described below. Typical fracture-matrix heat- and masstransfer terms do not represent the diffusive nature of matrix imbibition in the matrix block; consequently, the DKM underpredicts the fracture-to-matrix liquidphase flux during the early stages of matrix imbibition and thereby tends to overpredict the early stages of decay-heat-driven condensate shedding around emplacement drifts. The DKM does not treat fractures as spatially discrete features; rather, the effects of fracture flow are averaged over the whole spatial domain. In effect, fractures are treated as a porous medium. The DKM is used in the following:

- Drift-scale T-H models supporting TSPA-VA. The DKM is applied to all of the line-averaged-heat-source, drift-scale T-H (LDTH) model calculations (see Section 4) required by the multi-scale $\mathrm{T}-\mathrm{H}$ modeling approach to predict nearfield and EBS T-H conditions. In this family of models, the fracture-to-matrix liquid-phase flow is strongly influenced by the fracture-matrix-connectivity parameter (FMX), which is specified for each of the hydrological-model units. This parameter, which varies between 0 and 1 , quantifies the fraction of the fracture surfaces that are wetted by the liquid phase. This fraction, together with the specified fracture spacing, quantifies the interfacial flow area per unit volume of matrix block which is available for liquid-phase fracture-to-matrix mass transfer. It is important to note that matrix-to-fracture and matrix-to- 
matrix mass transfer are not affected by the FMX parameter. For the TSPA-VA T-H calculations, the matrix-to-fracture (MFX) and matrix-to-matrix (MMX) parameters are assumed to be equal to one. It is mathematically possible to independently specify MFX and MMX parameter values between 0 and 1 . It is also mathematically possible to specify anisotropic values of FMX, MFX, and MMX.

The FMX parameter accounts for the tortuosity of percolation channels as the liquid phase "fingers" through the fracture network under ambient-flow conditions. However, this factor probably underrepresents the wetted surface area of fractures that occurs during decay-heat-driven condensate drainage. Other approaches [Ho et al., 1997] attempt to dynamically account for the influence of decay-heat-driven condensate drainage on the interfacial flow area between the fractures and matrix blocks. In such approaches, the FMXlike parameter increases with the magnitude of liquid-phase flux. Because decay heat drives much larger liquid-phase fluxes than occur under ambient conditions and because decay-heat-driven condensate flow is probably much more ubiquitously distributed than ambient percolation in fractures, this dynamic FMX approach results in a much larger value of FMX during the early stages of decay-heat-driven condensate flow. As the decay-heat-driven liquid-phase flux declines asymptotically to ambient percolation-flux values, the dynamic FMX parameter declines to its ambient value. Note that the driftscale T-H calculations supporting TSPA-VA assume a constant value for FMX rather than the dynamic FMX approach.

The FMX, MFX, and MMX parameters described above only affect liquidphase flow. For gas-phase flow, it is mathematically possible to independently specify FMX, MFX, and MMX parameter values between 0 and 1. For the TSPA-VA T-H calculations, FMX, MFX, and MMX are all effectively specified to be equal to one for gas-phase flow.

C. Discrete Fracture-Matrix Model (DFM). This model spatially discretizes the space occupied by the fractures and the matrix blocks using finite-difference gridblocks (or elements). Because the location and morphology of individual fractures are not usually well known, their geometric characteristics are either (1) interpolated from field data, (2) randomly generated, or (3) represented using an idealized geometry. The third approach is commonly used [Buscheck et al., 1991; Nitao et al., 1993; Nitao and Buscheck, 1996]. The DFM is, by far, the most computationally intensive of the three approaches described here. Moreover, available data on the fracture networks may not justify using the DFM. The DFM more accurately represents fracture-to-matrix liquid-phase flow and matrix-to-fracture gas-phase flow, particularly at early time when the DKM tends to underpredict mass transfer between the fractures and matrix. The DFM has been used in the following modeling studies:

- Analysis of episodic nonequilibrium percolation events [Buscheck et al., 1991; Nitao et al., 1993].

- Analysis of the G-Tunnel heater test [Nitao and Buscheck, 1996]. 
The selection of an approach (ECM, DKM, or DFM) for representing fracturematrix interaction must weigh the trade-off between computational complexity and physical accuracy. Factors that should be considered include (1) the magnitude of liquid-phase fluxes in fractures, (2) the size of the domain being modeled, and (3) the scale over which predicted results are desired. The DFM is probably not practical for repository-scale and mountain-scale calculations, but it can be used to determine phenomenological parameters needed for the DKM. The DFM can also be useful in interpreting the results of laboratory-scale experiments. Complementary use of these three approaches is probably the only effective way of incorporating some of the effects of nonequilibrium fracture-matrix behavior at any practical scale of analysis.

\subsection{Numerical Simulation Codes}

All of the T-H calculations in direct support of TSPA-VA [Buscheck et al., 1997; Nitao, 1997a; 1997b; 1997c; Dunlap et al., 1997; Francis et al., 1997] and all of the post1995 calculations in support of the field-scale thermal tests used the NUFT code [Nitao, 1993, 1995]. Many of the T-H calculations conducted prior to 1995 were conducted with the V-TOUGH code [Nitao, 1990]. Both V-TOUGH and NUFT use the integrated-finite-difference method and simulate the transport of air, water, energy. NUFT also simulated the transport of other species, such as radionuclides. Both V-TOUGH and NUFT determine the spatial and temporal distribution of gasand liquid-phase pressure, gas- and liquid-phase saturation, air mass fraction in gas and liquid phases, water mass fraction in gas and liquid phases, and temperature. NUFT can treat the mechanical dispersion of components and can handle additional fluid phases, such as a nonaqueous hydrocarbon phase.

The V-TOUGH code was qualified for quality-affecting work, according to the Individual Software Plan (ISP) for V-TOUGH [Wilgus, 1995]. The NUFT code has been successfully benchmarked against the V-TOUGH code (which had already been qualified) and, as a result of that successful benchmarking, has also been qualified for quality-affecting work, according to the Individual Software Plan (ISP) for NUFT [Lewis, 1997; Lewis and Leibee, 1998].

The NUFT (Nonisothermal Unsaturated-Saturated Elow and Transport) code is a unified suite of multi-phase, multi-component codes for the numerical simulation of nonisothermal flow and transport in fractured porous media with application to geological, nuclear-waste storage and subsurface, environmental, contaminanttransport problems. NUFT is a highly computationally efficient and robust code that has been used to model and analyze a very wide range of computationally demanding problems. NUFT contains the entire suite of alternative models in a single source code, instead of multiple source-code versions and, consequently is easily maintained. The model-input format is user friendly and highly flexible and is designed to be upwardly compatible-that is, to facilitate future extensions to the capabilities of the code without conflicting with earlier model-input files. 
The following description pertains primarily to the USNT module of NUFT, which is used for solving the nonisothermal flow and transport equations of a multi-phase system with multiple components. Local thermodynamic equilibrium is assumed and partitioning coefficients are used for calculating the relative amount of species between the fluid phases. Vapor-pressure lowering is always turned on for the Yucca Mountain Project T-H calculations. The effective-continuum model (ECM) and dual-permeability model (DKM) options are used to represent fracturematrix interaction. Stochastically generated 3-D heterogeneous thermal- and hydrological-property fields with spatial correlation are generated from a userspecified autocorrelation function. The NUFT code can solve 1-, 2-, and 3-D problems. Heat transfer by thermal radiation is included in the code.

The distinct models implemented by the NUFT code utilize a common set of utility routines and input-file format. The various models are essentially isolated from each other and, hence future models can be added without affecting existing models. This also allows for easy maintenance and future enhancements. Global variables are virtually nonexistent. an embedded Lisp interpreter for the Scheme dialect reads the input file, which is in Lisp syntax, and performs data checking. The NUFT code is written in the C language and runs under the Unix and MS-DOS operating systems.

The following is the mathematical description of the balance equations solved by the USNT model in NUFT. Some features available in NUFT, such as kinetic chemical reactions, are not described here because they are not used in the T-H modeling. The convention used in this section to describe variables and component species is as follows. Variable superscripts refer to the component species and subscripts refer to the fluid phase. In general, any number of components and fluid phases is possible. Yucca Mountain Project T-H simulations assume two components, air (a) and water (w), and two fluid phases, gas (gas) and liquid (liq). The solid phase is assumed to be nondeformable although NUFT has the ability to handle isotropic solid compressibility in response to fluid pressure.

The mass balance equations for the air and water are

$$
\begin{aligned}
& \frac{\partial}{\partial t}\left(\rho_{\mathrm{B}} K_{\mathrm{d}}^{\gamma} \rho_{\alpha_{\mathrm{w}}} \omega_{\alpha_{\mathrm{w}}}^{\gamma}+\sum_{\alpha=\text { gas,liquid }} \phi \rho_{\alpha} s_{\alpha} \omega_{\alpha}^{\gamma}\right) \\
& \quad+\sum_{\alpha=\text { gas,liquid }} \nabla \cdot \phi \rho_{\alpha} \mathrm{s}_{\alpha}\left(\omega_{\alpha}^{\gamma} \mathrm{v}_{\alpha}+\mathrm{J}_{\mathrm{h} \alpha}^{\gamma}+\mathrm{J}_{\alpha}^{*}\right)=0, \quad \gamma=a, w,
\end{aligned}
$$

where Fickian laws for dispersive and diffusive fluxes are given by

$$
\begin{gathered}
\mathrm{J}_{\mathrm{h} \alpha}^{\gamma}=-D_{\mathrm{h} \alpha}^{\gamma} \nabla \omega_{\alpha}^{\gamma} \\
\mathrm{J}_{\alpha}^{* \gamma}=-D_{\alpha}^{* \gamma} \nabla \omega_{\alpha}^{\gamma}
\end{gathered}
$$

and Darcy's law gives 
$s_{\alpha} \phi \mathrm{V}_{\alpha}=-\frac{k_{\alpha}\left(s_{\alpha}\right)}{\mu_{\alpha}} \cdot\left(\nabla p_{\alpha}+\rho_{\alpha} g \nabla z\right)$

The retention pressure ("capillary pressure") relationships are given by $p_{\alpha}=p_{\text {gas }}-p_{\text {c } \alpha}\left(s_{\delta}\right), \quad \alpha \neq g$.

The various variables that are used are defined as follows:

$\omega_{\alpha}^{\gamma}=$ mass fraction of $\gamma$-component in phase $\alpha$

$S_{\alpha}=$ liquid saturation of $\alpha$-phase

$\phi=$ porosity

$\rho_{\alpha}=$ mass phase density

$\omega_{\alpha}^{\gamma}=$ mass fraction

$\mathbf{V}_{\alpha}=$ liquid phase velocity

$\mathbf{J}_{\mathrm{h} \alpha}^{\gamma}=$ hydrodynamic dispersive flux

$\mathrm{J}_{\alpha}^{* \gamma}=$ mass diffusive flux

$D_{\mathrm{h} \alpha}=$ dispersion tensor

$D_{\alpha}^{* \gamma}=$ diffusion coefficient

$k_{\alpha}=$ permeability function

$\mu_{\alpha}=$ liquid phase viscosity

$p_{\alpha}=$ phase pressure

$p_{\mathrm{c} \alpha}=$ retention pressure function

$\rho_{B}=$ bulk solid density

$K_{\mathrm{d}}^{\gamma}=$ solid adsorption coefficient

$\alpha_{\mathrm{w}}=$ wetting phase

For the non-isothermal problems such thermal-hydrology calculations the following balance equation for energy is solved in conjunction with the mass balance equations,

$$
\begin{aligned}
& \frac{\partial}{\partial t}\left[\sum_{\alpha=\text { gas,liquid }} \phi \rho_{\alpha} u_{\alpha} S_{\alpha}+(1-\phi) \rho_{\mathrm{s}} \mathrm{C}_{\mathrm{p}}\left(T-T_{\text {ref }}\right)\right]= \\
& \quad-\sum_{\gamma=\alpha, \mathrm{w} \alpha=\text { gas,liquid }}\left[\nabla \cdot \phi h_{\alpha}^{\gamma} \rho_{\alpha} s_{\alpha}\left(\omega_{\alpha}^{\gamma} V_{\alpha}+\mathrm{J}_{\text {h } \alpha}^{\gamma}+\mathrm{J}_{\alpha}^{* \gamma}\right)\right]+\nabla \cdot K_{\mathrm{H}} \nabla T,
\end{aligned}
$$


where

$T=$ temperature

$\mathrm{C}_{\mathrm{p}}=$ specific heat of solid

$\rho_{\mathrm{s}}=$ solid density

$u_{\alpha}=$ specific internal energy

$h_{\alpha}^{\gamma}=$ partial specific enthalpy

$K_{\mathrm{H}}=$ thermal conductivity

The balance equations are discretized in space using the integrated-finitedifference method, and discretized in time using the fully implicit backward Euler method. All three partial differential equations are fully-coupled. The resulting nonlinear system of equations are solved at each time step using the Newton Raphson method. Methods for solving the system of linear equations are (1) the direct-solution method using D4 ordering and (2) the preconditioned, conjugategradient method with various preconditioning schemes, including incomplete ILU with D4 or natural ordering. The primary solution variables predicted by the model are fluid pressure, mass fraction of water, liquid-phase saturation, and temperature.

\subsection{Numerical Models and Assumptions for TSPA-VA T-H Predictions}

The T-H models described in this section (Fig. 4) are those used by the multi-scale $\mathrm{T}-\mathrm{H}$ modeling approach to predict T-H conditions in the EBS for TSPA-VA (Table 2). The multi-scale modeling approach is outlined in Section 2.4. The EBS T-H predictions are for the reference areal mass loading (AML) of $85 \mathrm{MTU} / \mathrm{acre}$, which is based on the total MTU of emplaced commercial spent nuclear fuel (CSNF) and which neglects the MTU of other waste forms such as defense high-level waste. The inventory of WPs that is assumed to be emplaced at Yucca Mountain consists of several major WP types, including:

- Commercial spent nuclear fuel (CSNF) WPs, roughly half of which contains pressurized-water reactor (PWR) fuel assemblies and the other half containing boiling-water-reactor (BWR) fuel assemblies. The heat output from CSNF WPs varies widely from design-basis fuel (DBF) WPs that have a high heat output to older WPs that have a relatively low heat output.

- Co-disposal defense high-level waste (DHLW) WPs that contain DHLW glass logs and SNF. The heat output from co-disposal DHLW WPs is relatively low.

- Direct-disposal DOE SNF WPs that contain Department of Energy spent nuclear fuel. The heat output from these WPs is relatively low.

For mountain-scale model calculations, it is assumed that the repository-wide thermal-loading conditions can be characterized by a uniform radioactive heat-ofdecay curve (Table 3 ), which is a blend of the heat-of-decay curves from the entire 
inventory of WPs emplaced in the repository [Bahney, 1997]. This curwe is based on the total number of assemblies of the two major CSNF types (BWR and PWR), the total heat output from DHLW, and the major heat component of the DOE SNF. The repository-wide heat output assumes 63,000 MTU of CSNF, 4667 MTU of DHLW, 2333 MTU of the DOE SNF waste. For 85-MTU/acre repository, this results in a repository area of 741 acres. The actual repository area is slightly larger because 2 out of the 104 emplacement drift locations (about 2\%) do not contain WPs; therefore, the actual repository area is 758 acres, which is about $2 \%$ larger than 741 acres.

For drift-scale model calculations, it is assumed that the heat-of-decay curves for 7 WP types in Table 3.4 is representative of the wide range of WPs to be emplaced in the repository. These 7 WP types, which include both PWR and BWR CSNF WPs, co-disposal DHLW WPs, and direct-disposal DOE SNF WPs, span the range of heatof-decay curves, from the very high-heat-output design-basis fuel (DBF) CSNF WPs to low-heat-output DHLW WPs.

There are 4 different model-geometry/scale types (Table 4) used by the multiscale T-H modeling approach to predict EBS T-H conditions, including:

1. Smeared-heat-source, mountain-scale thermal-conduction (SMT) model.

2. Smeared-heat-source, drift-scale, thermal-conduction (SDT) model.

3. Line-averaged-heat-source, drift-scale, T-H (LDTH) model that uses the DKM.

4. Discrete-heat-source, drift-scale, thermal-conduction (DDT) model.

5. Line-averaged-heat-source, drift-scale, $\underline{T}-\underline{H}$, seepage (LDTH-S) model.

Model-geometry/scale types 1-4 are described in Section 3. Additional modelgeometry/scale types have been used during the course of sensitivity analysis and model-abstraction testing, including:

6. Smeared-heat-source, drift-scale, thermal-hydrological (SDTH) model.

7. Line-averaged-heat-source, drift-scale, $\mathrm{T}-\mathrm{H}$ (LDTH) model that uses the ECM.

8. Line-averaged-heat-source, drift-scale, T-H (LDTH) model that uses the DFM.

9. Discrete-heat-source, drift-scale, T-H (DDTH) model.

\subsubsection{Smeared-Heat-Source, Mountain-Scale T (SMT) Model}

The mountain-scale model used in the multi-scale $\mathrm{T}-\mathrm{H}$ modeling approach is a 3-D thermal-conduction ( $T$ ) model. This model was selected because its computational economy allowed for the use of fine lateral and vertical grid-block spacing in the repository area. At the repository edges, a lateral grid-block spacing of $15 \mathrm{~m}$ was used. In the vertical interval that corresponds to the dryout zone in T-H models, a vertical grid-block spacing of about $4 \mathrm{~m}$ was used. One of the test cases that would be useful to consider during the model-abstraction testing phase of TSPA-VA involves replacing the SMT model in the multi-scale T-H modeling approach with a smeared-heat-source, mountain-scale T-H (SMTH) model. 
The 3-D smeared-heat-source, mountain-scale thermal-conduction(SMT) model (Fig. 4d) incorporates the following processes, conditions, and assumptions:

- 3-D mountain-scale heat flow in the UZ and SZ is accounted for. The mode of heat flow is thermal conduction in the UZ and in the upper $1000 \mathrm{~m}$ of the SZ.

- Convective heat flow in the upper $1000 \mathrm{~m}$ of the $\mathrm{SZ}$ that is driven by regional groudwater flow can also be considered in the model-abstraction testing phase for a range of assumed horizontal fluxes in the SZ. However, for the base-case TSPA-VA EBS T-H predictions, the influence of regional groundwater flow on heat flow is assumed to be negligible.

- Topography, stratigraphy, thermal properties, and temperature $T$ boundary conditions of the site-scale UZ model (Bodvarsson and Bandurraga, 1996; Bodvarsson et al., 1997) are accounted for. Because the SMT model extends below the lower boundary of the site-scale UZ model, it is necessary to vertically extrapolate the $T$ distribution in the site-scale UZ model to below the water table. The initial $T$ distribution at the repository horizon in the SMT is the same as that in the site-scale UZ model.

- The influence of dryout on rock thermal conductivity $K_{\text {th }}$ is approximated with the use of a $K_{\text {th }}$ versus $T$ relationship. The dependence of $K_{\text {th }}$ on liquidphase saturation $S_{\mathrm{liq}}$ is approximated by correlating $T$ in a 1-D SDT model to $S_{\text {liq }}$ in a corresponding 1-D SDTH model and developing a corresponding functional relationship between $K_{\text {th }}$ and $T$ predicted by the T model. The $K_{\text {th }}$ versus $T$ relationship in the T model mimics the $K_{\text {th }}$ versus $S_{\text {liq }}$ in the T-H model.

- The vertical and areal geometry of the reference 85-MTU/acre repository design is closely approximated in the SMT. The $1.6 \%$ northward dip of the repository horizon is represented in the SMT, with the southern end of the repository having a higher elevation than the northern end. The areal extent of the repository is slightly idealized in the SMT (Fig. 1c). The actual repository area differs slightly from this idealized representation along the northern, western, and southern edges of the repository.

- Homogeneous thermal properties within any given hydrological-model unit.

- Thermal-loading conditions of the reference 85-MTU/acre repository is represented as a uniform 4.52-m-thick, smeared-heat source, which is a blend of the heat-of-decay curves for the entire waste inventory. The SMT assumes the same heat-producing area as the actual repository (758 acres or $\left.3.07 \mathrm{~km}^{2}\right)$.

The SMT captures the gross 3-D mountain-scale temperature distribution that arises from variations in stratigraphy, thermal-property distribution, topography, repository-wide thermal-load conditions, and edge-cooling effects.

The SMT-model input to the multi-scale $\mathrm{T}-\mathrm{H}$ modeling approach is:

- Location-specific repository host-rock temperature $T_{\text {rep }}(\mathrm{SMT})$. 
Further details of the multi-scale T-H modeling approach are discussed in Section 4 . The use of the SMT to predict the repository host-rock temperature $T_{\text {rep }}$ distribution requires the following assumptions:

- Mountain-scale, buoyant, gas-phase convection in the UZ does not significantly influence the $T_{\text {rep }}$ distribution.

- Mountain-scale condensate flow in the UZ does not significantly influence the $T_{\text {rep }}$ distribution.

- Mountain-scale, buoyant, liquid-phase convection in the SZ does not significantly influence the $T_{\text {rep }}$ distribution.

- The influence of regional groundwater flow does not significantly influence the $T_{\text {rep }}$ distribution.

It is important to note that the multi-scale $\mathrm{T}-\mathrm{H}$ modeling approach modifies the SMT-predicted repository host-rock temperature distribution to account for the influence of drift-scale T-H behavior on heat flow from the repository. This approach also translates host-rock temperatures, which effectively are an average between the drift wall and mid-pillar location, to the equivalent perimeter-averaged temperature at the drift wall. Details of this approach are described in Section 4. All of the above assumptions can be tested by replacing the SMT model with an equivalent SMTH model for the multi-scale T-H modeling approach.

\subsubsection{Smeared-Heat-Source, Drift-Scale T (SDT) Model}

The 1-D smeared-heat-source, drift-scale thermal-conduction (SDT) model (Fig. 4a) incorporates the following processes, conditions, and assumptions:

- At the mountain scale, 1-D vertical heat flow in the UZ is accounted for, which is equivalent to that of the LDTH and DDT models. For base-case TSPA-VA EBS T-H predictions, the water table is assumed to be a constant temperature boundary in the SDT, LDTH, and DDT models, with the local water-table temperature taken from the site-scale UZ flow model. 1-D vertical heat flow in the SZ can also be considered during model-abstraction testing.

- At the drift scale, 1-D heat flow is represented in the near-field rock.

- Local topography, stratigraphy, thermal properties, and temperature $T$ boundary conditions of the site-scale UZ model (Bodvarsson and Bandurraga, 1996; Bodvarsson et al., 1997). The SDT-model calculations are made throughout the repository area in either a slightly irregular $3 \times 5$ grid or a uniform $5 \times 7$ grid (Fig. 1c and Table 5a). The 3x5 grid with 15 drift-scale-model locations was used for sensitivity analysis [Buscheck et al., 1997]. The $5 \times 7$ grid with 35 drift-scale-model locations is used for the TSPA-VA EBS T-H predictions. Figures 6-12 give the vertical hydrostratigraphy for the 35 driftscale-model locations. The SDT-model calculations are made in parallel with the LDTH model calculations. 
- Homogeneous thermal properties within any given hydrological-model unit.

- The thermal load is represented as a 4.52 -m-thick, smeared-heat source, just as in the SMT model; however, the SDT model does not use the same heatof-decay curve as the SMT model.

- The smeared-heat source in the SDT model uses a heat-of-decay curve that is an areal average of the heat-of-decay curves used in the LDTH and DDT models. The SDT, LDTH, and DDT models all assume the same 7 WP-types that are described in Table 3.

- AMLs of $85,56.67$, and $42.5 \mathrm{MTU} /$ acre are assumed for SDT-model calculations, as with the LDTH-model calculations. The lower 2 AML calculations are required to represent cooler areas of the repository; in particular, the edge locations of the repository.

One of the primary roles for the SDT model in the multi-scale T-H modeling approach is to provide a functional relationship between repository host-rock temperatures predicted with a thermal-conduction model and the perimeteraveraged drift-wall temperature predicted by a $\mathrm{T}-\mathrm{H}$ model. This functional relationship allows the mapping of the LDTH-model-predicted perimeter-averaged drift-wall temperature $T_{\mathrm{dw}}$ (LDTH) onto the SMT-model-predicted repository hostrock temperature distribution $T_{\text {rep }}(\mathrm{SMT})$.

The SDT-model input to the multi-scale T-H modeling approach is:

- Repository host-rock temperature $T_{\text {rep }}(\mathrm{SDT})$.

Further details of the multi-scale T-H modeling approach are given in Section 4.

\subsubsection{Line-Averaged-Heat-Source, Drift-Scale T-H (LDTH) Model}

The 2-D line-averaged-heat-source, drift-scale thermal-hyydrological (LDTH) model (Fig. 4b) incorporates the following processes, conditions, and assumptions:

- At the mountain scale, 1-D vertical heat flow in the UZ is accounted for, which is equivalent to that of the SDT and DDT models. For base-case TSPAVA EBS T-H predictions, the water table is assumed to be a constant temperature boundary in the SDT, LDTH, and DDT models, with the local water-table temperature taken from the site-scale UZ flow model. 1-D vertical heat flow in the SZ can also be considered during model-abstraction testing.

- Point-load and line-load designs are considered.

- At the drift scale, 2-D heat flow is represented in the near-field rock and in the emplacement drifts. Heat flow in and near the drifts is primarily radial.

- The cross-sectional 2-D geometry of the emplacement drifts is represented, including the invert, WP, and the open drift lying below, above, and to the side of the WP. The open space in the drift is filled with engineered backfill for the backfill scenarios. As was demonstrated in an earlier modeling study 
[Buscheck, 1996], a circular WP in a circular drift can be accurately represented by a square WP in a square drift, provided that the circular cross-sectional areas are equal to the equivalent square cross-sectional areas. Accordingly, the circular cross-sectional geometry of the WP and drift are approximated with squares having the same cross-sectional areas as their circular counterparts (Fig. 13). The 5.1-m diameter drift is represented as being $4.52 \mathrm{~m} \times 4.52 \mathrm{~m}$ in cross section. All WPs are assumed to have a diameter of $1.63 \mathrm{~m}$; WPs are represented as being $1.445 \mathrm{~m} \times 1.445 \mathrm{~m}$ in cross section. The invert, which is at the bottom of the drift, is assumed to occupy $16.6 \%$ of the drift cross section. Note that the cross-sectional drift geometry is the same in the LDTH and DDT models.

- Thermal-radiative heat transfer is represented between all surfaces in the emplacement drifts, with the primary component of heat flow being between the WPs and the adjacent drift-wall and drift-floor surfaces.

- Local topography, hydrostratigraphy, thermal properties, hydrological properties, and boundary conditions $\left(T, X_{\text {air,gas }}, P_{\text {gas }}\right)$ of the site-scale UZ model (Bodvarsson and Bandurraga, 1996; Bodvarsson et al., 1997). The LDTH model calculations are made throughout the repository area in either a slightly irregular $3 \times 5$ grid or a uniform $5 \times 7$ grid (Fig. 1c and Table 5a). Figures 6-12 give the vertical hydrostratigraphy for the 35 drift-scale-model locations. The LDTH model calculations are made in parallel with the SDT model calculations.

- Local infiltration flux from the Flint and Hevesi [1996] infiltration map. For the $3 \times 5$ grid, an exponential area weighting function is used with a length scale of $100 \mathrm{~m}$; for the $5 \times 7$ grid, the length scale is $50 \mathrm{~m}$. The assumed infiltration flux values for the $3 \times 5$ and $5 \times 7$ grid are given in Table $5 \mathrm{~b}$.

- Homogeneous thermal and hydrological properties within any given hydrological-model unit.

- The line-averaged-heat source in the LDTH model uses a heat-of-decay curve that is an average of the heat-of-decay curves of the 8 individual WPs (including 7 WP types) represented in the DDT model. In other words, the LDTH model smears out the heat output from 8 WPs into a line-averaged heat source. The SDT, LDTH, and DDT models all assume the same 7 WPtypes that are described in Table 3.

- The dual-permeability model (DKM) is used to represent fracture-matrix interaction. The effective-continuum model (ECM) can also be used in the model-abstraction testing phase.

- AMLs of 85, 56.67, and 42.5 MTU/acre are assumed for LDTH-model calculations, as with the SDT-model calculations. The lower 2 AML calculations are required to represent cooler areas of the repository; in particular, the edge locations of the repository. 
One of the primary roles for the LDTH model in the multi-scale $\mathrm{T} \times \mathrm{H}$ modeling approach is to provide a functional relationship between repository host-rock temperatures predicted with a thermal-conduction model and the perimeteraveraged drift-wall temperature predicted by a T-H model. This relationship allows the mapping of the LDTH-model-predicted perimeter-averaged drift-wall temperature $T_{\mathrm{dw}}(\mathrm{LDTH})$ onto the SMT-model-predicted repository host-rock temperature distribution $T_{\text {rep }}(\mathrm{SMT})$, yielding the equivalent of a line-averaged-heatsource, mountain-scale T-H (LMTH) model prediction of the perimeter-averaged drift-wall temperature $T_{\mathrm{dw}}(\mathrm{LMTH})$ throughout the repository area.

Another important role for the LDTH model in the multi-scale T-H modeling approach is to provide a functional relationship between the $T_{\mathrm{dw}}(\mathrm{LDTH})$ and
hydrological conditions in the near field and in the EBS, including the perimeteraveraged relative humidity $R H$ in the rock at the drift wall $R H_{\mathrm{dw}}(\mathrm{LDTH})$, the liquidphase flux $3 \mathrm{~m}$ above the drift, the gas-phase, air-mass fraction $X_{\text {air,gas }}(\mathrm{LDTH})$ in the drift, and the liquid-phase saturation in the invert $S_{\text {liq,inv }}$ (LDTH).

The LDTH-model inputs to the multi-scale $\mathrm{T}-\mathrm{H}$ modeling approach are:

- Perimeter-averaged, drift-wall temperature $T_{\mathrm{dw}}(\mathrm{LDTH})$.

- Perimeter-averaged, drift-wall relative humidity $R H_{\mathrm{dw}}$ (LDTH).

- Perimeter-averaged, drift-wall liquid-phase saturation $S_{\text {liq }}$ (LDTH).

- Gas-phase, air-mass fraction in the drift $X_{\text {air,gas }}($ LDTH).

- Liquid-phase flux $3 \mathrm{~m}$ above the drift $q_{\text {liq }}$ (LDTH).

- Liquid-phase saturation in the invert $S_{\text {liq,inv }}(\mathrm{LDTH})$.

Further details of the multi-scale T-H modeling approach are given in Section 4.

\subsubsection{Discrete-Heat-Source, Drift-Scale $T$ (DDT) Model}

The 3-D discrete-heat-source, drift-scale thermal-conduction (DDT) model (Fig. $4 c)$ incorporates the following processes, conditions, and assumptions:

- At the mountain scale, 1-D vertical heat flow in the UZ is accounted for, which is equivalent to that of the SDT and LDTH models. For base-case TSPAVA EBS T-H predictions, the water table is assumed to be a constant temperature boundary in the SDT, LDTH, and DDT models, with the local water-table temperature taken from the site-scale UZ flow model. 1-D vertical heat flow in the SZ can also be considered during model-abstraction testing.

- Point-load and line-load designs are considered as well as no-backfill and backfill scenarios.

- At the drift scale, 3-D heat flow is represented in the near-field rock and in the emplacement drifts. For the point-load design, heat flow in and near the drifts is spherical at early time, becoming primarily radial at later time. For the lineload design, heat flow in and near the drifts is primarily radial. 
- The full 3-D geometry of the emplacement drifts is represented; including the invert, WP, the open drift lying below, above, and to the side of the WPs, and the open drift lying between WPs (Fig. 14). The open space in the drift is filled with engineered backfill for the backfill scenarios. The circular cross-sectional geometry of the WP and drift are approximated with squares having the same cross-sectional areas as their circular counterparts (Figs. 6-12). The 5.1-m diameter drift is represented as being $4.52 \mathrm{~m} \times 4.52 \mathrm{~m}$ in cross section. All WPs are assumed to have a diameter of $1.63 \mathrm{~m}$; WPs are represented as being 1.445 $\mathrm{m} \times 1.445 \mathrm{~m}$ in cross section. The invert, which is at the bottom of the drift, is assumed to occupy $16.6 \%$ of the drift cross section. Note that the crosssectional drift geometry is the same in the LDTH and DDT models.

- Thermal-radiative heat transfer is represented between all surfaces in the emplacement drifts, with the primary component of heat flow being between the WPs and the adjacent drift-wall and drift-floor surfaces. For the line-load design, thermal-radiative heat flow between WPs is also important, particularly for the line-load design.

- Local topography, stratigraphy, thermal properties, and temperature $T$ boundary conditions of the site-scale UZ model (Bodvarsson and Bandurraga, 1996; Bodvarsson et al., 1997). For the base-case TSPA-VA VA EBS T-H predictions, DDT model calculations are conducted for the center location of the repository, which is the $13 \mathrm{c} 2$ drift-scale-model location in the $3 \times 5$ grid and the 14c3 location in the $5 \times 7$ grid (Table 5a). Other drift-scale-model locations can be considered in the model-abstraction testing phase.

- Homogeneous thermal properties within any given hydrological-model unit.

- The DDT model discretely represents decay-heat output from 8 WPs, with different heat-of-decay curves for 7 WP types being considered (Table 3 ). The DDT represents 6 full WPs and 2 half WPs. The SDT, LDTH, and DDT models all assume the same 7 WP-types that are described in Table 3.

- An AML of $85 \mathrm{MTU} /$ acre is assumed for the DDT-model calculations for the base-case TSPA-VA EBS T-H predictions. Other AMLs can be considered in the model-abstraction testing phase.

The LDTH model determines average T-H behavior along emplacement drifts that result from lineally averaged heating conditions. The LDTH cannot represent the influence of (1) WP length, (2) axial WP spacing, and (3) decay-heat-output variability among WPs on axial temperature variability along the drift; the DDT model captures the influence of these three factors on the axial temperature distribution along the emplacement drift, including the drift-surface and WP temperatures. 
The LDTH model assumes 2-D radial heat flow between the WP and drift surfaces, while for the point-load design, WP-to-drift-surface heat transfer is spherical (i.e., 3-D). The efficiency of WP-to-drift-surface heat transfer determines the temperature difference between the WP and drift surfaces (called $\Delta T_{\mathrm{wp}}$ ). Whether it is heat transfer by thermal radiation, as occurs in the no-backfill case, or heat transfer by thermal conduction, as occurs in the backfill case, it is crucial to fully represent 3-D heat flow in the emplacement drift. The DDT model captures the influence of 3-D heat flow on $\Delta T_{\mathrm{wp}}$.

One of the primary roles for the DDT model in the multi-scale T-H modeling approach is to represent the drift-wall temperature deviations that occur between specific WP locations and the average drift-wall temperature along the drift (called $\left.\Delta T_{\mathrm{dw}}\right)$. The other primary role is to determine the temperature difference between the WP and the average drift-wall temperature $\Delta T_{\mathrm{wp}}$.

The DDT-model inputs to the multi-scale T-H modeling approach are:

- WP-location-specific temperature deviations $\Delta T_{\mathrm{dw}}$ from the average drift-wall temperature along the drift.

- WP-location-specific temperature difference $\Delta T_{\text {wp }}$ between the WP and the average drift-wall temperature along the drift.

A sensitivity study was conducted to determine whether a DDT model adequately represents how 3-D heat flow in the drift and in the near-field rock determines $\Delta T_{\mathrm{dw}}$ and $\Delta T_{\mathrm{wp}}$ or whether a DDTH model is required to determine $\Delta T_{\mathrm{dw}}$ and $\Delta T_{\mathrm{wp}}$ at each of the WP locations. Although the DDT model predicted higher drift-wall and WP temperatures than the DDTH model, the DDT and DDTH models produced very similar values of $\Delta T_{\mathrm{dw}}$ and $\Delta T_{\mathrm{wp}}$ at each of the $8 \mathrm{WP}$ locations in the models. These models produce similar values of $\Delta T_{\mathrm{dw}}$ and $\Delta T_{\mathrm{wp}}$ in spite of treating heat flow differently in the near-field rock.

The relative difference in temperature between hotter and cooler intervals along the emplacement drift is controlled by the mechanisms that determine the heat-flux distribution along the surfaces of the drift. It is important to note that the mechanisms that control the heat-flux distribution occur entirely within the drift: thermal radiation for the no-backfill case; thermal conduction in the backfill for the backfill case. Advective-heat-flow processes, which are driven by T-H behavior in the near-field rock, impart little additional influence on the axial temperature distribution along the drift wall beyond that which arises from thermal radiation in the drift and thermal conduction in the rock. In other words, the advective-heatflow mechanisms in the near-field rock do little to enhance the efficiency of heat flow in the axial direction beyond that which already results from thermal radiation in the drift and thermal conduction in the rock.

On the basis of this sensitivity analysis, it is sufficient to use the DDT model to determine $\Delta T_{\mathrm{dw}}$ and $\Delta T_{\mathrm{wp}}$ at each of the WP locations. This finding is particularly useful since it requires several days to conduct a single DDTH-model calculation on a Sun Ultra2 Sparc workstation, while it only takes about 1 hour to conduct a single DDT-model calculation. 


\subsubsection{Line-Averaged-Heat-Source, Drift-Scale, T-H, Seepage (LDTH-S) Model}

The 2-D line-averaged-heat-source, drift-scale, thermal-hydrological, seepage (LDTH-S) model is similar to the LDTH with respect to model geometry, boundary conditions, thermal properties, and hydrological properties. Numerically, the LDTH-S model is nested inside of the LDTH model. This nested region is a very fine-grid representation of the emplacement drift, WP, and near field. The fine-grid region allows the LDTH-S to represent the circular cross-sectional geometry of the emplacement drift and WP. The fine-grid region also allows for representing spatial heterogeneity in the hydrological properties at a fine scale. Because of the realistic representation of the drift geometry, the LDTH-S model is able to represent how $\therefore \quad$ much liquid-phase flow is diverted around the drift versus seeping into the drift. The LDTH-S model incorporates the following processes, conditions, and assumptions:

- At the mountain scale, 1-D vertical heat flow in the UZ is accounted for, which is equivalent to that of the SDT, LDTH, and DDT models. For base-case TSPA-VA EBS T-H predictions, the water table is assumed to be a constant temperature boundary in the SDT, LDTH, LDTH-S, and DDT models, with the local water-table temperature taken from the site-scale UZ flow model. 1-D vertical heat flow in the $\mathrm{SZ}$ can also be considered during model-abstraction testing.

- Point-load and line-load designs are considered.

- At the drift scale, 2-D heat flow is represented in the near-field rock and in the emplacement drifts. Heat flow in and near the drifts is primarily radial.

- The cross-sectional 2-D geometry of the emplacement drifts is represented, including the invert, WP, and the open drift lying below, above, and to the side of the WP.

- Thermal-radiative heat transfer is represented between all surfaces in the emplacement drifts, with the primary component of heat flow being between the WPs and the adjacent drift-wall and drift-floor surfaces.

- Local topography, hydrostratigraphy, thermal properties, hydrological properties, and boundary conditions $\left(T, X_{\text {air,gas }}, P_{\text {gas }}\right)$ of the site-scale UZ model (Bodvarsson and Bandurraga, 1996; Bodvarsson et al., 1997). The LDTH-S model calculations are conducted for the geographic center of the repository area; either the $13 \mathrm{c} 2$ location for the $3 \times 5$ grid or the $14 \mathrm{c} 3$ location for the $5 \times 7$ grid (Table 5a). The LDTH-S model calculations are made in parallel with the LDTH model calculations at the geographic center of the repository.

- Local infiltration flux at the geographic center of the repository taken from the Flint and Hevesi [1996] infiltration map. A wide range of alternative infiltration flux values are also considered. 
- Homogeneous thermal and hydrological properties within anyegiven hydrological-model unit outside of the near field.

- Heterogeneous or homogeneous thermal and hydrological properties in the near field (which is represented by the finely-gridded nested region of the numerical mesh). Subdomains can be specified, each with its own statistically consistent stochastic field. For example, each lithological unit can have it own statistical properties. Any set of thermal or hydrological parameters within a subdomain can be a function of up to three independent stochastic fields. For example, the fracture permeability can be equal to one random field $X$ and the van Genuchten alpha parameter can be equal to $X^{1 / 2}+Y$ where $X$ and $Y$ are statistically uncorrelated.

- The line-averaged-heat source in the LDTH-S model uses the same heat-ofdecay curve as does the LDTH model, which is based on an average of the heat-of-decay curves of the 8 individual WPs (including 7 WP types) represented in the DDT model (Table 3).

- The dual-permeability model (DKM) is used to represent fracture-matrix interaction for the isothermal-model calculations. For the nonisothermalmodel calculations, the effective-continuum model (ECM) is used.

- An AML of $85 \mathrm{MTU} /$ acre is assumed.

The primary role of the LDTH-S model is to provide input to the multi-scale T-H modeling approach for predicting seepage into drifts $q_{\text {seep }}$. This input is particularly important during the period of decay-heat-mobilized condensate flow. The multiscale T-H modeling approach predicts the liquid-phase flux $q_{\text {liq }}$ in the near-field rock $3 \mathrm{~m}$ above emplacement drifts throughout the entire repository area. This prediction of $q_{\text {liq }}$ is for the assumption of homogeneous thermal and hydrological properties in any given hydrological-model unit. Moreover, the LDTH model, which is used in the multi-scale T-H modeling approach, does not have fine enough gridding around the drift to determine how much (if any) of the liquid-phase flow around the drift is able to seep into the drift.

The LDTH-S model calculations are conducted in parallel with an equivalent LDTH model to develop the functional relationship between the LDTH-modelpredicted $q_{\mathrm{liq}} 3 \mathrm{~m}$ above the emplacement drift and the LDTH-S-model-predicted $q_{\text {seep. }}$. With the use of the LDTH-S model input, the multi-scale T-H modeling approach is able to account for the influence of heterogeneity in the near-field rock on seepage into emplacement drifts.

The LDTH-S-model inputs to the multi-scale T-H modeling approach are:

- Drift-seepage flux $q_{\text {seep }}$ (LDTH-S).

- Liquid-phase flux that contacts the WP $q_{\text {liq,wp }}($ LDTH-S).

Further details of the multi-scale T-H modeling approach are discussed in Section 4. 


\section{Multi-Scale T-H Modeling Approach}

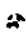

\subsection{Purpose of the Multi-Scale T-H Modeling Approach}

A multi-scale T-H modeling approach has been developed that integrates the results from 1-, 2-, and 3-D drift-scale models and a 3-D mountain-scale model (Fig. 4) to provide a full description of the T-H variables (Table 2) affecting the performance of the engineered barrier system (EBS). This information is required by Total Systems Performance Assessment for the Viability Assessment (TSPA-VA) to assess waste-package (WP) corrosion, waste-form dissolution, and radionuclide transport in the EBS. The T-H variables (Table 2) are provided to TSPA-VA as a function of the following:

- Location in the repository area, including the influence of the local hydrostratigraphy and percolation flux.

- WP type, such as commercial spent nuclear fuel (CSNF) versus defense highlevel waste (DHLW), WP age and burnup, WP spacing, and WP sequencing.

- Design options such as the line-load design or backfill.

The influence of the following model assumptions and boundary conditions can be assessed:

- Alternative thermal-property sets.

- Alternative hydrological-property sets.

- Infiltration-flux distributions, including the influence of climate change.

- Conceptual models of fracture-matrix interaction, such as the effectivecontinuum model (ECM) and dual-permeability model (DKM).

- Heat-flow assumptions at the water table, such as a fixed-temperature assumption versus explicitly representing heat flow in the SZ.

This multi-scale modeling approach uses complementary thermal-hydrological (T-H) and thermal-conduction (T) models at various scales and conceptualizations that are described in Section 3.4. A complementary suite of model types and scales is required to capture mountain-scale heat flow driven by the overall repository thermal-loading conditions and drift-scale T-H behavior driven by spatially variable decay-heat flux from individual WPs, each having distinctively different (and sometimes widely varying) heat-output histories. To explicitly account for these effects in a monolithic multi-scale T-H model would require approximately 60 million gridblocks, which is computationally beyond the capability of the current generation of T-H numerical-simulation codes. With the use of the NUFT numerical-simulation code, a complete set of 424 model runs; which is required by the multi-scale T-H modeling approach to predict EBS T-H conditions for a single 
TSPA-VA scenario, usually requires 12-16 hours to run on 9 Sun Ultza2 Sparc workstation processors.

\subsection{Outline of Calculational Procedure to Predict EBS T-H Conditions}

The multi-scale T-H modeling approach is outlined in Fig. 15. This procedure involves seven major calculational steps, with several of the steps consisting of several parts. The incremental results of the calculational procedure are show as the orange boxes in Fig. 15. The interpolation/calculational steps are show as the green boxes. The major steps are the following.

1. Conduct numerical-model calculations with the use of the NUFT code (shown as the blue boxes in Fig. 15).

2. Construct the functional relationships, which are called "scanning curves" between the model-output variables from complementary drift-scale models (shown as the yellow boxes in Fig. 15).

3. Interpolate the distribution of average drift-wall temperature in the repository using a mountain-scale model and the scanning curves from step 2. The result of this step is the drift-wall temperature distribution in the "abstracted" LMTH model.

4. Interpolate the distribution of drift-wall temperature in the repository for each WP type the temperature distribution from step 3 and the scanning curves from step 2 . The result of this step is the drift-wall temperature distribution from the abstracted DMTH model.

5. Interpolate the distribution of near-field and in-drift hydrological conditions in the repository for each WP type using the temperature distribution from step 3 and the scanning curves from step 2. The result of this step are the following DMTH-model-predicted distributions:

- Drift-wall relative humidity distribution $R H_{\mathrm{dw}}$.

- Drift-wall liquid-phase saturation distribution $S_{\text {liq. }}$

- Liquid-phase flux distribution $3 \mathrm{~m}$ above the drift $q_{\text {liq. }}$

- Gas-phase, air-mass fraction in the drift (next to the WP) $X_{\text {air,gas. }}$

- Liquid-phase saturation in the invert (below the WP) $S_{\text {liq,inv. }}$.

6. Determine the distribution of temperature on WPs throughout the repository area for each WP type using the drift-wall temperature distribution from step 3 and scanning curves from step 2. The result of this step is the DMTH-modelpredicted WP temperature distribution $T_{\text {wp }}$ for each WP type.

7. Determine the distribution of relative humidity on WPs throughout the repository area for each WP type using the drift-wall temperature $T_{\mathrm{dw}}$ distribution from step 3 , the WP temperature $T_{w p}$ distribution from step 5 , and and the relationship $R H_{\mathrm{wp}}=R H_{\mathrm{dw}}\left[P_{\text {sat }}\left(T_{\mathrm{dw}}\right) / P_{\text {sat }}\left(T_{\mathrm{wp}}\right)\right]$, where $P_{\text {sat }}$ is equal to the 
saturated vapor pressure. The result of this step is the DMTH-model-predicted WP relative humidity distribution $R H_{\mathrm{wp}}$ for each WP type.

\subsubsection{Calculational Procedure to Predict EBS $\mathbf{T}-\mathrm{H}$ Conditions} steps:

The multi-scale T-H modeling approach (Fig. 15) involves 6 major calculational

1. Conduct numerical-model calculations with the use of the NUFT code, including the following models:

- Smeared-heat-source, mountain-scale thermal-conduction (SMT) model.

- Smeared-heat-source, drift-scale, thermal-conduction (SDT) model.

- Line-averaged-heat-source, drift-scale, T-H (LDTH) model that uses the DKM.

- Discrete-heat-source, drift-scale, thermal-conduction (DDT) model.

- Line-averaged-heat-source, drift-scale, I- $\mathrm{H}$, seepage (LDTH-S) model.

2. Construct the functional relationships (called "scanning curves") between the model-output variables, including the following relationships:

- $T_{\text {rep }}(S M T ; x, y)$ distribution, which is the SMT-model predicted host-rock temperature as a function of the coordinate $(x, y)$ location in the repository area.

- $T_{d w}(\mathrm{LDTH})$ versus $T_{\text {rep }}$ (SDT), which is the LDTH-model-predicted drift-wall temperature $T_{\mathrm{dw}}$ versus the SDT-model-predicted, host-rock temperature $T_{\text {rep }}$ (Fig. 16a). This requires the parallel use of both the LDTH and SDT models. The variable $T_{\mathrm{dw}}$ is the average over the perimeter of the drift wall. This relationship is developed for all 35 drift-scale-model locations and AMLs of 85, 56.67, and 42.5 MTU/acre. The three different AML "scanning" curves in Fig. 16a guide the interpolation (described in step 3) of the local scanning curve that reflects the influence of local heating conditions and percolation flux on $T_{\mathrm{dw}}$ in a given region of the repository. At the center of the repository it is likely that the 85-MTU/acre curve will apply, while close to the repository edge, edge cooling may cause the local scanning curve to lie between the 42.5and 56.67-MTU/acre curves.

- $R H_{\mathrm{dw}}(\mathrm{LDTH})$ versus $T_{\mathrm{dw}}(\mathrm{LDTH})$, which is the LDTH-model-predicted, driftwall relative humidity $R H_{\mathrm{dw}}$ versus drift-wall temperature $T_{\mathrm{dw}}$ (Fig. 16b). The variables $T_{\mathrm{dw}}$ and $R H_{d w}$ are averages over the perimeter of the drift wall. This relationship is developed for all 35 drift-scale-model locations and AMLs of 85, 56.67, and 42.5 MTU/acre. The three different AML scanning curves in Fig. $16 \mathrm{~b}$ guide the interpolation (described in step 3 ) of the local scanning curve that reflects the influence of local heating conditions and percolation flux on dryout behavior in a given region of the repository. During the heat-up phase, nonequilibrium fracture-matrix behavior causes a lag in rock dryout (and $R H$ reduction), making it necessary for $T_{\mathrm{dw}}$ to rise well above the 
nominal boiling point before dryout begins. During the cooldown, rewetting (and $R H$ rise) lag behind the decline in $T_{\mathrm{dw}}$.

- $S_{1 \mathrm{liq}}(\mathrm{LDTH})$ versus $T_{\mathrm{dw}}(\mathrm{LDTH})$, which is the LDTH-model-predicted, drift-wall liquid-phase saturation $S_{\text {liq }}$ versus drift-wall temperature $T_{\mathrm{dw}}$ (Fig. 16c) The variables $T_{\mathrm{dw}}$ and $S_{\mathrm{liq}}$ are averages over the perimeter of the drift wall. This relationship is developed for all 35 drift-scale-model locations and AMLs of 85, 56.67, and 42.5 MTU/acre. The three different AML scanning curves in Fig. $16 \mathrm{c}$ guide the interpolation (described in step 3 ) of the local scanning curve that reflects the local heating conditions and dryout conditions in a given region of the repository. During the heat-up phase, nonequilibrium fracturematrix behavior causes a lag in rock dryout (and $S_{\text {liq }}$ reduction), making it necessary for $T_{\mathrm{dw}}$ to rise well above the nominal boiling point before dryout begins. During the cooldown, rewetting (and $S_{\text {liq }}$ rise) lag behind the decline in $T_{\mathrm{dw}}$.

- $q_{\mathrm{liq}}(\mathrm{LDTH})$ versus $T_{\mathrm{dw}}(\mathrm{LDTH})$, which is the LDTH-model-predicted, liquidphase flux $q_{\text {liq }} 3 \mathrm{~m}$ above the drift versus drift-wall temperature $T_{\mathrm{dw}}$ (Fig. 16d). This relationship is developed for all 35 drift-scale-model locations and AMLs of $85,56.67$, and $42.5 \mathrm{MTU} /$ acre. . The three different AML scanning curves in Fig. 16d guide the interpolation (described in step 3) of the local scanning curve that reflects the influence of local heating conditions and percolation flux on liquid-phase flux in a given region of the repository.

- $X_{\text {air,gas }}(\mathrm{LDTH})$ versus $T_{\mathrm{dw}}(\mathrm{LDTH})$, which is the LDTH-model-predicted, gasphase, air-mass fraction in the drift (adjacent to the WP) versus drift-wall temperature $T_{\mathrm{dw}}$ (Fig. 16e). This relationship is developed for all 35 drift-scalemodel locations and AMLs of 85, 56.67, and $42.5 \mathrm{MTU} / \mathrm{acre}$. The three different AML scanning curves in Fig. 16e guide the interpolation (described in step 3) of the local scanning curve that reflects the influence of local heating conditions on gas-phase, air-mass fraction in a drift in a given region of the repository.

- $S_{\mathrm{liq}, \mathrm{inv}}(\mathrm{LDTH})$ versus $T_{\mathrm{Idw}}(\mathrm{LDTH})$, which is the LDTH-model-predicted liquidphase saturation in the invert versus the temperature $T_{1 d w}$ at the lower drift wall (Fig. 16f). This relationship is developed for AMLs of 85, 56.67, and 42.5 MTU/acre and the 14c3 drift-scale model location. The three different AML scanning curves in Fig. 16f guide the interpolation (described in step 3) of the local scanning curve that reflects the influence of local heating conditions on dryout behavior in the invert of a drift in a given region of the repository.

- $\Delta T_{\mathrm{dw}}$ (DDT; WP-type), which is the DDT-model-predicted temperature deviation $\Delta T_{\mathrm{dw}}$ from the average drift-wall temperature along the drift for a given WP type (Fig. 17a). This step is required to modify the LDTH-modelpredicted $T_{\mathrm{dw}}$ to account for the influence of the local heating conditions. The value of $\Delta T_{\mathrm{dw}}$ will generally be positive for the point load design because of the large gaps (in the axial direction) between WPs. Hot WP locations will have a large positive $\Delta T_{\mathrm{dw}}$, particularly at early time, while cool WP locations will have a negative $\Delta T_{\mathrm{dw}}$. The value $\Delta T_{\mathrm{dw}}$ is determined for each WP 
location in the DDT model by subtracting the average $T_{\mathrm{dw}}$ along the entire drift in the DDT model from the local $T_{\mathrm{dw}}$ at a given WP location. This relationship is developed for an AML of $85 \mathrm{MTU} /$ acre and the $14 \mathrm{c} 3$ drift-scale model location, which is at the geographic center of the repository.

- $\Delta T_{\text {wp }}$ (DDT; WP-type), which is the DDT-model-predicted temperature difference $\Delta T_{\text {wp }}$ between the WP and drift wall for a given WP type (Fig. 17b). This step is required to predict the WP temperature. The value of $\Delta T_{\text {wp }}$ will always be positive for all WP locations. Hot WP locations will have a large $\Delta T_{\text {wp }}$, particularly at early time, while cool WP locations will have a smaller $\Delta T_{\text {wp }}$. For backfill cases, $\Delta T_{\text {wp }}$ will be extremely large, particularly immediately after backfill is emplaced. The value $\Delta T_{\mathrm{wp}}$ is determined for each WP in the DDT model by subtracting the average $T_{\mathrm{dw}}$ along the entire drift in the DDT model from the WP temperature $T_{\mathrm{wp}}$. This relationship is developed for an AML of $85 \mathrm{MTU} /$ acre and the 14c3 drift-scale model location, which is at the geographic center of the repository.

3. Interpolate the distribution of average drift-wall temperature in the repository, using the following calculational steps to determine the following:

- $T_{\mathrm{dw}}(\mathrm{LMTH} ; \mathrm{x}, \mathrm{y})$ distribution in the repository is calculated for average driftwall conditions using the $T_{\text {rep }}(\mathrm{SMT} ; x, y)$ distribution and the $T_{\mathrm{dw}}(\mathrm{LDTH})$ versus $T_{\text {rep }}(\mathrm{SDT})$ relationships at the $35 \mathrm{drift}$-scale-model locations and 3 AMLs (Fig. 16a). This process involves spatial interpolation between the 35 drift-scale-model locations. This process also involves interpolating between the 3 AML scanning curves in Fig. 16a. The net result of this calculational step is the distribution of average drift-wall temperatures as a function of location in the repository. Because the result of this process is equivalent to having a line-average-heat-source, mountain-scale, T- $\mathrm{H}$ (LMTH) model prediction of the distribution of $T_{\mathrm{dw}}$ in the repository; hence, the resulting distribution is called $T_{\mathrm{dw}}(\mathrm{LMTH} ; \mathrm{x}, \mathrm{y})$, where $\mathrm{x}$ and $\mathrm{y}$ refer to the coordinate location in the repository.

4. Interpolate the distribution of drift-wall temperature in the repository for each WP type, using the following calculational step:

- $T_{\mathrm{dw}}(\mathrm{DMTH} ; x, y, W P-t y p e)$ distribution in the repository is calculated for each WP type by adding $\Delta T_{d w}(D D T ; W P-t y p e)$ to the $T_{d w}(L M T H ; x, y)$ distribution (which was determined in the previous step). This calculational step determines the distribution of drift-wall temperature as a function of WP type and location in the repository. The net result of this step is equivalent to having a discrete-heat-source, mountain-scale, $\mathrm{T}-\mathrm{H}$ (DMTH) model prediction of the $T_{\mathrm{dw}}$ distribution in the repository for each WP type; hence the resulting distribution is called $T_{\mathrm{dw}}(\mathrm{DMTH} ; \mathrm{x}, \mathrm{y}, \mathrm{WP}$-type), where $x$ and $y$ refer to the coordinate location in the repository.

5. Interpolate the distribution of near-field and in-drift hydrological conditions in the repository for each WP type, using the following calculational steps to determine the following: 
- $R H_{\mathrm{dw}}$ (DMTH; $\left.x, y, W P-t y p e\right)$ distribution in the repository is caleulated for each WP type using the $T_{\mathrm{dw}}$ (DMTH; $x, y$, WP-type) distribution and the drift-wall relative humidity $R H_{\mathrm{dw}}(\mathrm{LDTH})$ versus $T_{\mathrm{dw}}(\mathrm{LDTH})$ relationships at the 35 drift-scale-model locations and 3 AMLs (Fig. 16b). This process involves spatial interpolation between the 35 drift-scale-model locations. This process also involves interpolating between the 3 AML scanning curves in Fig. 16b. This calculational step determines the distribution of drift-wall relative humidity $R H_{\mathrm{dw}}$ as a function of WP type and location in the repository. The result of this step is equivalent to having a discrete-heat-source, mountainscale, $\mathrm{T}-\mathrm{H}$ (DMTH) model prediction of the distribution of $R H_{\mathrm{dw}}$ in the repository for each WP type; hence, the resulting distribution is called $R H_{\mathrm{dw}}(\mathrm{DMTH} ; \mathrm{x}, \mathrm{y}, \mathrm{WP}$-type), where $\mathrm{x}$ and $\mathrm{y}$ refer to the coordinate location in the repository.

- $S_{\mathrm{liq}}(\mathrm{DMTH} ; \mathrm{x}, \mathrm{y}, \mathrm{WP}$-type) distribution in the repository is calculated for each WP type using the $T_{\mathrm{dw}}$ (DMTH; $x, y$, WP-type) distribution and the drift-wall liquid-phase saturation $S_{\text {liq }}\left(\right.$ LDTH) versus $T_{d w}($ LDTH) relationships at the 35 drift-scale-model locations and 3 AMLs (Fig. 16c). This process involves spatial interpolation between the 35 drift-scale-model locations. This process also involves interpolating between the 3 AML scanning curves in Fig. 16c. This calculational step determines the distribution of drift-wall liquid-phase saturation $S_{\text {liq }}$ as a function of WP type and location in the repository. The result of this step is equivalent to having a discrete-heat-source, mountainscale, I- $\underline{H}$ (DMTH) model prediction of the distribution of $S_{\text {liq }}$ in the repository for each WP type; hence, the resulting distribution is called $S_{\text {liq }}$ (DMTH; $x, y, W P-t y p e)$, where $x$ and $y$ refer to the coordinate location in the repository.

- $q_{\mathrm{liq}}$ (DMTH; $x, y$, WP-type) distribution in the repository is calculated for each WP type using the $T_{\mathrm{dw}}(\mathrm{DMTH} ; \mathrm{x}, \mathrm{y}, \mathrm{WP}$-type $)$ distribution and the liquid-phase flux $3 \mathrm{~m}$ above the drift $q_{\text {liq }}(\mathrm{LDTH})$ versus $T_{\mathrm{dw}}(\mathrm{LDTH})$ relationships at the 35 drift-scale-model locations and 3 AMLs (Fig. 16d). This process involves spatial interpolation between the 35 drift-scale-model locations. This process also involves interpolating between the 3 AML scanning curves in Fig. 16d. This calculational step determines the distribution of liquid-phase flux $3 \mathrm{~m}$ above the drift $q_{\text {liq }}$ as a function of WP type and location in the repository. The result of this step is equivalent to having a discrete-heat-source, mountainscale, T- $\underline{H}$ (DMTH) model prediction of the distribution of $q_{\text {liq }}$ in the repository for each WP type; hence, the resulting distribution is called $q_{\text {liq }}$ (DMTH; $x, y, W P$-type), where $x$ and $y$ refer to the coordinate location in the repository.

- $X_{\text {air,gas }}$ (DMTH; $\left.x, y, W P-t y p e\right)$ distribution in the repository is calculated for each WP type using the $T_{\mathrm{dw}}$ (DMTH; $x, y, W P$-type) distribution and the gasphase, air-mass fraction $X_{\text {air,gas }}(\mathrm{LDTH})$ versus $T_{\mathrm{dw}}(\mathrm{LDTH})$ relationships at the 35 drift-scale-model locations and 3 AMLs (Fig. 16e). This process involves spatial interpolation between the 35 drift-scale-model locations. This process 
also involves interpolating between the 3 AML scanning curves in Fig. 16e. This calculational step determines the distribution of gas-phase air-mass fraction $X_{\text {air,gas }}$ as a function of WP type and location in the repository. The result of this step is equivalent to having a discrete-heat-source, mountainscale, $\mathrm{I}-\mathrm{H}$ (DMTH) model prediction of the distribution of $X_{\text {air,gas }}$ in the repository for each WP type; hence, the resulting distribution is called $X_{\text {air,gas }}$ (DMTH; $x, y, W P$-type), where $x$ and $y$ refer to the coordinate location in the repository.

- $S_{\text {liq,inv }}$ (DMTH; $\left.x, y, W P-t y p e\right)$ distribution in the repository is calculated for each WP type using the $T_{\mathrm{dw}}(\mathrm{DMTH} ; \mathrm{x}, \mathrm{y}, \mathrm{WP}$-type) distribution and the invert liquid-phase saturation $S_{\text {liq,inv }}($ LDTH) versus lower drift-wall temperature $T_{\text {ldw }}($ LDTH) relationships at the 35 drift-scale-model locations and 3 AMLs (Fig. 16f). This process involves spatial interpolation between the 35 driftscale-model locations. This process also involves interpolating between the 3 AML scanning curves in Fig. 16f. This calculational step determines the distribution of liquid-phase saturation in the invert $S_{l i q, i n v}$ as a function of WP type and location in the repository. The result of this step is equivalent to having a discrete-heat-source, mountain-scale, $\mathrm{T}-\mathrm{H}$ (DMTH) model prediction of the distribution of $S_{\text {liq,inv }}$ in the repository for each WP type; hence, the resulting distribution is called $S_{\mathrm{liq}, \text { inv }}$ (DMTH; $x, y, W P$-type), where $x$ and $y$ refer to the coordinate location in the repository.

6. Determine the distribution of temperature on WPs throughout the repository area for each WP type, using the following calculational step:

- $T_{\mathrm{wp}}(\mathrm{DMTH} ; \mathrm{x}, \mathrm{y}, \mathrm{WP}$-type) distribution in the repository is calculated for each WP type by adding $\Delta T_{\mathrm{wp}}\left(\mathrm{DDT} ; \mathrm{WP}\right.$-type) to the $T_{\mathrm{dw}}(\mathrm{LMTH} ; \mathrm{x}, \mathrm{y})$ distribution. This calculational step determines the distribution of WP temperature as a function of WP type and location in the repository. The net result of this step is equivalent to having a discrete-heat-source, mountain-scale, T-H (DMTH) model prediction of the $T_{\mathrm{wp}}$ distribution in the repository for each WP type; hence the resulting distribution is called $T_{\text {wp }}(\mathrm{DMTH} ; \mathrm{x}, \mathrm{y}, \mathrm{WP}$-type), where $\mathrm{x}$ and $y$ refer to the coordinate location in the repository.

7. Determine the distribution of relative humidity on WPs throughout the repository area for each WP type, using the following calculational step:

- $R H_{\text {wp }}(D M T H ; x, y, W P-t y p e)$ distribution in the repository is calculated for each WP type by using the $T_{\mathrm{dw}}$ (DMTH; $x, y, W P$-type) and $T_{\text {wp }}(\mathrm{DMTH} ; \mathrm{x}, \mathrm{y}, \mathrm{WP}$-type) distributions and the relationship $R H_{\mathrm{wp}}=R H_{\mathrm{dw}}\left[P_{\text {sat }}\left(T_{\mathrm{dw}}\right) / P_{\text {sat }}\left(T_{\mathrm{wp}}\right)\right]$, where $P_{\text {sat }}$ is equal to the saturated vapor pressure. This calculational step determines the distribution of WP relative humidity $R H_{\mathrm{wp}}$ as a function of WP type and location in the repository. The net result of this step is equivalent to having a discrete-heat-source, mountain-scale, T-H (DMTH) model prediction of the $R H_{\text {wp }}$ distribution in the repository for each WP type; hence the resulting distribution is called $R H_{\mathrm{wp}}$ (DMTH; $\mathrm{x}, \mathrm{y}, \mathrm{WP}$-type), where $\mathrm{x}$ and $\mathrm{y}$ refer to the coordinate location in the repository. 


\subsection{Constructing Probability Density Functions of EB.S T-H Conditions}

The EBS T-H predictions from the multi-scale T-H modeling approach are utilized by several modeling and analysis groups that support TSPA-VA, including:

1. Waste package (WP) corrosion.

2. Near-field environment (NFE) geochemistry.

3. Waste-form dissolution.

4. EBS transport.

It is possible to provide the full set of near-field and EBS T-H variables (Table 2) for the 7 major WP types (Table 3) at every WP location in the repository area. However, it is not be feasible to perform the necessary calculations in categories 1-4 above. Consequently, it is necessary to group or categorize or WP environmental (WPE) conditions into "bins."

The process of "binning" the WP environments for WP corrosion analysis involves several steps. First, the repository area is subdivided into 6 major subdomains with respect to infiltration flux $q_{\text {inf. }}$ The boundaries between the subdomains (Fig. 18a) were chosen to minimize the variability of $q_{\text {inf }}$ within any given subdomain. Thus, there are low- $q_{\text {inf }}$ subdomains, such as the SW subdomain, as well as high- $q_{\text {inf }}$ subdomains, such as the CC subdomain (Fig. 18). The rationale for grouping the WPE into the $q_{\text {inf }}$ subdomains is that $q_{\text {inf }}$ is a major factor in determining whether WPE conditions are relatively hot and dry versus cool and humid. Consequently, the range of WPE conditions within a $q_{\text {inf }}$ subdomain would be narrowed somewhat by virtue of sharing a common $q_{\text {inf. }}$. Furthermore, for the purposes of drift-seepage modeling and performance analysis, $q_{\text {inf }}$ is a major factor determining the tendency for water to seep into emplacement drifts. The $6 q_{\text {inf }}$ subdomains correspond to northeast and northwest corners of the repository area (NE \& $\mathrm{NW}$ ), the central (CC) region, the south-central (SC) region, and the southwest and southeast (SW \& SE) corners of the repository area.

The second step of binning WP environmental conditions is to group the 5 CSNF WP types into a single CSNF-WP category and to group the co-disposal DHLW WPs and direct-disposal DOE SNF WPs into a single DHLW-WP category.

The third and fourth steps of binning WP environmental conditions involves developing probability density functions of temperature $T$ and relative humidity $R H$ conditions for the CSNF-WP category and for the DHLW-WP category in each of the $6 q_{\text {inf }}$ subdomains. The probability density functions are expressed as $R H$ and $T$ histograms. The environmental conditions on WPs are binned according to the time required by WPs rewet to $R H=85 \%$ and $T$ on the WP surface at $5000 \mathrm{yr}$. An $R H$ of $85 \%$ was selected because it is a typical of the critical $R H$ (called $R H_{\text {crit }}$ ) for atmospheric corrosion-that is, the value of $R H$ where atmospheric corrosion is initiated. Once $R H>R H_{\text {crit, }}$ the corrosion rate for the outer corrosion allowance material on the WP also depends on $T$ on the WP surface. Because $R H$ generally exceeds $85 \%$ within $5000 \mathrm{yr}$ (unless an engineered backfill is used), $T$ at $5000 \mathrm{yr}$ is a good indicator of whether the WP environment is relatively hot once it is relatively humid as opposed to being relatively cool at the time it becomes humid. 
In each of the $q_{\text {inf }}$ subdomains, the CSNF- and DHLW-WP categories are each grouped into $10 R H$ bins and each $R H$ bin is then subdivided into $3 T$ bins, resulting in a total of 30 WP bins for CSNF WPs and $30 \mathrm{WP}$ bins for DHLW WPs (noncommercial WPs). For example, if all WPs attain $R H=85 \%$ within $3000 \mathrm{yr}$, the WPs could then be subdivided into groups where $R H=85 \%$ is attained within 0 to $300 \mathrm{yr}$, 300 to $600 \mathrm{yr}$, and so on, with the last $R H$ bin containing WPs that attain $R H=85 \%$ from 2700 to $3000 \mathrm{yr}$. Step 3 of the WPE binning process is complete when all of the WPs have been placed in their respective $R H$ bins.

Step 4 of the WPE binning process involves subdividing the WPs in a given $R H$ bin group into $3 T$ bins, corresponding to $T$ on the WP at $5000 \mathrm{yr}$. After completing step 4, all CSNF WPs will fall somewhere within $30 R H$ and $T$ bins, as will all WPs in the DHLWWP category. Each CSNF-WP RH \& T bin will comprise between 0 and $100 \%$ of the CSNF WPs. The sum of the probabilities for the 30 bins will sum to $100 \%$; the same is also true for the DHLW-WP RH \& $T$ bins. It is possible for many of the RH \& $T$ bins to contain no WPs.

Step 5 of the WPE binning process involves selecting a "typical" WP location for each of the 30 bins that contain a non-zero probability. The mean rewetting time (to $R H=85 \%$ ) and the mean $T$ at $5000 \mathrm{yr}$ is calculated for all WPs in an $R H \& T$ bin. Least squares minimization is used to find the WP location that is closest to having the mean $R H=85 \%$ rewetting time and the mean $T$ at $5000 \mathrm{yr}$. The $T$ and $R H$ history for a typical WP within each WP bin is provided to TSPA-VA WP-corrosion analysis, along with the probabilities for each of the $R H$ and $T$ bins. The other NFE conditions listed inTable 2 are also provided to TSPA-VA for each of these typical WPs.

The procedure for binning NFE conditions for geochemistry analysis results in a smaller number of bins than are generated for WP-corrosion analysis. For each $q_{\text {inf }}$ subdomain, a "typical" CSNF- and DHLW-WP location is selected on the basis of the shortterm, medium-term, and long-term temperature $T$ history. The mean $T$ on WPs is determined for 100,1000, and $5000 \mathrm{yr}$ for all CSNF WPs. Least squares minimization is used to find the CSNF-WP location with the smallest sum of the squares of the deviations in $T$ (from the mean $T$ for all CSNF WPs) at 100,1000, and $5000 \mathrm{yr}$, with equal weight given to each of these 3 times. This procedure is repeated for the DHLW-WP group.

A full set of NFE conditions, including the liquid-phase saturation in the invert $S_{\text {liq,inv }}$ is provided to TSPA-VA for the typical CSNF WP and the typical DHLW WP in each of the $6 q_{\text {inf }}$ subdomains. This information is also used by the groups analyzing EBS transport and waste-form dissolution. 


\section{References and Bibliography}

Bahney, R.H. (1997). "Preliminary Design Basis for WP Thermal Analysis." (DI \#BBAA00000-01717-0200-00019, Rev. 00). Las Vegas, NV: Civilian Radioactive Waste Management System, Management and Operating Contractor. [MOL.19980127.0718]

Bear, J., and Y. Bachmat (1990). Introduction to Modeling of Transport Phenomena in Porous Media. Dordrecht, The Netherlands: Kluwar Acad. Publishers. [NNA.19930507.0079]

Birkholzer, J.T., C.F. Tsang, and J.S.Y. Wang (1996). "Drift Scale Modeling." S.J. Altman et al. (primary authors). Multi-Scale Modeling to Evaluate Scaling Issues, Percolation Flux, and Other Processes for PA Recommendations. (WBS 1.2.5.4.6, WA-210 Rev. 00, Level 3 Milestone T6540) [MOL.19970512.0010]

Bodvarsson, G.S., and T.M. Bandurraga (1996). "Development and Calibration of the Three-Dimensional Site-Scale Unsaturated Zone Model of Yucca Mountain, Nevada." Berkeley, CA: Lawrence Berkeley National Laboratory, Earth Sciences Division. [MOL.19970211.0176]

Bodvarsson, G.S., T.M. Bandurraga, and Y.S. Wu (1997). "The Site-Scale Unsaturated Zone Model of Yucca Mountain, Nevada, for the Viability Assessment." June 1997. (LBNL-40376, UC-814). Berkeley, CA: Lawrence Berkeley National Laboratory, in collaboration with the U.S. Geological Survey. [MOL.19971014.0232]

Buesch, D.C., R.W. Spengler, T.C. Moyer, and J.K. Greslin (1995). "Revised Stratigraphic Nomenclature and Macroscopic Identification of Lithostratigraphic Units of the Paintbrush Group Exposed at Yucca Mountain, Nevada." Open-File Report. (OFR 94-469). Denver, CO: U.S. Geological Survey. [MOL.19960702.0036]

Buscheck, T.A. (1996). "Hydrothermal Modeling." D. G. Wilder (ed.). Near-Field and Altered-Zone Environment Report (Volume II). Livermore, CA: Lawrence Livermore National Laboratory. Section 1.0. (UCRL-JC124998) [MOL.19961212.0122]

Buscheck, T.A. (1997). "Analysis of Thermal-Hydrological Behavior During the Heating Phase of the Single-Heater Test at Yucca Mountain." Milestone report for the CRWMS Management and Operating Contractor, U.S. Department of Energy. Livermore, CA: Lawrence Livermore National Laboratory. [MOL.19980109.0241] 
Buscheck, T.A., J. Gansemer, T. Delorenzo, J.J. Nitao, R.J. Shaffer, M.J.«Cordery, and K.H. Lee (1997a). "Thermal-Hydrological Models of the Distribution of Temperature, Relative Humidity, and Gas-Phase Air-Mass Fraction in Repository Drifts." Milestone report for the CRWMS Management and Operating Contractor, U.S. Department of Energy. (SPLD1M4 and SPLD2M4). Livermore, CA: Lawrence Livermore National Laboratory. [MOL.19980109.0248]

Buscheck, T.A., and J.J. Nitao (1988). "Estimates of the Width of the Wetting Zone Along a Fracture Subjected to an Episodic Infiltration Event in Variably Saturated, Densely Welded Tuff." (UCID-21579). Livermore, CA: Lawrence Livermore National Laboratory. [HQX.19890522.0064]

Buscheck, T.A., and J.J. Nitao (1993). "Repository-heat-driven-hydrothermal flow at Yucca Mountain, Part II: Large-scale in situ heater tests." Nucl. Tech. 104(3):449-471. (Also UCRL-JC-114132-P-2, Lawrence Livermore National Laboratory, Livermore, CA). [235095]

Buscheck, T.A., and J.J. Nitao (1995). "Thermal-Hydrological Analysis of Large-Scale Thermal Tests in the Exploratory Studies Facility at Yucca Mountain." (UCRL-ID-121791). Livermore, CA: Lawrence Livermore National Laboratory. [MOL.19960501.0392; 223657]

Buscheck, T.A., J.J. Nitao, J. Birkholzer, and Y.W. Tsang (1997b). "Recommended Guidelines for Hydrological Parameters Used by TSPA-VA." Lawrence Livermore National Laboratory: memo to G.S. Bodvarsson, Lawrence Berkeley National Laboratory. September 8, 1997.

Buscheck, T.A., J.J. Nitao, and D.A. Chesnut (1991). "The impact of episodic nonequilibrium fracture-matrix flow on geological repository performance." In proceedings from A.N.S. FOCUS '91 Conference on Nuclear Waste Packaging. Las Vegas, NV: Sept. 29-Oct. 2, 1991. (Also UCRL-JC-106759-SUM, Lawrence Livermore National Laboratory, Livermore, CA) [NNA.911231.0023; 2032525]

Buscheck, T.A., J.J. Nitao, and D.A. Chesnut (1993). "Hydrothermal Modeling." D.G. Wilder (ed.). Preliminary Near-Field Environment Report, Vol. II: Scientific Overview of Near-Field Environment and Phenomena. (Chapter 1) Livermore, CA: Lawrence Livermore National Laboratory. pp. 5-27. (UCRL-LR-107476, Vol. II) [226944]

Buscheck, T.A., J.J. Nitao, and L.D. Ramspott (1996). "Near-field thermalhydrological behavior for alternative repository designs at Yucca Mountain." In proceedings from XX International Symposium Science Basis Nuclear Waste Management. Boston, MA: Dec. 2, 1996. Mater. Res. Soc. (Also UCRL-JC-124629, Lawrence Livermore National Laboratory, Livermore, CA) [MOL.19961014.0031]

Buscheck, T.A., R.J. Shaffer, K.H. Lee, and J.J. Nitao (1997c). “1997 Analysis of Thermal-Hydrological Behavior During the Heating Phase of the 
Single-Heater Test at Yucca Mountain." Supplemental submission of milestone report for the CRWMS Management and Operating Contractor, U.S. Department of Energy. (SP9266M4). Livermore, CA: Lawrence Livermore National Laboratory. [MOL.19980109.0262]

Buscheck, T.A., R.J. Shaffer, and J.J. Nitao (1997d). "Pretest Thermal-Hydrological Analysis of the Drift-Scale Thermal Test at Yucca Mountain." (SP9318M4). Livermore, CA: Lawrence Livermore National Laboratory.

CRWMS M\&O (1996a). "Characterization of the ESF Thermal Test Area." (B00000000-01717-5705-00047, Rev. 1). Las Vegas, NV: Civilian Radioactive Waste Management System Management and Operation Contractor: TRW Environmental Safety Systems, Inc. [MOL.19970116.0187]

CRWMS M\&O (1996b). "Test Design, Plans, and Layout for the First ESF Thermal Test." (BAB000000-01717-4600-00025, Rev. 1). Las Vegas, NV: Civilian Radioactive Waste Management System Management and Operation Contractor: TRW Environmental Safety Systems, Inc. [MOL.19970114.0166]

CRWMS M\&O (1997). "Waste Isolation Study." May 13, 1997. (B00000000-01717-570500062 Rev. 00). Las Vegas, NV: Civilian Radioactive Waste Management System Management and Operating Contractor: TRW Environmental Safety Systems, Inc. [234282]

Dunlap, B., N.D. Francis, C.K. Ho, and M.L. Wilson (1997). "Provide Input to XPA07, PA204, PA208, PA210 Models." Las Vegas, NV: CRWMS M\&O/INTERA, Inc., and Sandia National Laboratories (Albuquerque, NM). [MOL.19980205.0250]

Edlefsen, N.E., and A.B.C. Anderson (1943). "Thermodynamics of Soil Moisture." Hilgardia 15:31-298.

Flint, A., J.A. Hevesi, and L.E. Flint (1996a). "Conceptual and Numerical Model of Infiltration for the Yucca Mountain Area, Nevada." Water Resources Investigation Report. (3GUT623M). Denver, CO: U.S. Geological Survey. (U.S.G.S. Survey Milestone Report) [MOL.19970409.0087]

Flint, L.E., A.L. Flint, C.A. Rautman, and J.D. Istok (1996b). "Physical and Hydrologic Properties of Rock Outcrop Samples at Yucca Mountain, Nevada." Open File Report. (95-280). Denver, CO: U.S. Geological Survey. [225884]

Francis, N.D., C.K. Ho, and M.T. Itamura (1997). “UZ-Thermohydrology: Complete VA T/H Sensitivity Analysis." (SLX09F9). Albuquerque, NM: Sandia National Laboratories. [MOL.19980210.0914]

Ho, C.K. (1997). "Models of fracture-matrix interactions during multiphase heat and mass flow in unsaturated fractured porous media." In proceedings from 1997 ASME International Mechanical Engineering Congress and Exposition. Dallas, TX: ASME Fluids Engineering Division. [MOL.19971125.0236] 
Klavetter, E.A., and R.R. Peters (1986). "Estimation of Hydrologic Properties of an Unsaturated, Fractured Rock Mass." (SAND-84-2642). Albuquerque, NM: Sandia National Laboratories. [NNA.870317.0738; 202727]

Lee, K.H. (1995). "Progress Report on Pre-Test Calculations for the Large Block Test." (UCRL-ID-118699). Livermore, CA: Lawrence Livermore National Laboratory. [MOL.19950314.0178; 214965]

Lee, K.H. (1996). "Forecast Thermo-Hydrologic Results of the Single Heater Test." Milestone report for the CRWMS Management and Operating Contractor, U.S. Department of Energy. (SP911M4). Livermore, CA: Lawrence Livermore National Laboratory. [MOL.19970121.0144]

Lee, K.H., and T.-S. Ueng (1991). "Air-Injection Field Test to Determine the Effect of a Heat Cycle on the Permeability of Welded Tuff." (UCRL-ID-105163). Livermore, CA: Lawrence Livermore National Laboratory. [NNA.19910912.0001; 203447]

Lin, W., D. Wilder, S. Blair, T. Buscheck, W. Daily, G. Gdowski, W. Glassley, K. Lee, A. Meike, A. Ramirez, J. Roberts, D. Ruddle, J. Wagoner, D. Watwood, T. Williams, R. Carlson, and D. Neubauer (1998). "An overview of progress on the large-block test of the ESF thermal tests." In proceedings from 1998 International High-Level Radioactive Waste Management Conference. May 11-14, 1998. Am. Nucl. Soc. (Also UCRL-JC-128796 Ext. Abs., October 1997 preconference print by Lawrence Livermore National Laboratory, Livermore, CA) [MOL.19980120.0041]

Mualem, Y. (1976). "A new model for predicting the hydraulic conductivity of unsaturated porous media." Water Resour. Res. 12:513-522.

[NNA.19881228.0005; 217339]

Nitao, J.J. (1988a). "Numerical Modeling of the Thermal and Hydrological

Environment Around a Nuclear Waste Package Using the Equivalent Continuum Approximation: Horizontal Emplacement." (UCRL-ID21444). Livermore, CA: Lawrence Livermore National Laboratory. [NNA.890317.0021; 201832]

Nitao, J.J. (1988b). "VTOUGH-An Enhanced Version of the TOUGH Code for Thermal and Hydrologic Simulation of Large-Scale Problems in Nuclear Waste Isolation." (UCID-21954). Livermore, CA: Lawrence Livermore National Laboratory.

Nitao, J.J. (1991). "Theory of matrix and fracture flow regimes in unsaturated, fractured porous media." In proceedings from Second International High-Level Radioactive Waste Management Conference. Las Vegas, NV:. (Also UCRL-104933-SUM, Lawrence Livermore National Laboratory, Livermore, CA) [NNA.910523.0117; 234964] 
Nitao, J.J. (1993). "The NUFT Code for modeling nonisothermal, multiphase, multicomponent flow and transport in porous media." In proceedings from EOS. Washington, DC.: American Geophysical Union.

Supplement 73:31. (Also UCRL-JC-14769 Abs, Lawrence Livermore National Laboratory, Livermore, CA)

Nitao, J.J. (1995). Reference Manual for the NUFT Flow and Transport Code, Version 1.0. Livermore, CA: Lawrence Livermore National Laboratory. (UCRL-IC-113520)

Nitao, J.J (1997a). "Distribution of Post-Emplacement Seepage into the Repository Drifts with Parametric Variation of Intrinsic Properties: Models and Bounds for Post-Emplacement Seepage into the Repository." Milestone report for the CRWMS Management and Operating Contractor, U.S. Department of Energy. (SPLC2M4 and SPLC3M4). Livermore, CA: Lawrence Livermore National Laboratory. [MOL.19980107.0400]

Nitao, J.J. (1997b). "Models for the Distribution of Percolation at the Repository Level and Seepage into Drifts under Pre-Emplacement Conditions." Milestone report for the CRWMS Management and Operating Contractor, U.S. Department of Energy. (SPLB2M4). Livermore, CA: Lawrence Livermore National Laboratory.

Nitao, J.J. (1997c). "Preliminary Bounds for the Drift-Scale Distribution of Percolation and Seepage at the Repository Level under PreEmplacement Conditions." Letter report to CRWMS Management and Operating Contractor, U.S. Department of Energy. Livermore, CA: Lawrence Livermore National Laboratory. [LLYMP 9703034; 234515]

Nitao, J.J., and J. Bear (1994). "Potentials and Their Role in Transport in Porous Media." (UCRL-JC-111741). Livermore, CA: Lawrence Livermore National Laboratory.

Nitao, J.J., and T.A. Buscheck (1995). "Discrete-fracture modeling of thermalhydrological processes at Yucca Mountain and the LLNL G-Tunnel field test." In proceedings from Mater. Res. Soc. XIX Internat. Symp. Sci. Basis Nuclear Waste Management. Pittsburgh, PA: Nov. 27-Dec. 1, 1995. Mater. Res. Soc. [MOL.19970825.0089]

Nitao, J.J., T.A. Buscheck, and D.A. Chesnut (1993). "Implications of episodic nonequilibrium fracture-matrix flow on repository performance." Nucl. Technol. 104(3):385-402. (Also UCRL-JC-109216, Lawrence Livermore National Laboratory, Livermore, CA). [NNA.19930727.0005; 208836]

Pruess, K. (1991). "TOUGH2: A General-Purpose Numerical Simulator for Multiphase Fluid and Heat Flow." (LBL-29400, EC-251). Berkeley, CA: Lawrence Berkeley National Laboratory. [213489] 
Pruess, K., and Y. Tsang (1994). "Thermal Modeling for a Potential High-Level Nuclear Waste Repository at Yucca Mountain, Nevada." (LBL-35381). Berkeley, CA: Lawrence Berkeley National Laboratory. [NNA.19940427.0248; 212744]

Pruess, K., J.S.Y. Wang, and Y.W. Tsang (1990). “On thermohydrologic conditions near

high-level nuclear wastes emplaced in partially saturated fractured tuff, Part I: Simulation studies with explicit consideration of fracture effects." Water Resour. Res. 26(6):1235-1248. [NNA.19910328.0073]

TRW (1997). "Waste-Package Size Study Report." Prepared for the U.S. Department of Energy by the CRWMS M\&O Contractor, TRW Environmental Safety Systems, Inc. (B00000000-01717-5705-00079 Rev 00). Las Vegas, NV: TRW Environmental Safety Systems, Inc. (Concurrence Draft B, October 1997)

Tsang, C.-F., J. Birkholzer, G. Li, and Y. Tsang (1997). “Drift Scale Modeling: Progress in Studies of Seepage into a Drift." Milestone report. (SP331CM4). Berkeley, CA: Lawrence Berkeley National Laboratory. [MOL.19971204.0420]

van Genuchten, M.T. (1980). "A closed form equation for predicting the hydraulic conductivity unsaturated soils." Soil Sci. Soc. Am. J. 44:892-898. [NNA.19890522.0287; 217327]

Vanmarcke, E. (1988). Random Fields. Cambridge, MA: MIT Press.

Wang, J.S.Y. (1992). "Variations of hydrological parameters of tuff and soil." In proceedings from Third Annual International High-Level Radioactive Waste Management Conference. Las Vegas, NV: Am. Nucl. Soc., La Grange, IL. pp. 727-731.

Wang, J.S.Y. (1996). "Evaluation of Moisture Evolution in the Exploratory Studies Facility." Berkeley, CA: Lawrence Berkeley National Laboratory. (Tracking no. TR31K6M) [MOL.19961231.0089]

Wilder, D.G., W. Lin, S.C. Blair, T.A. Buscheck, R.C. Carlson, K. Lee, A. Meike, A.L. Ramirez, J.L. Wagoner, and J.S.Y. Wang (1997). "Large Block Test Status Report." (UCRL-ID-128776). Livermore, CA: Lawrence Livermore, CA. [234859]

Zimmerman, R.W., and G.S. Bodvarsson (1989). "An approximate solution for onedimensional absorption in unsaturated porous media." Water Res. Res. 25(6):1422-1428. [221942] 


\section{Appendix A: Tables}

Table 1 Relations among model hydrogeologic units and geologic formations, Lawrence Berkeley National Laboratory (LBNL) geologic framework model

\begin{tabular}{|c|c|c|c|}
\hline Geological Unit & $\begin{array}{c}\text { Welding } \\
\text { Intensity/Formation } \\
\text { Name } \\
\text { (Buesch et al., 1995) }\end{array}$ & $\begin{array}{c}\text { Model Layer } \\
\text { Name }\end{array}$ & $\begin{array}{c}\text { Hydrogeologic } \\
\text { Unit }\end{array}$ \\
\hline \multicolumn{4}{|c|}{ Paintbrush Group } \\
\hline \multirow[t]{3}{*}{ Tiva Canyon Tuff } & $\begin{array}{l}M, D^{1} \text { (Tpcpll) } \\
M, D^{1} \text { (Tpcpln) }\end{array}$ & $\begin{array}{l}\text { tcw11 } \\
\text { tcw12 }\end{array}$ & \multirow[t]{2}{*}{ Tiva Canyon (TCw) } \\
\hline & $\begin{array}{l}\text { D-Basal vitrophyre } \\
\text { (Tpcpv3) } \\
\text { M (Tpcpv2) }\end{array}$ & tcw13 & \\
\hline & N,P (Tpcpv1) & & \multirow{7}{*}{ Paintbrush (PTn) } \\
\hline Bedded Tuff & $N($ Tpbt4) & ptn21 & \\
\hline $\begin{array}{l}\text { Yucca Mountain } \\
\text { Tuff }\end{array}$ & N,P,M (Tpy) & ptn22 & \\
\hline Bedded Tuff & $\mathrm{N}($ Tpbt3) & ptn23 & \\
\hline \multirow[t]{2}{*}{ Pah Canyon Tuff } & N,P,M (Tpp) & ptn24 & \\
\hline & $N(T p b t 2)$ & ptn25 & \\
\hline Bedded Tuff & N,P (Tptrv3) & & \\
\hline \multirow[t]{7}{*}{$\begin{array}{l}\text { Topopah Spring } \\
\text { Tuff }\end{array}$} & $\begin{array}{l}\text { M (Tptrv2) } \\
\text { D-Upper vitrophyre } \\
\text { (Tptrv1) }\end{array}$ & tsw31 & \multirow[t]{7}{*}{$\begin{array}{l}\text { Topopah Spring } \\
\text { (TSw) }\end{array}$} \\
\hline & M,D (Tptrn) & tsw32 & \\
\hline & $\begin{array}{l}M, D, L^{2} \text { (Tptrl) } \\
M, D, L \text { (Tptpul) }\end{array}$ & tsw33 & \\
\hline & D (Tptpmn) & tsw34 & \\
\hline & M,D,L (Tptpll) & tsw35 & \\
\hline & D (Tptpln) & tsw36 & \\
\hline & $\begin{array}{l}\text { D-Basal vitrophyre } \\
\text { (Tptpv3) }\end{array}$ & tsw37 & \\
\hline & \multirow{2}{*}{$\begin{array}{l}\text { N,P,M; may be altered } \\
\text { (Tptpv1, Tptpv2) } \\
\text { N; may be altered (Tpbt1) }\end{array}$} & \multirow[t]{2}{*}{$\operatorname{ch} 1(v c$ or $z c)$} & \multirow[t]{5}{*}{ Calico Hills (CHn) } \\
\hline Bedded Tuff & & & \\
\hline \multirow{3}{*}{$\begin{array}{l}\text { Calico Hills } \\
\text { Formation }\end{array}$} & $\mathrm{N}$, unaltered (Tac-vitric) & $\operatorname{ch} 2(v c$ or $z c)$ & \\
\hline & N; altered (Tac-zeolitic) & $\operatorname{ch} 3(v c$ or $z c)$ & \\
\hline & $\mathrm{N}$; may be altered (Thtbt) & $\operatorname{ch} 4(\mathrm{vc}$ or $\mathrm{zc})$ & \\
\hline
\end{tabular}




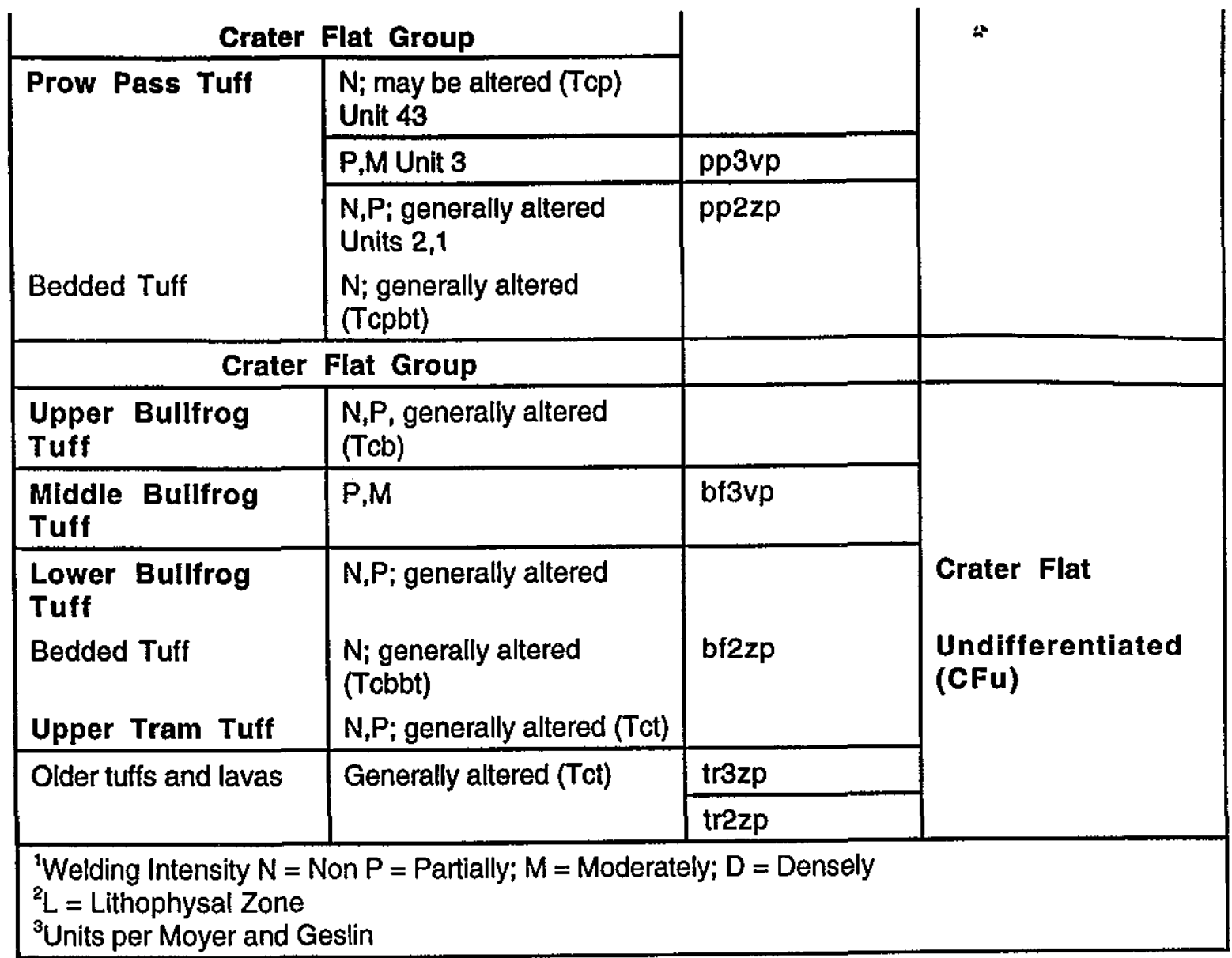

Table 2 Thermohydrologic measures estimated by the multi-scale TH modeling approach

Measures calculated for TSPA-VA are indicated by bold, uppercase $X$. Other measures also calculated by the approach are indicated by lowercase $x$. The measures are temperature $(T)$, relative humidity $(R H)$, gas-phase air-mass fraction $\left(X_{\text {air,gas }}\right)$, liquid phase saturation $\left(S_{1 \mathrm{lq}}\right)$, and liquid phase flux $\left(q_{1 \mathrm{liq}}\right)$.

\begin{tabular}{|l|c|c|c|c|c|}
\hline \multicolumn{1}{|c|}{ Location } & $\boldsymbol{T}$ & $\boldsymbol{R}$ & $\boldsymbol{X}_{\text {alr,gas }}$ & $\boldsymbol{S}_{\mathrm{liq}}$ & $\boldsymbol{q}_{\mathrm{llq}}$ \\
\hline \hline Rock above drift wall & $\mathrm{x}$ & $\mathrm{x}$ & $\mathrm{x}$ & $\mathrm{x}$ & $\mathrm{X}$ \\
\hline Rock at drift wall & $\mathrm{X}$ & $\mathrm{X}$ & $\mathrm{x}$ & $\mathrm{x}$ & $\mathrm{x}$ \\
\hline Drift above WP & & & $\mathrm{X}$ & & \\
\hline WP surface & $\mathrm{X}$ & $\mathrm{X}$ & & & \\
\hline Invert & $\mathrm{x}$ & $\mathrm{x}$ & $\mathrm{x}$ & $\mathrm{X}$ & \\
\hline
\end{tabular}


Table 3 Summary of the WP heat sources used in submodels for the multi-scale approach

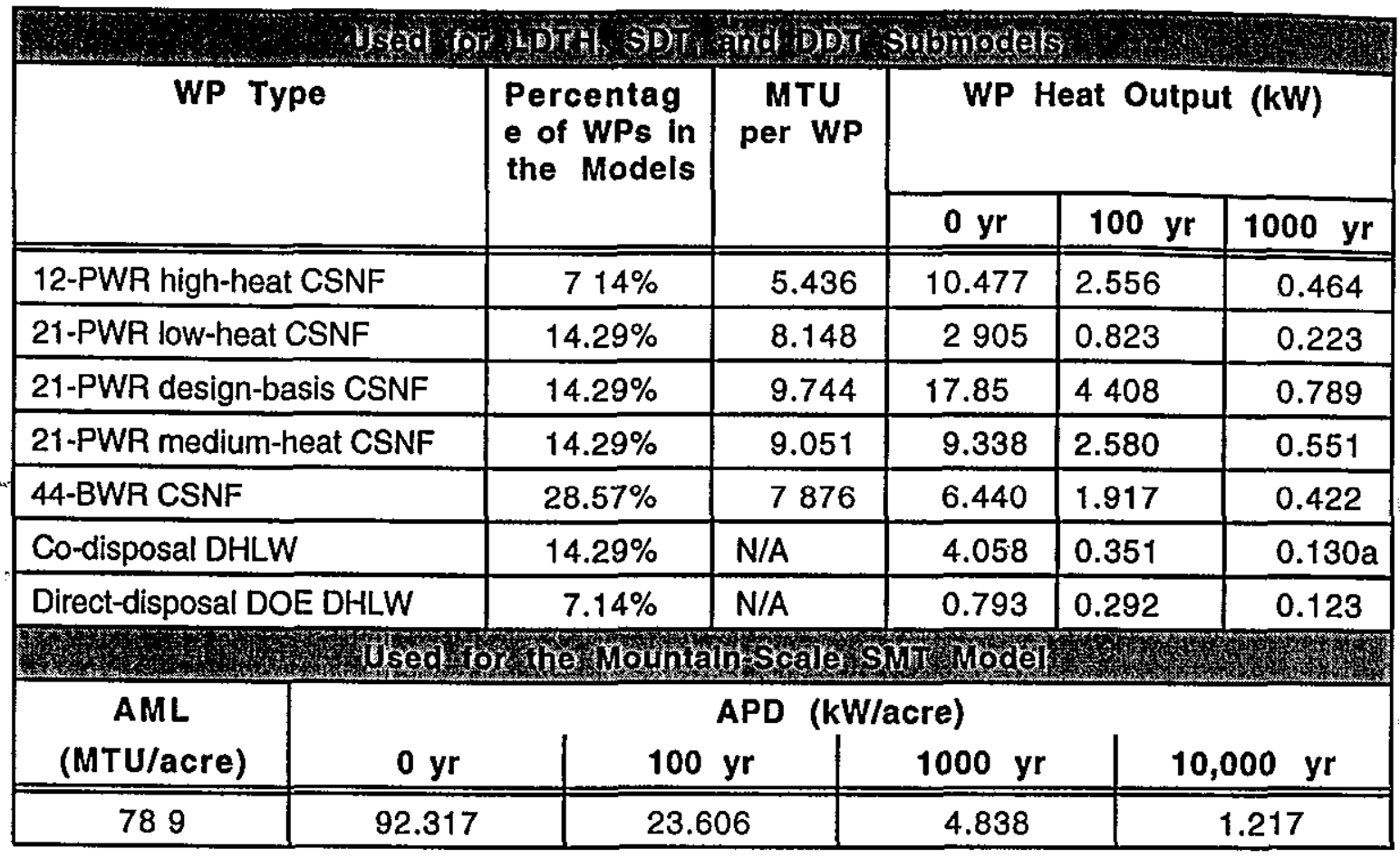


Table 4 Summary of model types used in the multi-scale TH modeling approach Process types are thermal-conduction $(\mathrm{T})$ and thermal-hydrologic (TH).

\begin{tabular}{|c|c|c|c|c|c|}
\hline $\begin{array}{l}\text { Model } \\
\text { Type }\end{array}$ & $\begin{array}{c}\text { Heat } \\
\text { Source }\end{array}$ & Dimensionality & $\begin{array}{l}\text { Process } \\
\text { Type }\end{array}$ & $\begin{array}{c}\text { In-Drift } \\
\text { Thermal } \\
\text { Radiation }\end{array}$ & $\begin{array}{c}\text { Use in TSPA- } \\
\text { VA } \\
\text { Multi-Scale TH } \\
\text { Modeling } \\
\text { Approach }\end{array}$ \\
\hline SMT & smeared & $\begin{array}{l}\text { 3-D mountain- } \\
\text { scale }\end{array}$ & $T$ & no & $\begin{array}{l}\text { Process-model } \\
\text { input }\end{array}$ \\
\hline SMTH & smeared & $\begin{array}{l}\text { 3-D mountain- } \\
\text { scale }\end{array}$ & $T$ & no & $\begin{array}{l}\text { Process-model } \\
\text { input }^{1}\end{array}$ \\
\hline LMTH & $\begin{array}{l}\text { line- } \\
\text { averaged }\end{array}$ & $\begin{array}{l}\text { 3-D mountain- } \\
\text { scale }\end{array}$ & $\mathrm{TH}$ & yes & Abstracted result ${ }^{2}$ \\
\hline DMTH & discrete & $\begin{array}{l}\text { 3-D mountain- } \\
\text { scale }\end{array}$ & $\mathrm{TH}$ & yes & Abstracted result ${ }^{2}$ \\
\hline SDT & smeared & 1-D drift-scale & $\mathrm{T}$ & no & $\begin{array}{l}\text { Process-model } \\
\text { input }\end{array}$ \\
\hline SDTH & smeared & 1-D drift-scale & $\mathrm{TH}$ & no & $\begin{array}{l}\text { Process-model } \\
\text { input }^{1}\end{array}$ \\
\hline LDTH & $\begin{array}{l}\text { line- } \\
\text { averaged }\end{array}$ & 2-D drift-scale & $\mathrm{TH}$ & yes & $\begin{array}{l}\text { Process-model } \\
\text { input }\end{array}$ \\
\hline DDT & discrete & 3-D drift-scale & $T$ & yes & $\begin{array}{l}\text { Process-model } \\
\text { input }\end{array}$ \\
\hline DDTH & discrete & 3-D drift-scale & $\mathrm{TH}$ & yes & $\begin{array}{l}\text { Model-abstraction } \\
\text { testing }\end{array}$ \\
\hline
\end{tabular}

1 To be used in a future version of the multi-scale TH modeling approach

2 See Figure 3-54. 
Table 5a Drift-scale model column locations

$\div$

Northing and easting values are given in the Nevada State Plane coordinate system.

\begin{tabular}{|c|c|c|c|c|c|}
\hline $\begin{array}{l}\text { Column } \\
\text { Name }\end{array}$ & $\begin{array}{l}\text { Easting } \\
(\mathrm{m})\end{array}$ & $\begin{array}{l}\text { Northing } \\
(\mathrm{m})\end{array}$ & $\begin{array}{c}\text { Repository } \\
\text { elevation } \\
\text { (m) }\end{array}$ & $\begin{array}{l}\text { Repository } \\
\text { depth }(m)\end{array}$ & $\begin{array}{c}\text { Repository } \\
\text { unit name }\end{array}$ \\
\hline 1101 & 170190 & 232406 & 1093.3 & 3873 & Tsw36 \\
\hline $11 \mathrm{c} 2$ & 170417 & 232394 & 10925 & 3653 & Tsw35 \\
\hline 1103 & 170644 & 232382 & 1091.6 & 335.2 & Tsw35 \\
\hline $11 c 4$ & 170871 & 232370 & 1090.8 & 2881 & Tsw35 \\
\hline 1105 & 171098 & 232358 & 1089.9 & 274.4 & Tsw34 \\
\hline $12 \mathrm{c1}$ & 170214 & 232857 & 1087.0 & 296.2 & Tsw36 \\
\hline $12 \mathrm{c} 2$ & 170441 & 232845 & 1086.2 & 369.8 & Tsw35 \\
\hline $12 c 3$ & 170668 & 232833 & 1085.4 & 341.5 & Tsw35 \\
\hline $12 c 4$ & 170895 & 232821 & 1084.5 & 278.9 & Tsw35 \\
\hline $12 \mathrm{c} 5$ & 171122 & 232809 & 1083.7 & 230.6 & Tsw34 \\
\hline $13 c 1$ & 170238 & 233308 & 1080.8 & 329.9 & Tsw36 \\
\hline $13 \mathrm{c} 2$ & 170464 & 233296 & 1079.9 & 382.6 & Tsw35 \\
\hline $13 c 3$ & 170691 & 233285 & 1079.1 & 298.8 & Tsw35 \\
\hline $13 c 4$ & 170918 & 233273 & 1078.2 & 258.5 & Tsw35 \\
\hline $13 c 5$ & 171145 & 233261 & 1077.4 & 256.0 & Tsw34 \\
\hline $14 c 1$ & 170261 & 233760 & 1074.5 & 369.8 & Tsw36 \\
\hline $14 c 2$ & 170488 & 233748 & 1073.7 & 386.6 & Tsw35 \\
\hline $14 \mathrm{c3}$ & 170715 & 233736 & 1072.8 & 352.6 & Tsw35 \\
\hline $14 c 4$ & 170942 & 233724 & 1072.0 & 293.7 & Tsw35 \\
\hline $14 c 5$ & 171169 & 233712 & 1071.1 & 253.7 & Tsw34 \\
\hline $15 c 1$ & 170285 & 234211 & 1068.3 & 400.1 & Tsw35 \\
\hline $15 c 2$ & 170512 & 234199 & 1067.4 & 384.3 & Tsw35 \\
\hline $15 c 3$ & 170739 & 234187 & 1066.6 & 357.0 & Tsw35 \\
\hline $15 c 4$ & 170966 & 234175 & 1065.7 & 303.2 & Tsw35 \\
\hline $15 c 5$ & 171193 & 234164 & 1064.9 & 281.9 & Tsw34 \\
\hline $16 c 1$ & 170309 & 234663 & 1062.0 & 365.0 & Tsw36 \\
\hline $16 \mathrm{c2}$ & 170535 & 234651 & 1061.2 & 396.9 & Tsw35 \\
\hline $16 \mathrm{c3}$ & 170762 & 234639 & 1060.3 & 340.2 & Tsw35 \\
\hline $16 c 4$ & 170989 & 234627 & 1059.5 & 295.7 & Tsw35 \\
\hline $16 c 5$ & 171216 & 234615 & 1058.6 & 243.0 & Tsw35 \\
\hline $17 c 1$ & 170332 & 235114 & 1055.7 & 408.8 & Tsw35 \\
\hline $17 c 2$ & 170559 & 235102 & 1054.9 & 3717 & Tsw35 \\
\hline 1703 & 170786 & 235090 & 1054.0 & 291.7 & Tsw35 \\
\hline $17 \mathrm{c4}$ & 171013 & 235078 & 1053.2 & 346.9 & Tsw35 \\
\hline $17 c 5$ & 171240 & 235066 & 1052.4 & 3178 & Tsw35 \\
\hline
\end{tabular}


Table 5b Infiltration $q_{\text {inp }}(\mathrm{mm} / \mathrm{yr})$ and liquid-phase saturation $S_{\text {liq rep }}$ at = the repository depth, for the columns modeled for TSPA-VA

\begin{tabular}{|c|c|c|c|c|c|c|}
\hline \multirow{2}{*}{$\begin{array}{l}\text { Column } \\
\text { Name }\end{array}$} & \multicolumn{3}{|c|}{$q_{\mathrm{int}}(\mathrm{mm} / \mathrm{yr})$} & \multicolumn{3}{|c|}{$S_{\text {llq rop }}$} \\
\hline & $0.2 \times q_{i n t}$ & $\begin{array}{l}1 \times \\
\text { qinf }\end{array}$ & $5 \times q_{i n t}$ & $0.2 \times q_{\operatorname{lnf}}$ & $1 \times q_{\mathrm{inf}}$ & $5 \times q_{1 \mathrm{nt}}$ \\
\hline $11 c 1$ & 2.48 & 12.4 & 61.9 & 0.946 & 0.936 & 0.944 \\
\hline $11 \mathrm{c} 2$ & 269 & 13.4 & 67.2 & 0.875 & 0866 & 0.898 \\
\hline $11 \mathrm{c3}$ & 1.41 & 7.0 & 352 & 0.850 & 0.841 & 0.869 \\
\hline $11 c 4$ & 1.08 & 5.4 & 26.9 & 0.922 & 0.900 & 0.929 \\
\hline $11 \mathrm{c5}$ & 0.96 & 4.8 & 23.9 & 0.965 & 0.958 & 0.964 \\
\hline $12 c 1$ & 0.67 & 3.3 & 16.6 & 0.936 & 0.926 & 0.931 \\
\hline $12 \mathrm{c} 2$ & 2.19 & 10.9 & 54.8 & 0.870 & 0.861 & 0.891 \\
\hline $12 c 3$ & 3.46 & 17.3 & 86.5 & 0.933 & 0.908 & 0.933 \\
\hline $12 c 4$ & 1.40 & 7.0 & 35.1 & 0.930 & 0.900 & 0.928 \\
\hline $12 \mathrm{c5}$ & 1.71 & 8.5 & 42.6 & 0.963 & 0.957 & 0.967 \\
\hline $13 c 1$ & 1.19 & 5.9 & 29.7 & 0.930 & 0.918 & 0.924 \\
\hline $13 \mathrm{c} 2$ & 3.47 & 17.4 & 86.8 & 0.887 & 0.877 & 0.913 \\
\hline $13 \mathrm{c} 3$ & 1.49 & 7.5 & 37.3 & 0.927 & 0.904 & 0.925 \\
\hline $13 c 4$ & 0.95 & 4.8 & 23.8 & 0.925 & 0.900 & 0.928 \\
\hline $13 c 5$ & 0.65 & 3.3 & 16.3 & 0.961 & 0.956 & 0.961 \\
\hline $14 c 1$ & 1.20 & 60 & 30.0 & 0.841 & 0.831 & 0.848 \\
\hline $14 c 2$ & 3.20 & 16.0 & 80.1 & 0.884 & 0.874 & 0.907 \\
\hline $14 c 3$ & 2.18 & 10.9 & 54.5 & 0.933 & 0.908 & 0.933 \\
\hline $14 c 4$ & 1.24 & 6.2 & 31.0 & 0.947 & 0.925 & 0.942 \\
\hline $14 c 5$ & 0.69 & 3.5 & 17.3 & 0.961 & 0.957 & 0.961 \\
\hline $15 c 1$ & 2.24 & 11.2 & 56.1 & 0.837 & 0.828 & 0.856 \\
\hline $15 c 2$ & 1.71 & 8.5 & 42.6 & 0.934 & 0.908 & 0.931 \\
\hline $15 \mathrm{c3}$ & 3.05 & 15.3 & 76.3 & 0.937 & 0.911 & 0.936 \\
\hline $15 c 4$ & 0.40 & 2.0 & 10.1 & 0.906 & 0.897 & 0.919 \\
\hline $15 c 5$ & 0.13 & 0.7 & 3.4 & 0.942 & 0.949 & 0.950 \\
\hline $16 c 1$ & 1.87 & 9.4 & 46.8 & 0.857 & 0.847 & 0.864 \\
\hline $16 c 2$ & 1.54 & 7.7 & 38.4 & 0.875 & 0.867 & 0.893 \\
\hline $16 c 3$ & 2.94 & 14.7 & 73.5 & 0.936 & 0.910 & 0.936 \\
\hline $16 c 4$ & 0.51 & 2.6 & 12.8 & 0.911 & 0.898 & 0.924 \\
\hline $16 c 5$ & 0.73 & 3.7 & 18.3 & 0.936 & 0.922 & 0.938 \\
\hline $17 c 1$ & 1.49 & 7.5 & 37.3 & 0.880 & 0.873 & 0.898 \\
\hline $17 \mathrm{c} 2$ & 0.59 & 2.9 & 14.6 & 0.866 & 0.864 & 0.887 \\
\hline $17 \mathrm{c3}$ & 0.83 & 4.2 & 20.8 & 0.918 & 0.898 & 0.917 \\
\hline $17 \mathrm{c} 4$ & 1.19 & 6.0 & 29.9 & 0.925 & 0.902 & 0.927 \\
\hline $17 c 5$ & 1.07 & 5.3 & 26.7 & 0.927 & 0.900 & 0.926 \\
\hline
\end{tabular}




\section{Appendix B: Figures}

Figure 1. Contour maps of (a) the repository depth $Z_{\text {rep }}$ below the ground surface and (b) infiltration-flux distribution [Flint et al., 1996a] are plotted over the SMTmodel representation of the repository area. (c) The SMT-model representation of the repository area is compared with the actual repository area, which is depicted in gray; also shown are the 35 drift-scale-model locations in the $5 \times 7$ grid used in the multi-scale T-H modeling approach. (d) Histogram of the infiltration-flux distribution is given for the repository area.

Figure 2. Drift-scale schematic showing decay-heat-driven $\mathrm{T}-\mathrm{H}$ flow and transport processes, including (1) radiative, conductive, and convective heat flow, (2) boiling in the rock matrix and matrix-to-fracture vapor transport, and (3) vapor flow in fractures, and (4) condensation and condensate drainage.

Figure 3. Mountain-scale schematic showing decay-heat-driven $\mathrm{T}-\mathrm{H}$ flow and transport processes that influence moisture redistribution and the moisture balance in the UZ.

Figure 4. Schematic of conceptual models used by the multi-scale T-H modeling approach, including (a) smeared-heat-source, drift-scale, thermal-conduction (SDT) model, (b) line-averaged-heat-source, drift-scale thermal-hydrological (LDTH) model, (c) discrete-heat-source, drift-scale, thermal-conduction (DDT) model, and (d) smeared-heat-source, mountain-scale thermal-conduction (SMT) model.

Figure 5. Plan view of the host-rock distribution (a) is shown for the SMT-model grid of the repository area as a function of the Nevada-State coordinates. (b) Contour

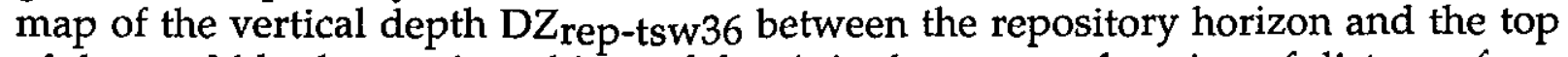
of the tsw36 hydrostratigraphic model unit is shown as a function of distance from the southwest corner of the repository area in the SMT model.

Figure 6. Vertical distribution of hydrostratigraphic model units is shown for several drift-scale model locations (in Nevada-State coordinates), including (a) 11c1 at Northing $=232406 \mathrm{~m},(\mathrm{~b}) 11 \mathrm{c} 2$ at Northing $=232394 \mathrm{~m},(\mathrm{c}) 11 \mathrm{c} 3$ at Northing $=232382$ $\mathrm{m}$, (d) $11 \mathrm{c} 4$ at Northing $=232370 \mathrm{~m}$, and (e) $11 \mathrm{c5}$ at Northing $=232358 \mathrm{~m}$.

Figure 7. Vertical distribution of hydrostratigraphic model units is shown for drift-scale model locations (in Nevada-State coordinates), including (a) $12 \mathrm{cl}$ at Northing $=232857 \mathrm{~m},(\mathrm{~b}) 12 \mathrm{c} 2$ at Northing $=232845 \mathrm{~m}$, (c) $12 \mathrm{c} 3$ at Northing $=232833$ $\mathrm{m}$, (d) $12 \mathrm{c} 4$ at Northing $=232821 \mathrm{~m}$, and (e) $12 \mathrm{c5}$ at Northing $=232809 \mathrm{~m}$.

Figure 8. Vertical distribution of hydrostratigraphic model units is shown for drift-scale model locations (in Nevada-State coordinates), including (a) $13 \mathrm{cl}$ at Northing $=233308 \mathrm{~m}$, (b) $13 \mathrm{c} 2$ at Northing $=233296 \mathrm{~m},(\mathrm{c}) 13 \mathrm{c} 3$ at Northing $=233285$ $\mathrm{m}$, (d) 13c4 at Northing $=233273 \mathrm{~m}$, and (e) $13 \mathrm{c5}$ at Northing $=233261 \mathrm{~m}$. 
Figure 9. Vertical distribution of hydrostratigraphic model units is:shown for drift-scale model locations (in Nevada-State coordinates), including (a) $14 \mathrm{c} 1$ at Northing $=233760 \mathrm{~m}$, (b) $14 \mathrm{c} 2$ at Northing $=233748 \mathrm{~m}$, (c) $14 \mathrm{c} 3$ at Northing $=233736$ $\mathrm{m}$, (d) $14 \mathrm{c} 4$ at Northing $=233724 \mathrm{~m}$, and (e) $14 \mathrm{c5}$ at Northing $=233712 \mathrm{~m}$.

Figure 10. Vertical distribution of hydrostratigraphic model units is shown for drift-scale model locations (in Nevada-State coordinates), including (a) $15 \mathrm{c} 1$ at Northing $=234211 \mathrm{~m}$, (b) $15 \mathrm{c} 2$ at Northing $=234199 \mathrm{~m}$, (c) $15 \mathrm{c} 3$ at Northing $=234187$ $\mathrm{m}$, (d) $15 \mathrm{c} 4$ at Northing $=234175 \mathrm{~m}$, and (e) $15 \mathrm{c} 5$ at Northing $=234164 \mathrm{~m}$.

Figure 11. Vertical distribution of hydrostratigraphic model units is shown for drift-scale model locations (in Nevada-State coordinates), including (a) $16 \mathrm{c} 1$ at Northing $=234663 \mathrm{~m},(\mathrm{~b}) 16 \mathrm{c} 2$ at Northing $=234651 \mathrm{~m},(\mathrm{c}) 16 \mathrm{c} 3$ at Northing $=234639$ $\mathrm{m}$, (d) $16 \mathrm{c} 4$ at Northing $=234627 \mathrm{~m}$, and (e) $16 \mathrm{c} 5$ at Northing $=234615 \mathrm{~m}$.

Figure 12. Vertical distribution of hydrostratigraphic model units is shown for drift-scale model locations (in Nevada-State coordinates), including (a) $17 \mathrm{c} 1$ at Northing $=235114 \mathrm{~m},(\mathrm{~b}) 17 \mathrm{c} 2$ at Northing $=235102 \mathrm{~m},(\mathrm{c}) 17 \mathrm{c} 3$ at Northing $=235090$ $\mathrm{m}$, (d) $17 \mathrm{c} 4$ at Northing $=235078 \mathrm{~m}$, and (e) $17 \mathrm{c} 5$ at Northing $=235066 \mathrm{~m}$.

Figure 13. Vertical cross section of the emplacement drift in the DDT and LDTH model is shown, including the thermal radiation connections between the surfaces in the drift.

Figure 14. Plan view of the waste-package layout represented in the DDT models for (a) the point-load design, which is the TSPA-VA base-case design, and (b) the line-load design, which is an alternative design for TSPA-VA.

Figure 15. Flow chart for the multi-scale T-H modeling approach. Process models are depicted in blue. Abstracted models are depicted in orange. See Table 3-4 for definition of model types.

Figure 16. Functional relationships are plotted for the process-model inputs to the multi-scale T-H modeling approach, including (a) LDTH-model-predicted driftwall temperature $T d w(L D T H)$ versus SDT-model-predicted repository host-rock temperature $T_{\text {rep }}(S D T),(b)$ LDTH-model-predicted drift-wall relative humidity $R H_{\mathrm{dw}}(\mathrm{LDTH})$ versus $T_{\mathrm{dw}}(\mathrm{LDTH}),(\mathrm{c})$ LDTH-model-predicted drift-wall liquid-phase saturation $S_{l i q, d w}(\mathrm{LDTH})$ versus $T_{\mathrm{dw}}(\mathrm{LDTH})$, (d) LDTH-model predicted liquidphase flux $3 \mathrm{~m}$ above the drift $q$ lig,dw (LDTH versus $T_{\mathrm{dw}}(\mathrm{LDTH}),(\mathrm{e})$ LDTH-modelpredicted gas-phase air-mass fraction in the drift $X_{a i r} d r(L D T H)$ versus $T_{d w}(L D T H)$, and ( $f$ LDTH-model-predicted liquid-phase saturation in the invert $S$ liq,inv(LDTH) versus $T_{d w}(L D T H)$.

Figure 17. Functional relationships are plotted for the process-model inputs to the multi-scale T-H modeling approach as functions of time, including (a) WPtype/location-specific temperature deviations $D T_{\mathrm{dw}}$ (WP-type) from the average drift-wall temperature along the drift and (b) WP-type/location-specific temperature difference $D T_{\mathrm{wp}}$ (WP-type) between the WP surface and the average drift-wall temperature along the drift for the point-load design. The relationships for $D T_{\mathrm{dw}}$ (WP-type) (c) and $D T_{w p}$ (WP-type) (d) are also given for the line-load design. 
Figure 18. The six infiltration-flux subdomains and the infiltration-flux $q_{\text {inf }}$ distribution [Flint et al., 1996a] are shown for the SMT-model representation of the repository area. The infiltration-flux subdomains are used to bin the WP environments for the purpose of EBS subsystem analysis for TSPA-VA. In increasing order of mean $q_{\text {inf }}$, the subdomains are: (1) southwest SW, (2) northeast NE, (3) southeast SE, (4) northwest NW, (5) south-central SC, and (6) central-central $\mathrm{CC}$. 

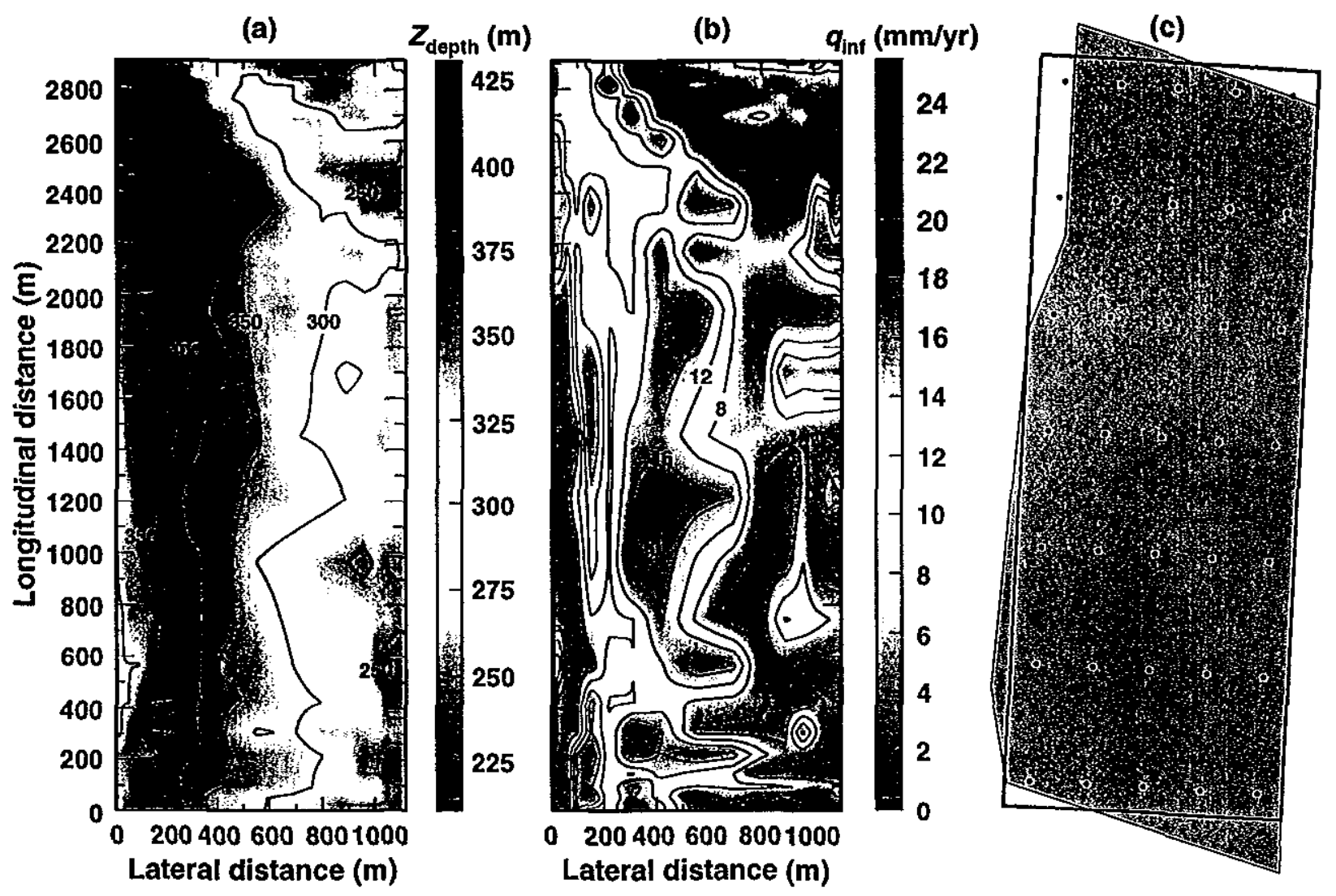

(d)

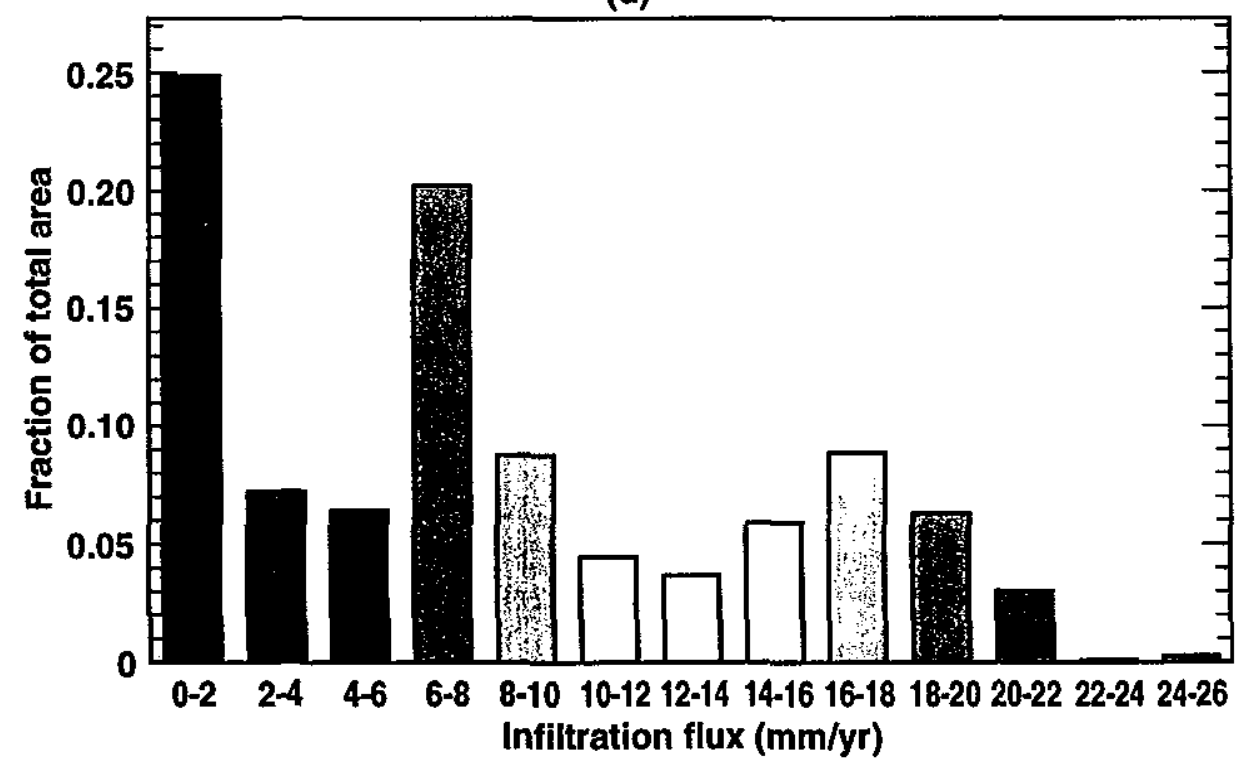

Figure 1. Contour maps of (a) the repository depth $Z_{\text {rep }}$ below the ground surface and (b) infiltration-flux distribution [Flint et al , 1996a] are plotted over the SMT-model representation of the repository area (c) The SMT-model representation of the repository area is compared with the actual repository area, which is depicted in gray; also shown are the 35 drift-scale-model locations in the $5 \times 7$ grid used in the multi-scale T-H modeling approach (d) Histogram of the infiltration-flux distribution is given for the repository area 


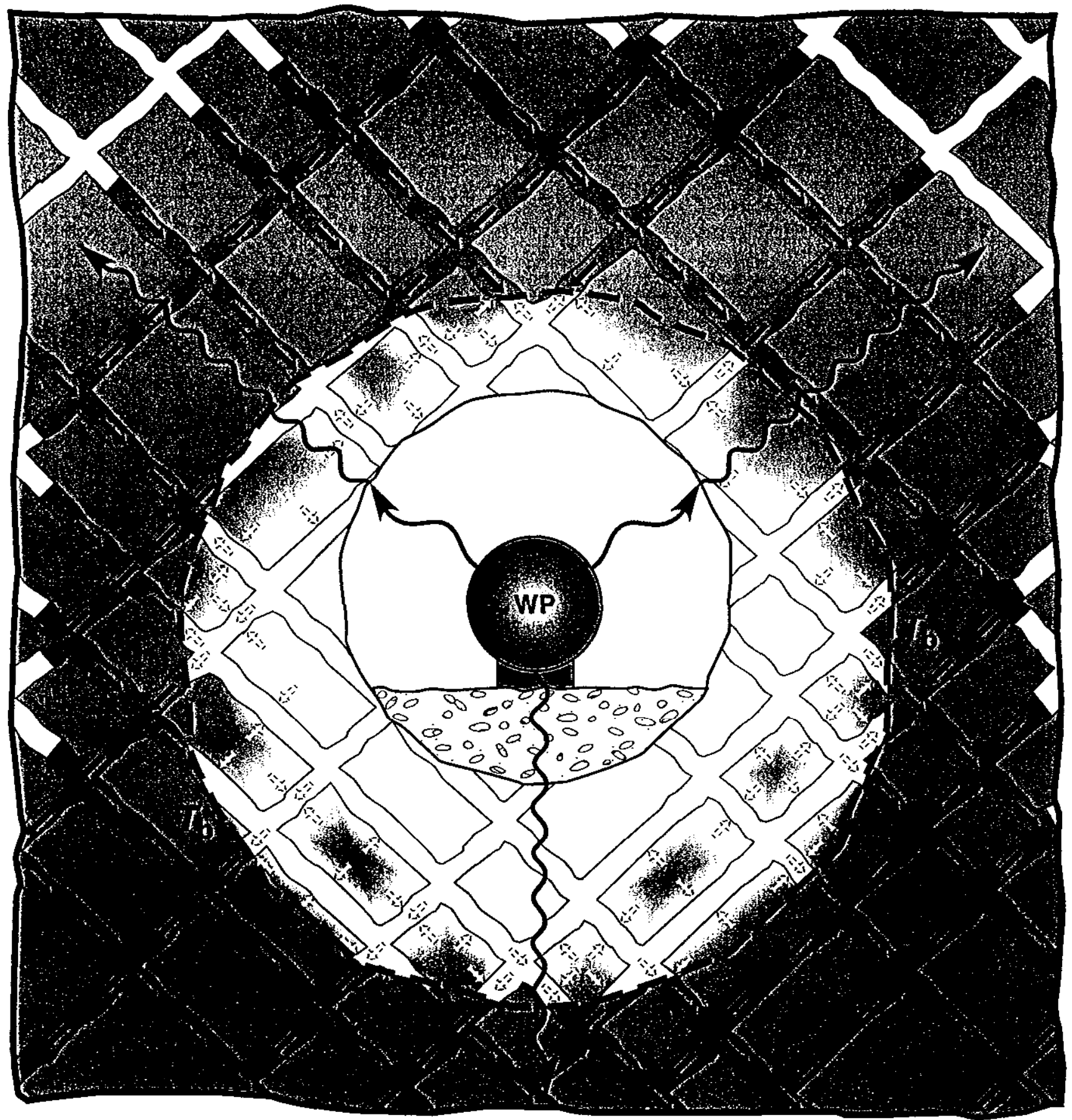

Figure 2. Drift-scale schematic showing decay-heat-driven T-H flow and transport processes, including (1) radiative, conductive, and convective heat flow, (2) boiling in the rock matrix and matrix-to-fracture vapor transport, and (3) vapor flow in fractures, and (4) condensation and condensate drainage 


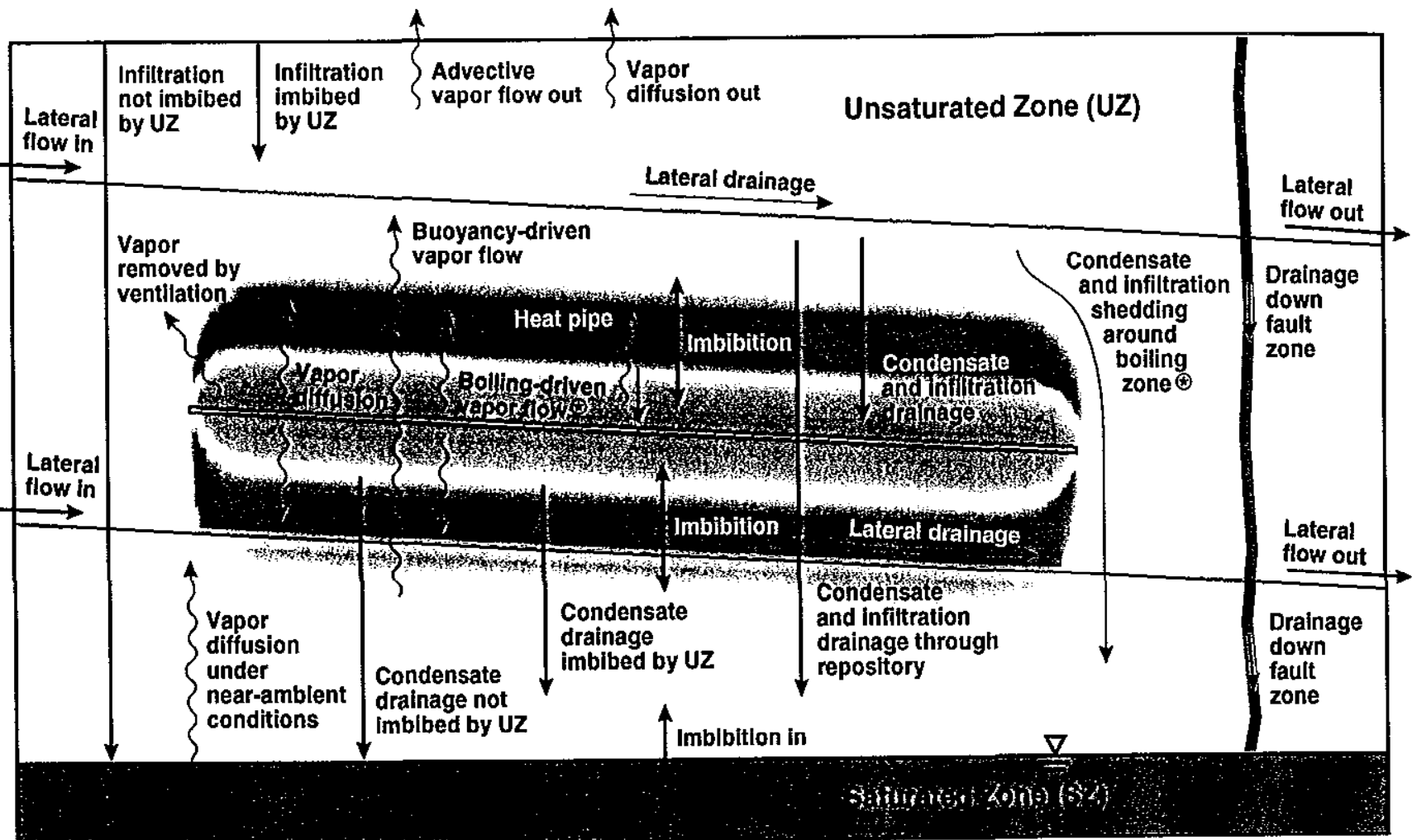

Figure 3. Mountain-scale schematic showing decay-heat-driven T-H flow and transport processes that influence moisture redistribution and the moisture balance in the $\mathrm{UZ}$ 
(a) SDT model

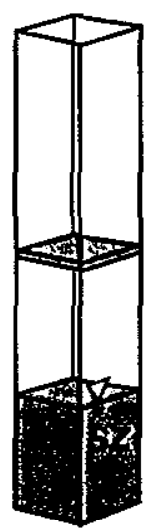

(b) LDTH model

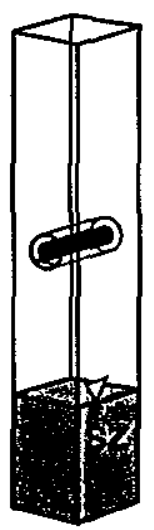

(c) DDT model

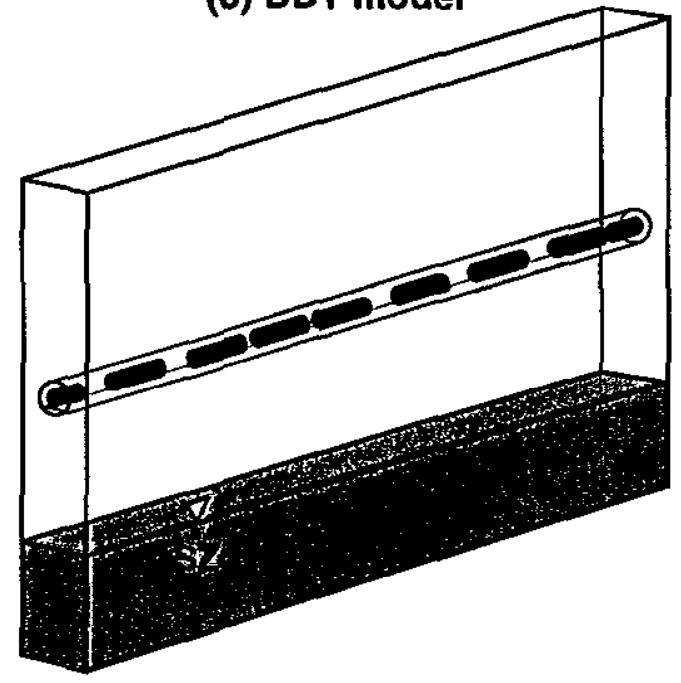

(d) SMT model

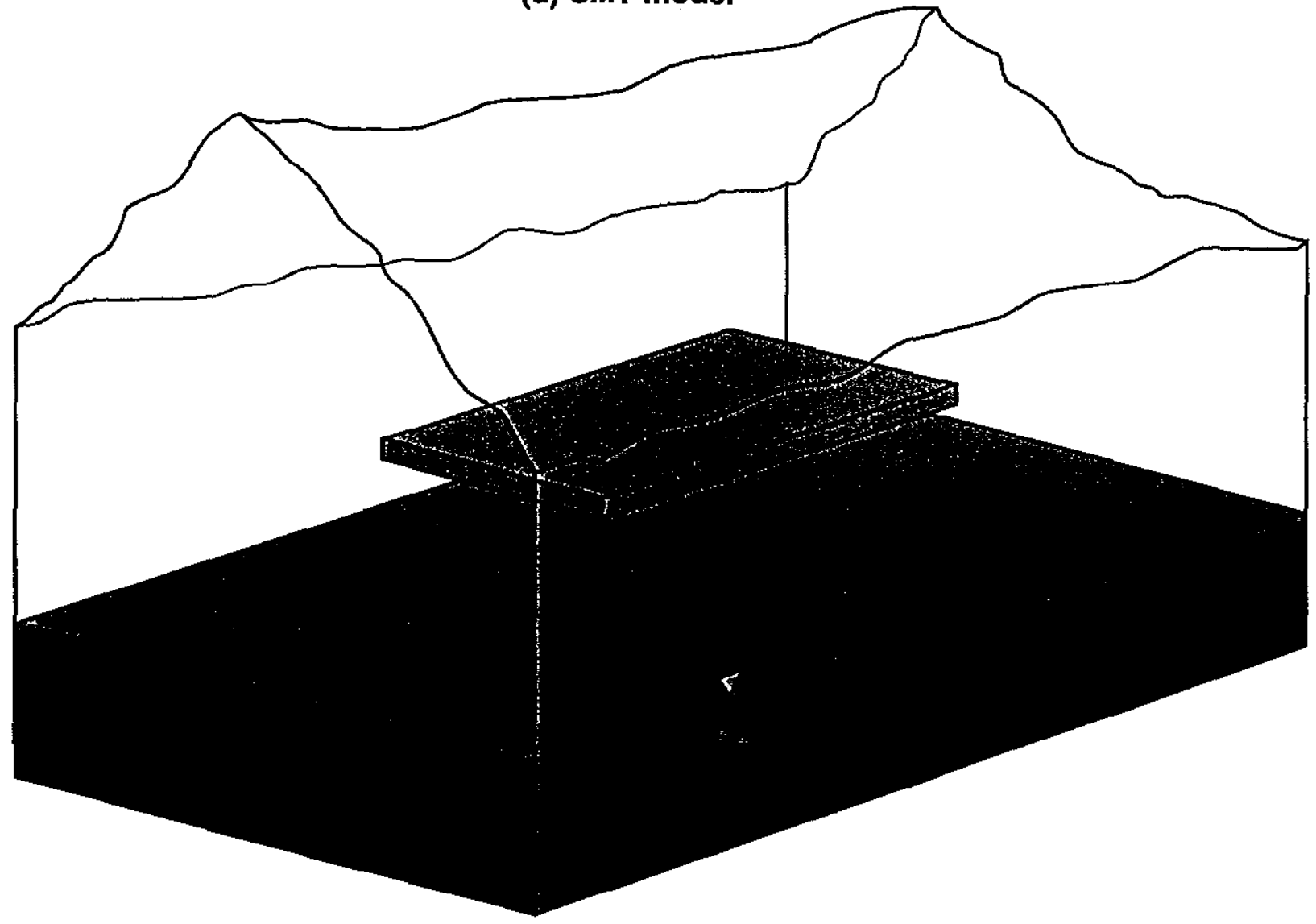

Figure 4. Schematic of conceptual models used by the multi-scale T-H modeling approach, including (a) smeared-heat-source, drift-scale, thermal-conduction (SDT) model, (b) line-averaged-heat-source, drift-scale thermal-hydrological (LDTH) model, (c) discrete-heat-source, drift-scale, thermal-conduction (DDT) model, and (d) smeared-heat-source, mountain-scale thermal-conduction (SMT) model 

(a)

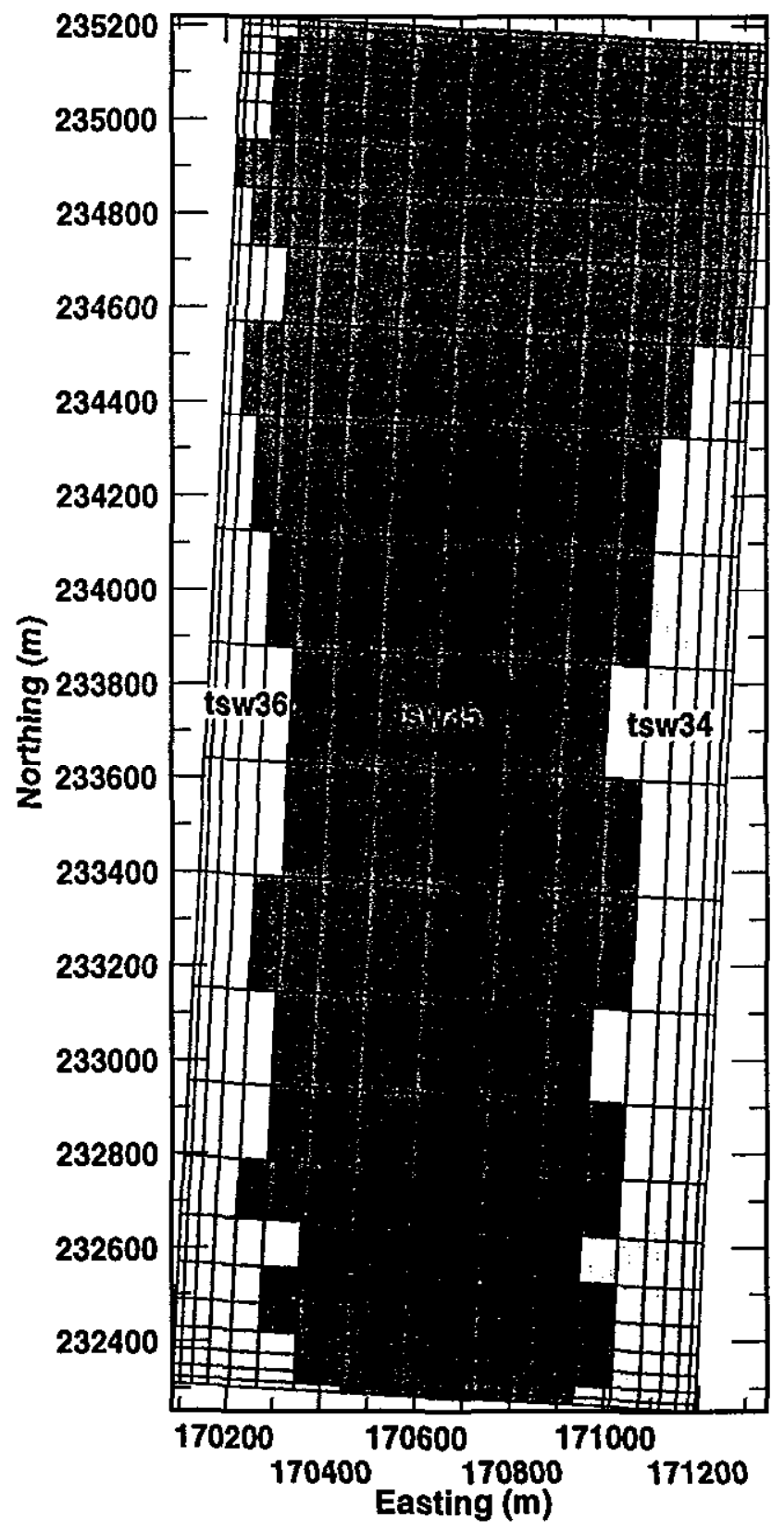

(b)

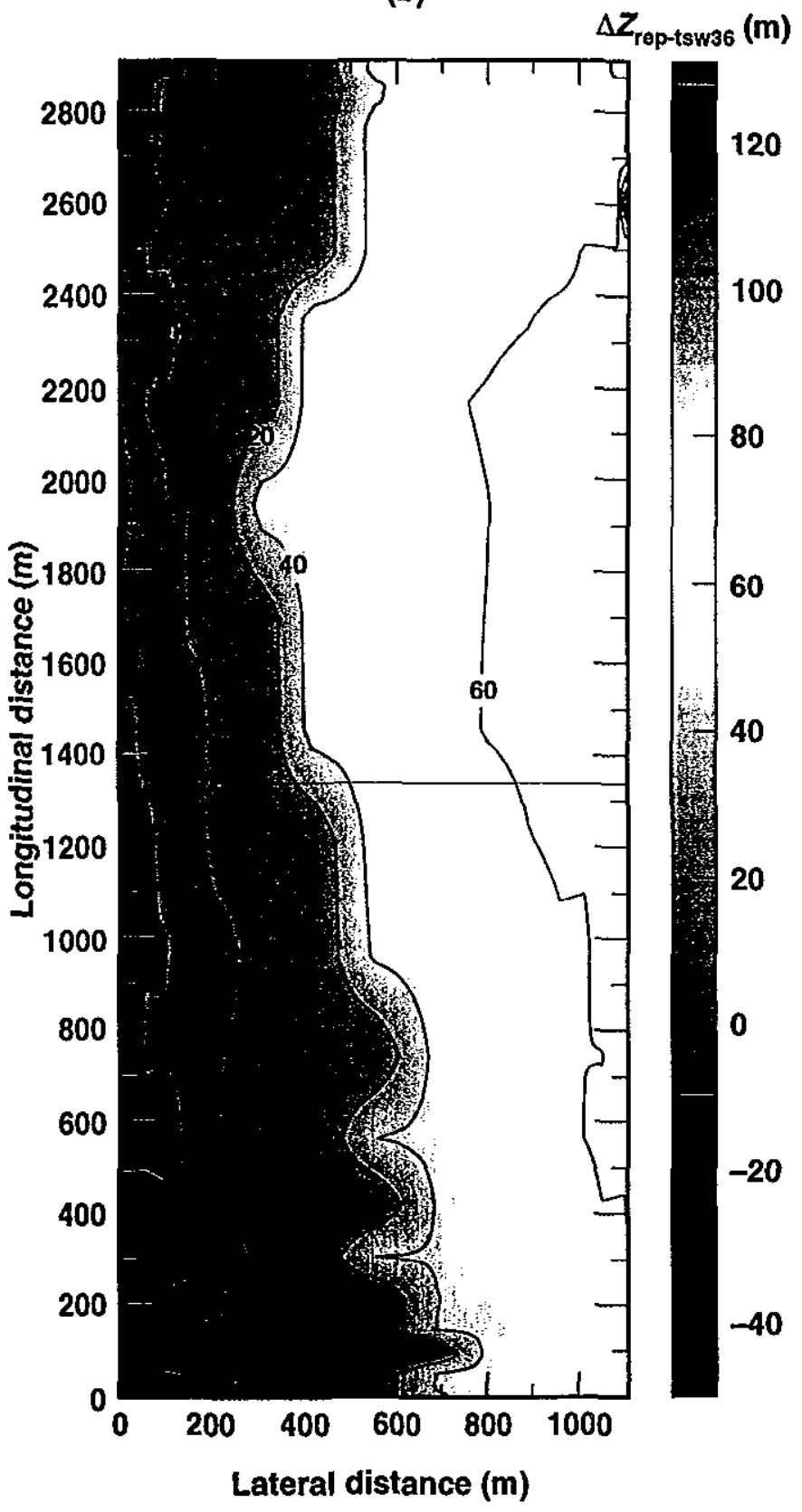

Figure 5. Plan view of the host-rock distribution (a) is shown for the SMT-model grid of the repository area as a function of the Nevada-State coordinates (b) Contour map of the vertical depth $\Delta Z_{\text {rep-tsw36 }}$ between the repository horizon and the top of the tsw36 hydrostratigraphic model unit is shown as a function of distance from the southwest corner of the repository area in the SMT model 


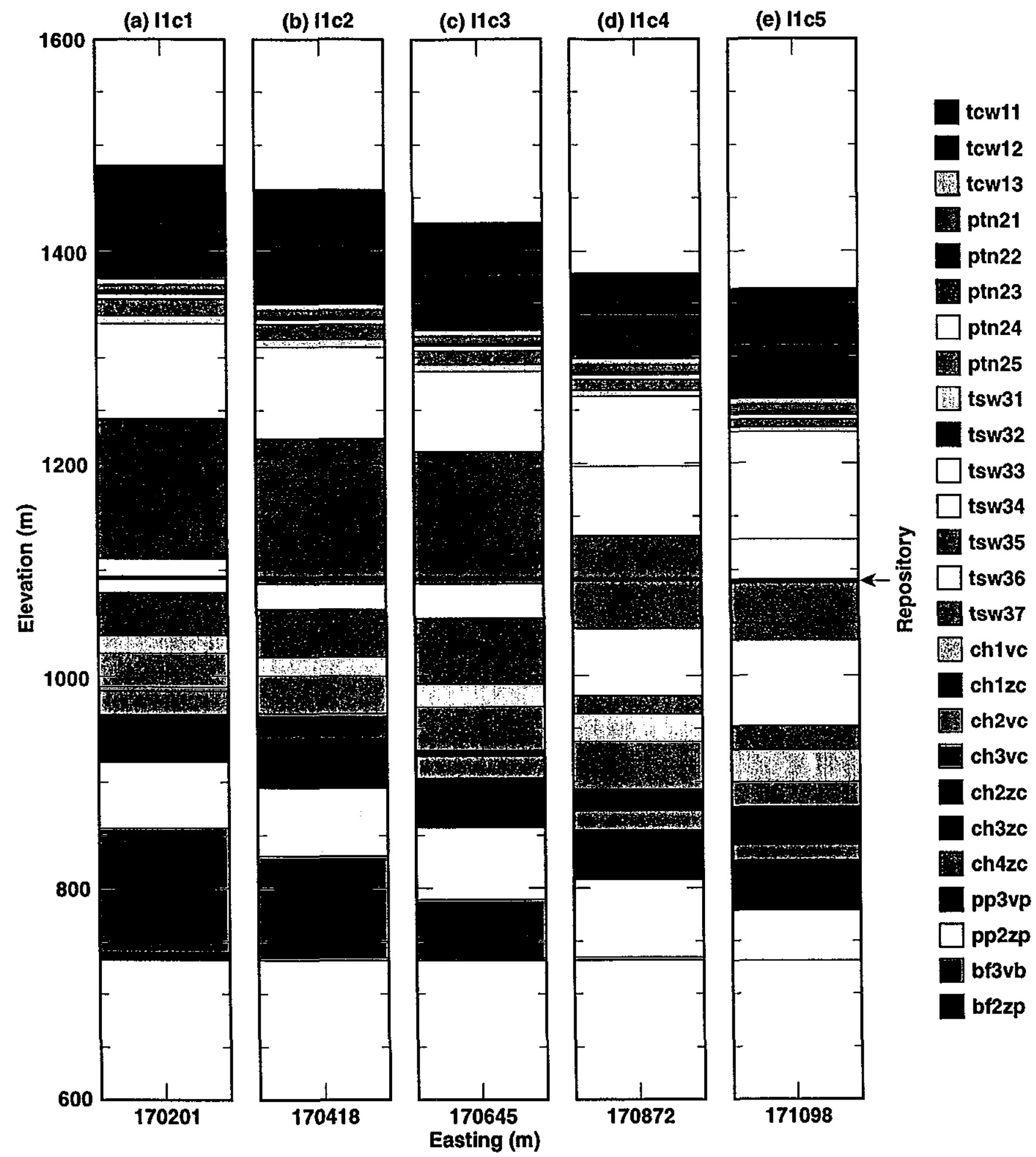

Figure 6. Vertical distribution of hydrostratigraphic model units is shown for several drift-scale model locations (in Nevada-State coordinates), including (a) $11 \mathrm{c1}$ at Northing $=232406 \mathrm{~m}$, (b) 11c2 at Northing $=232394$ $\mathrm{m},(\mathrm{c}) 11 \mathrm{c} 3$ at Northing $=232382 \mathrm{~m}$, (d) $11 \mathrm{c} 4$ at Northing $=232370 \mathrm{~m}$, and (e) $11 \mathrm{c5}$ at Northing $=232358 \mathrm{~m}$ 
$\sim$ 


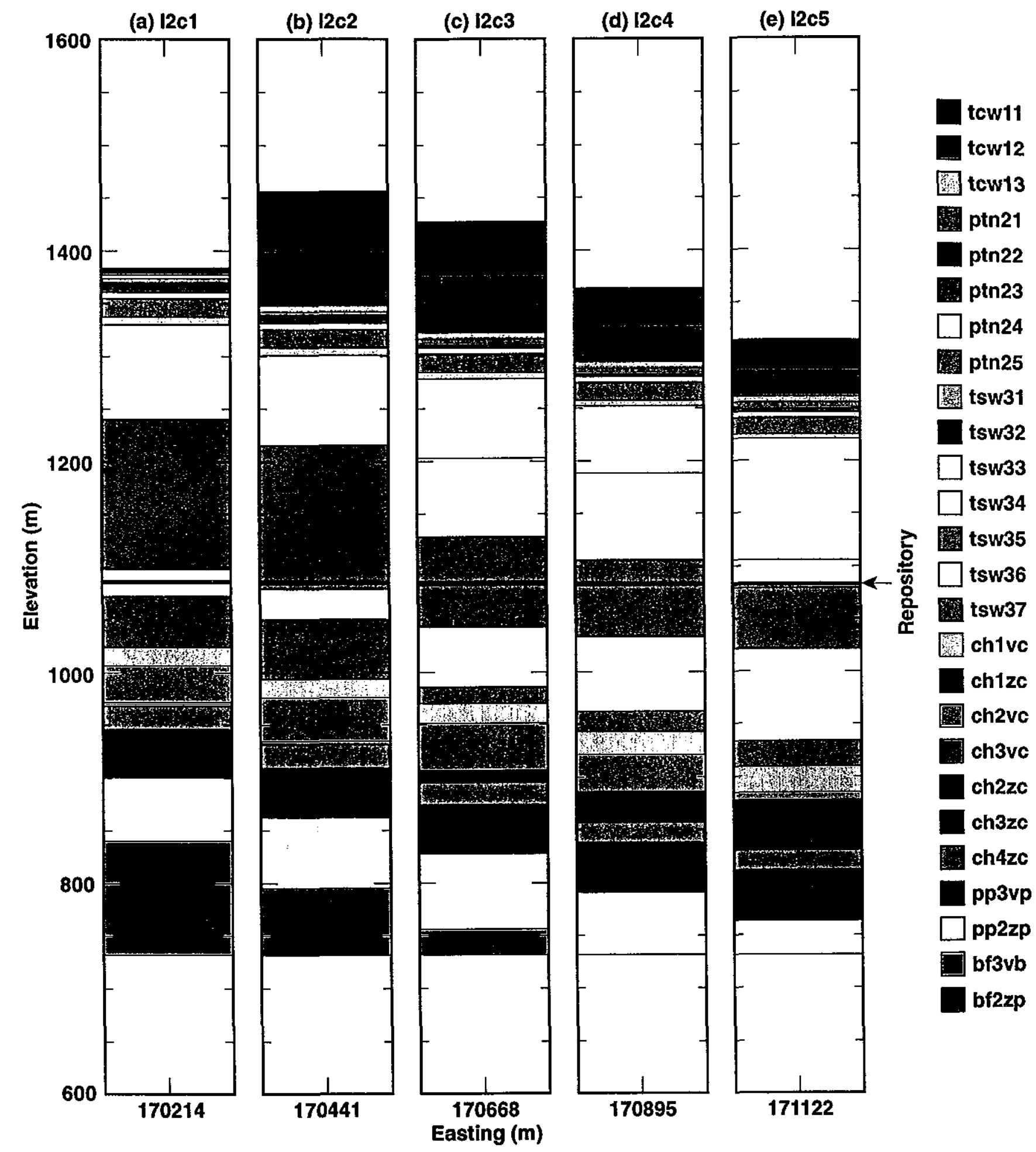

Figure 7. Vertical distribution of hydrostratigraphic model units is shown for drift-scale model locations (in Nevada-State coordinates), including (a) $12 \mathrm{c} 1$ at Northing $=232857 \mathrm{~m}$, (b) $12 \mathrm{c} 2$ at Northing $=232845 \mathrm{~m}$, (c) $12 \mathrm{c} 3$ at Northing $=232833 \mathrm{~m}$, (d) $12 \mathrm{c} 4$ at Northing $=232821 \mathrm{~m}$, and (e) $12 \mathrm{c5}$ at Northing $=232809 \mathrm{~m}$ 
$\vdots$

$-$ 


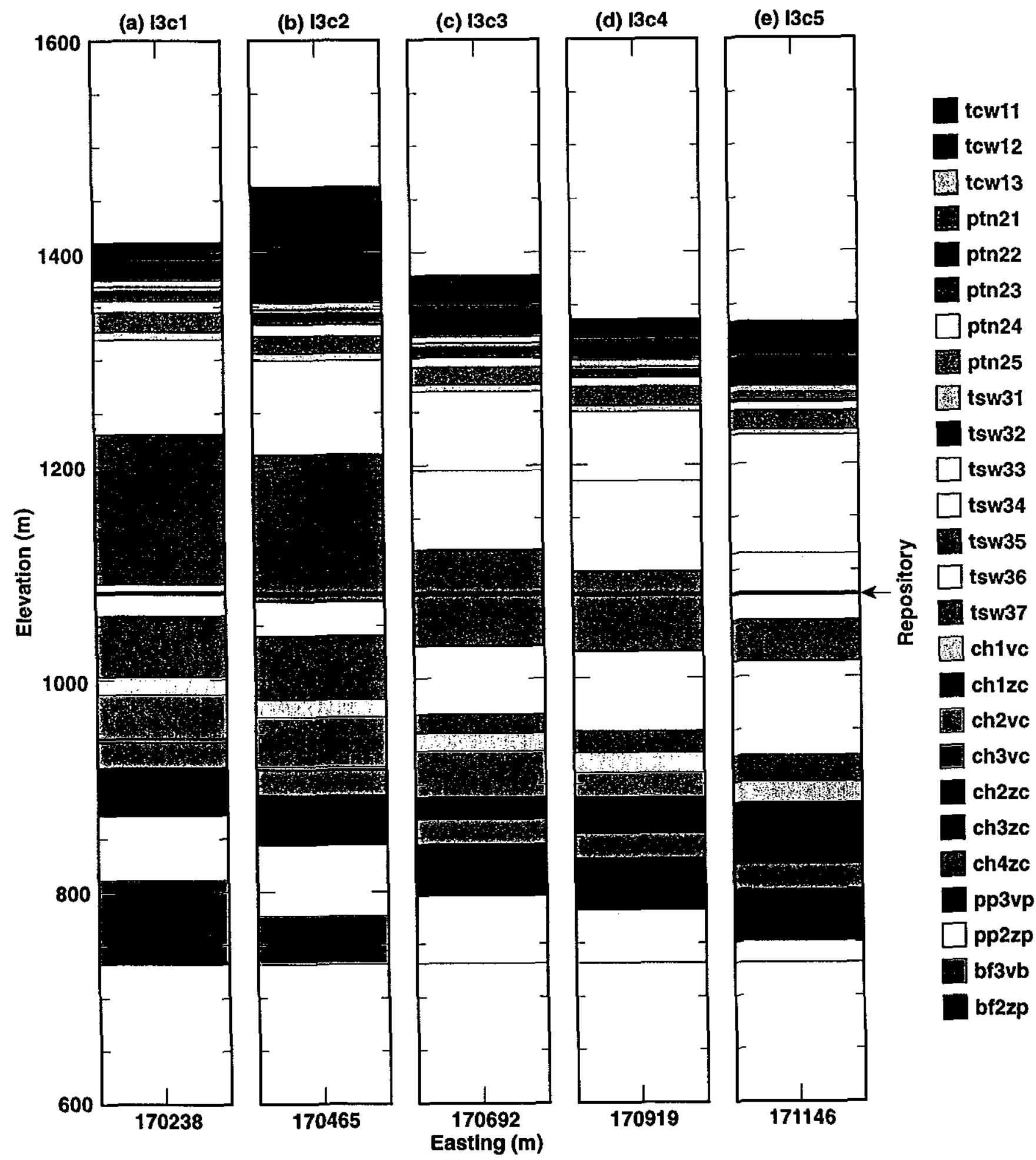

Figure 8. Vertical distribution of hydrostratigraphic model units is shown for drift-scale model locations (in Nevada-State coordinates), including (a) $13 \mathrm{cl}$ at Northing $=233308 \mathrm{~m}$, (b) $13 \mathrm{c} 2$ at Northing $=233296 \mathrm{~m},(\mathrm{c}) 13 \mathrm{c} 3$ at Northing $=233285 \mathrm{~m}$, (d) $13 \mathrm{c} 4$ at Northing $=233273 \mathrm{~m}$, and (e) $13 \mathrm{c5}$ at Northing $=233261 \mathrm{~m}$ 


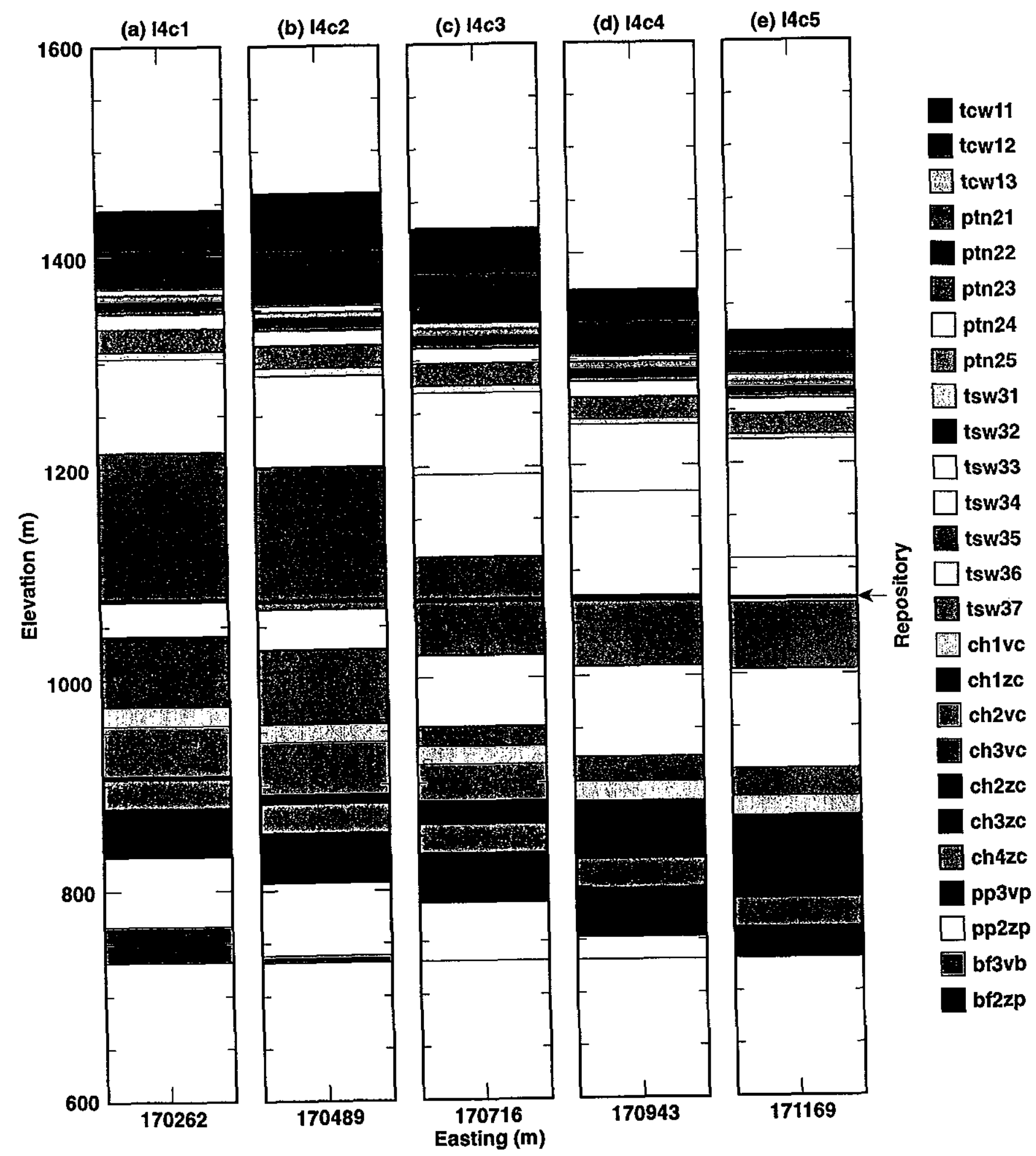

Figure 9. Vertical distribution of hydrostratigraphic model units is shown for drift-scale model locations (in Nevada-State coordinates), including (a) $14 \mathrm{c} 1$ at Northing $=233760 \mathrm{~m}$, (b) $14 \mathrm{c} 2$ at Northing $=233748 \mathrm{~m}$, (c) $14 \mathrm{c} 3$ at Northing $=233736 \mathrm{~m}$, (d) $14 \mathrm{c} 4$ at Northing $=233724 \mathrm{~m}$, and (e) $14 \mathrm{c} 5$ at Northing $=233712 \mathrm{~m}$ 


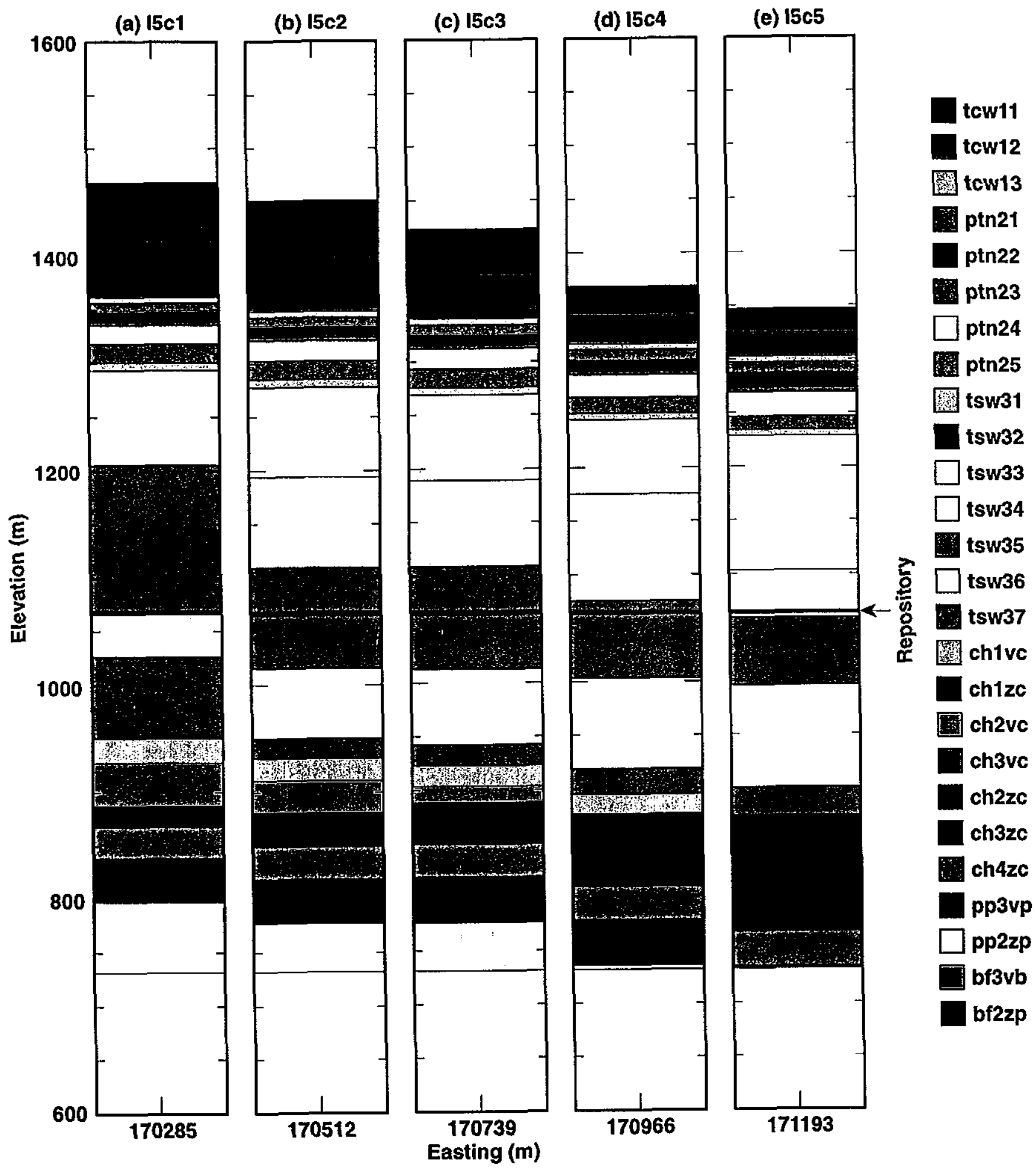

Figure 10. Vertical distribution of hydrostratigraphic model units is shown for drift-scale model locations (in Nevada-State coordinates), including (a) $15 \mathrm{c} 1$ at Northing $=234211 \mathrm{~m}$, (b) $15 \mathrm{c} 2$ at Northing $=234199 \mathrm{~m}$, (c) $15 \mathrm{c} 3$ at Northing $=234187 \mathrm{~m}$, (d) $15 \mathrm{c} 4$ at Northing $=234175 \mathrm{~m}$, and (e) $15 \mathrm{c5}$ at Northing $=234164$ m ayout, including dimensions and SHT-model coordinate system, in plan view and vertical Section A-A 


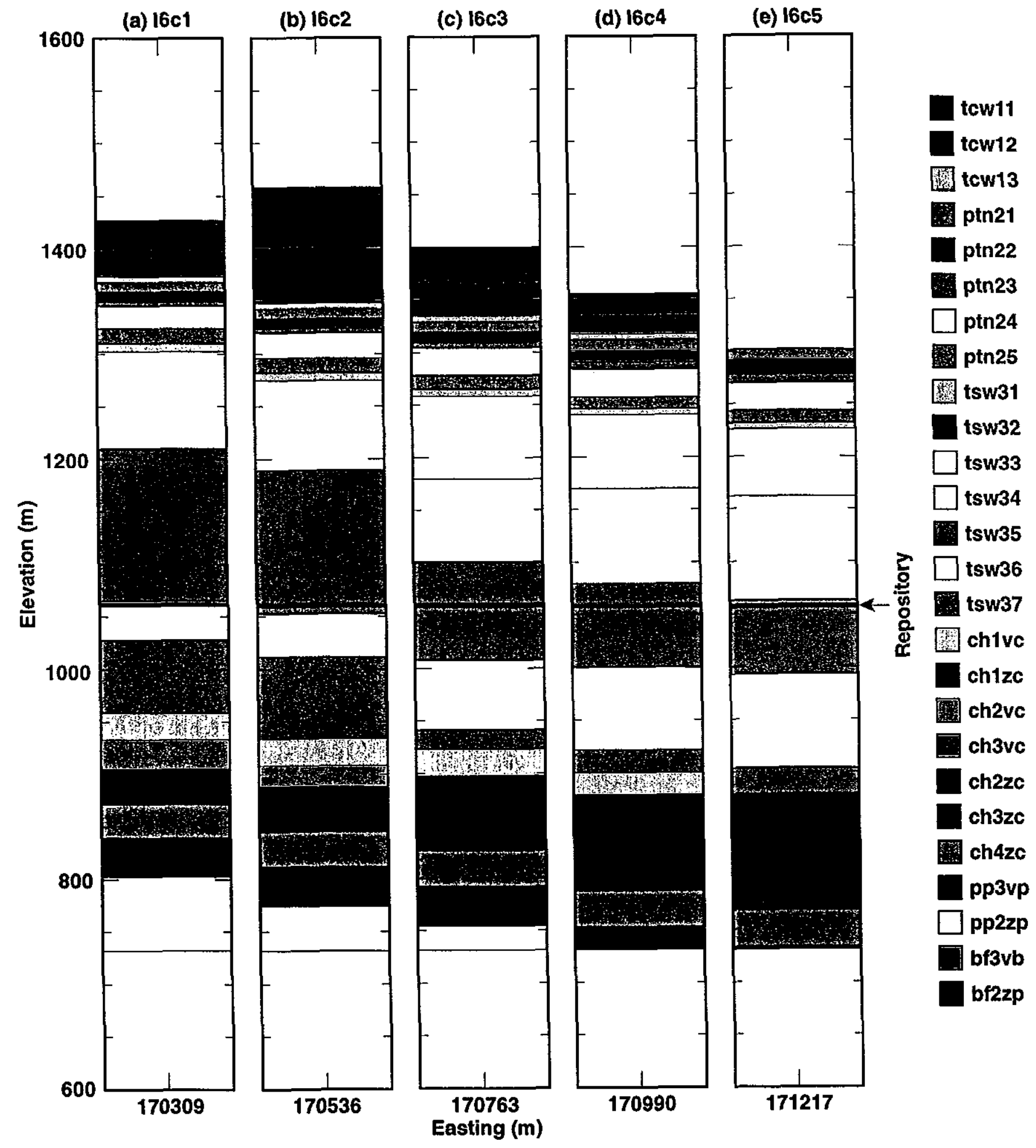

Figure 11. Vertical distribution of hydrostratigraphic model units is shown for drift-scale model locations (in Nevada-State coordinates), including (a) $16 \mathrm{c} 1$ at Northing $=234663 \mathrm{~m},(\mathrm{~b}) 16 \mathrm{c} 2$ at Northing $=234651 \mathrm{~m},(\mathrm{c}) 16 \mathrm{c} 3$ at Northing $=234639 \mathrm{~m}$, (d) $16 \mathrm{c} 4$ at Northing $=234627 \mathrm{~m}$, and (e) $16 \mathrm{c5}$ at Northing $=234615 \mathrm{~m}$ 


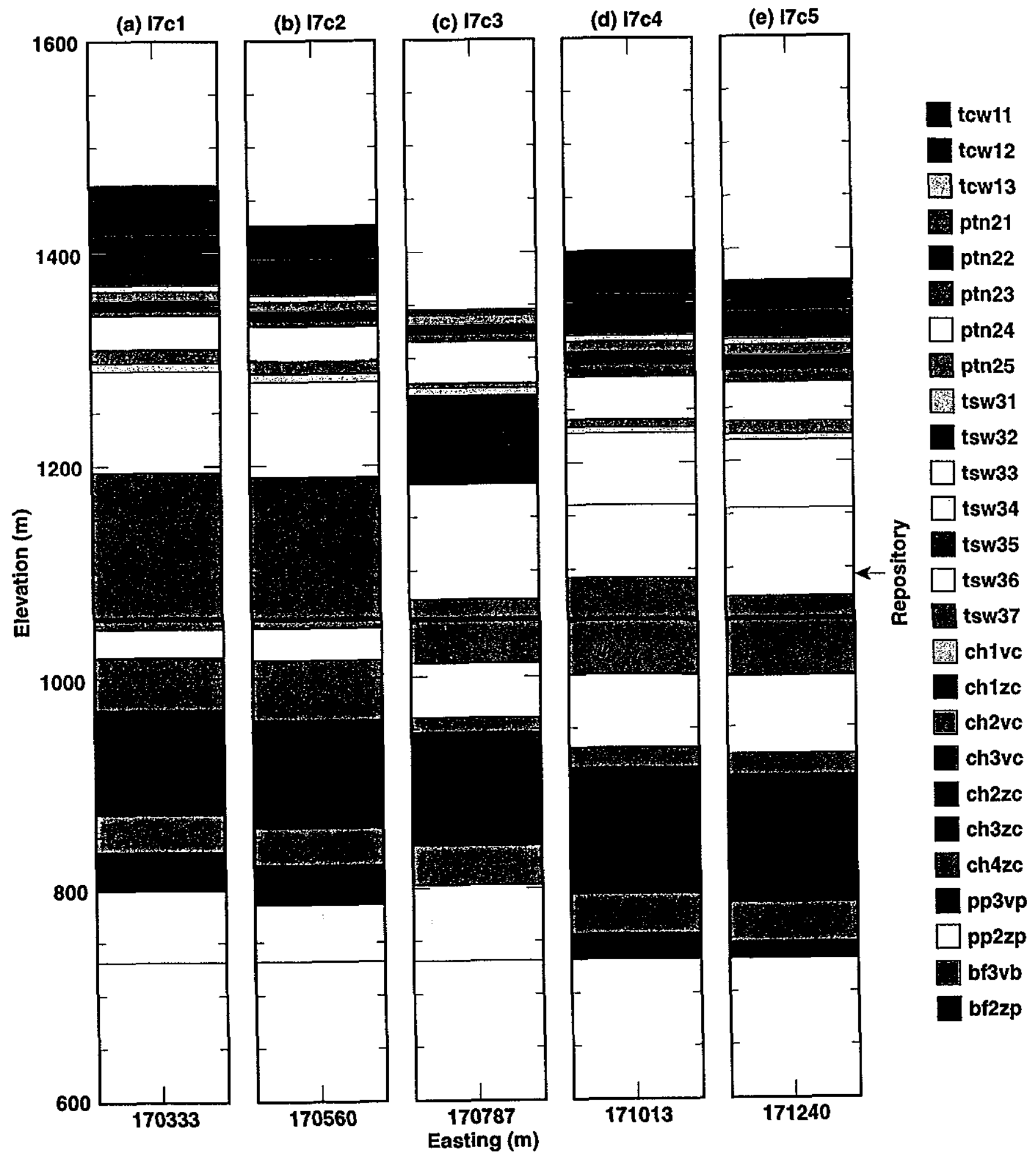

Figure 12. Vertical distribution of hydrostratigraphic model units is shown for drift-scale model locations (in Nevada-State coordinates), including (a) $17 \mathrm{c} 1$ at Northing $=235114 \mathrm{~m}$, (b) $17 \mathrm{c} 2$ at Northing $=235102 \mathrm{~m}$, (c) $17 \mathrm{c} 3$ at Northing $=235090 \mathrm{~m}$, (d) $17 \mathrm{c} 4$ at Northing $=235078 \mathrm{~m}$, and (e) $17 \mathrm{c} 5$ at Northing $=235066 \mathrm{~m}$ 


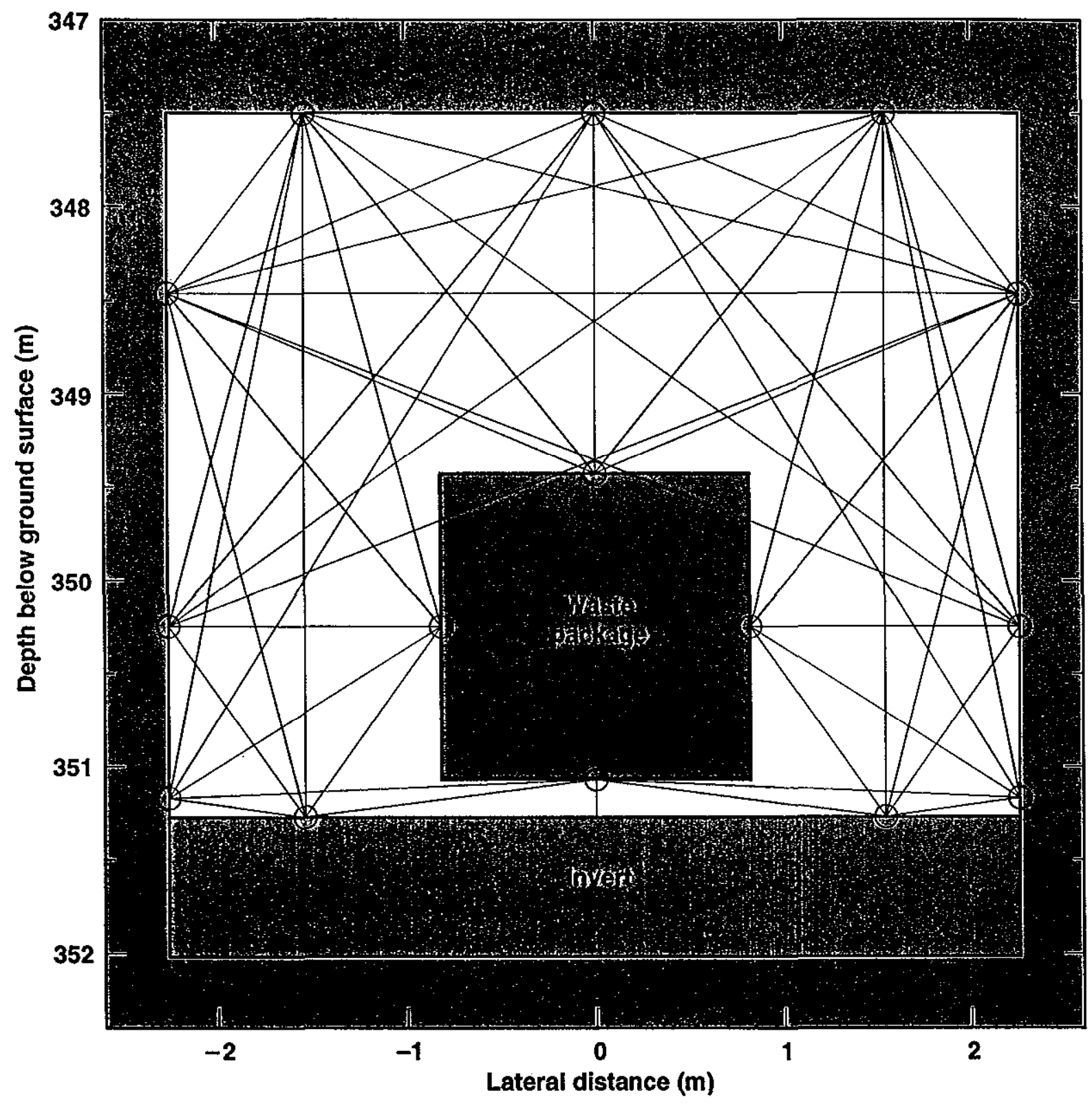

Figure 13. Vertical cross section of the emplacement drift in the DDT and LDTH model is shown, including the thermal radiation connections between the surfaces in the drift 


\section{-}


(a) Point-load design, LML $=0.588 \mathrm{MTU} / \mathrm{m}$

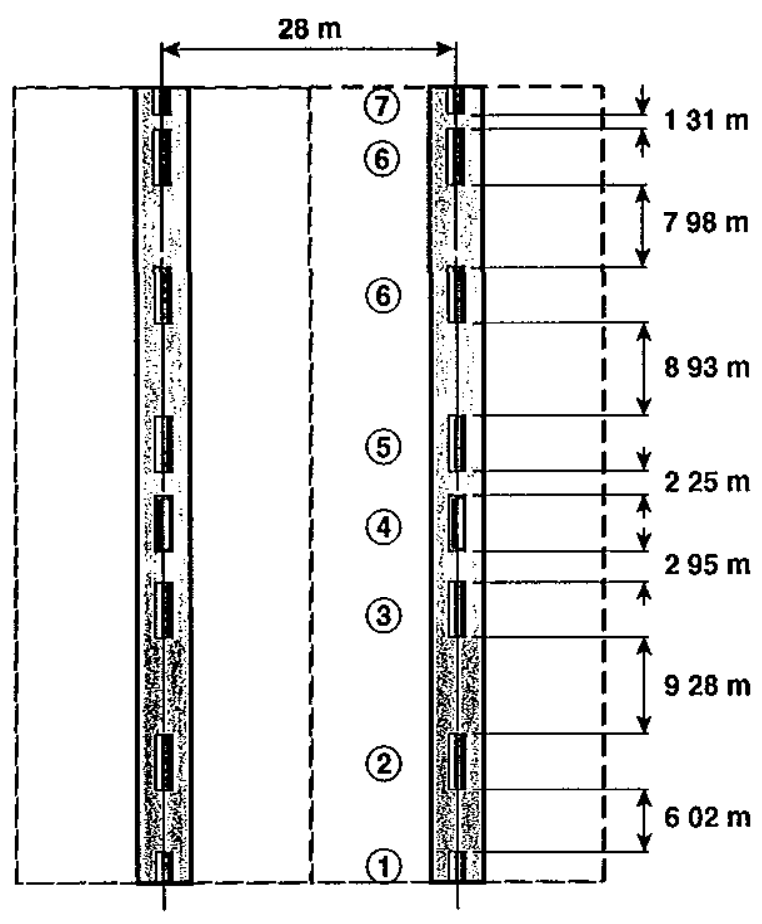

(b) Line-load design, LML $=1.189 \mathrm{MTU} / \mathrm{m}$

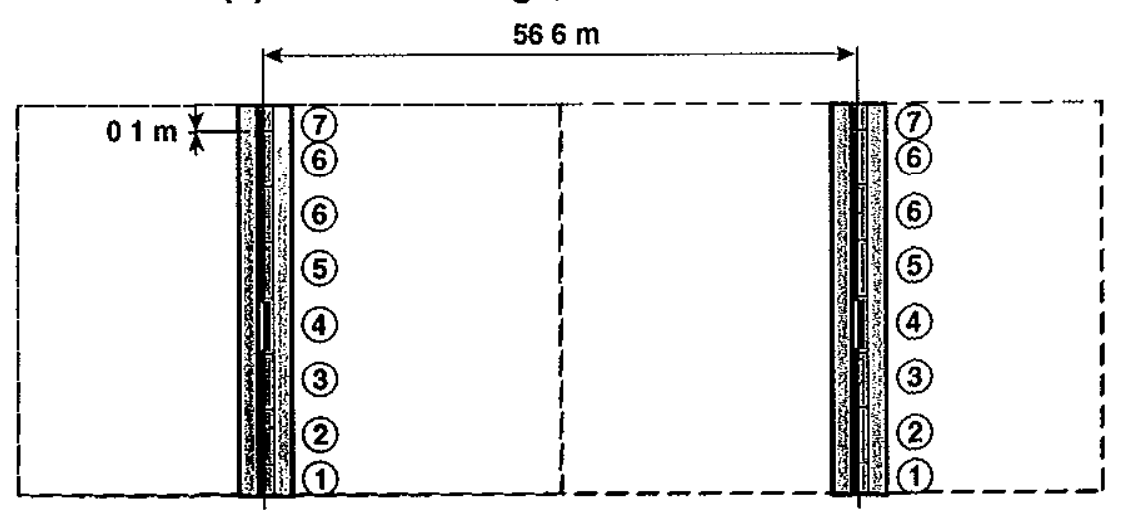

WP Diameter

$163 \mathrm{~m}$

\begin{tabular}{|c|c|c|c|c|c|c|}
\hline 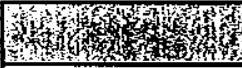 & 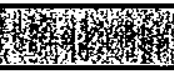 & 然 & 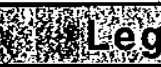 & Id & 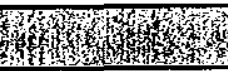 & 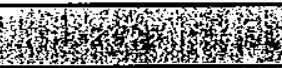 \\
\hline $\begin{array}{c}\text { (1) } \\
\frac{12 \text { PWR }}{(1 / 2) 6.25 \mathrm{MTU}} \\
(1 / 2) 10.48 \mathrm{~kW} \\
(1 / 2) 5.87 \mathrm{~m}\end{array}$ & $\begin{array}{c}\text { (2) } \\
21 \text { PWR } \\
7.4 \mathrm{MTU} \\
2.91 \mathrm{~kW} \\
5.3 \mathrm{~m}\end{array}$ & $\begin{array}{c}\text { (3) } \\
21 \text { PWR } \\
9.4 \mathrm{MTU} \\
17.85 \mathrm{~kW} \\
53 \mathrm{~m}\end{array}$ & $\begin{array}{c}\text { (4) } \\
21 \text { PWR } \\
8.93 \mathrm{MTU} \\
9.34 \mathrm{~kW} \\
53 \mathrm{~m}\end{array}$ & $\begin{array}{c}5 \\
2 \times 44 \text { PWR } \\
7.81 \mathrm{MTU} \\
6.44 \mathrm{~kW} \\
5.3 \mathrm{~m}\end{array}$ & $\begin{array}{c}\text { 6) } \\
\text { Co-Disposal } \\
4.06 \mathrm{~kW} \\
5.37 \mathrm{~m}\end{array}$ & $\begin{array}{c}(7) \\
\text { Direct-Disposal } \\
(1 / 2) 0.793 \mathrm{~kW} \\
(1 / 2) 5.37 \mathrm{~m}\end{array}$ \\
\hline
\end{tabular}

Figure 14. Plan view of the waste-package layout represented in the DDT models for (a) the point-load design, which is the TSPA-VA base-case design, and (b) the line-load design, which is an alternative design for TSPA-VA 


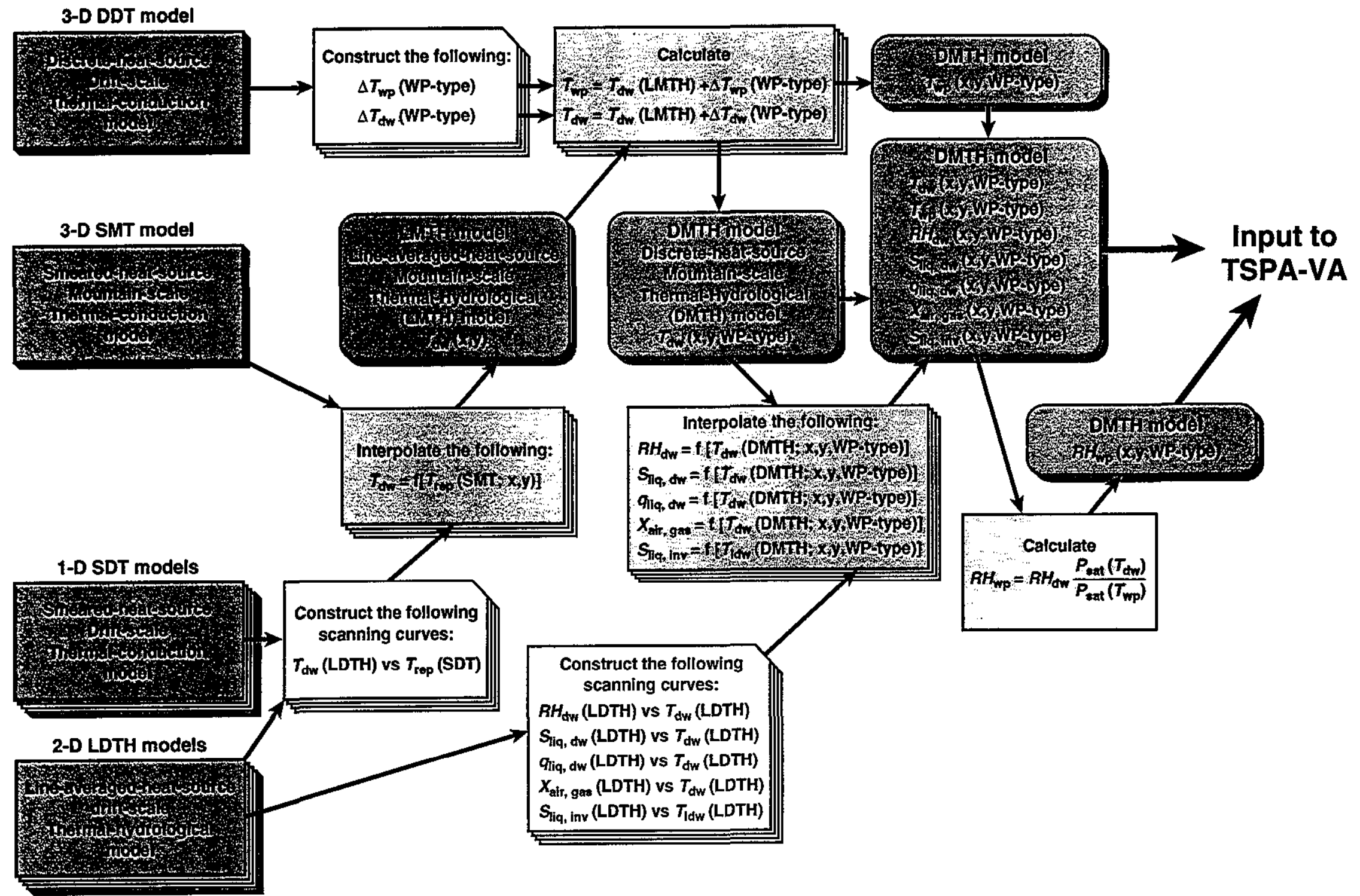

Figure 15. Flow chart for the multı-scale T-H modeling approach. Process models are depicted in blue. Abstracted models are depicted in orange. See Table 3-4 for definition of model types. 


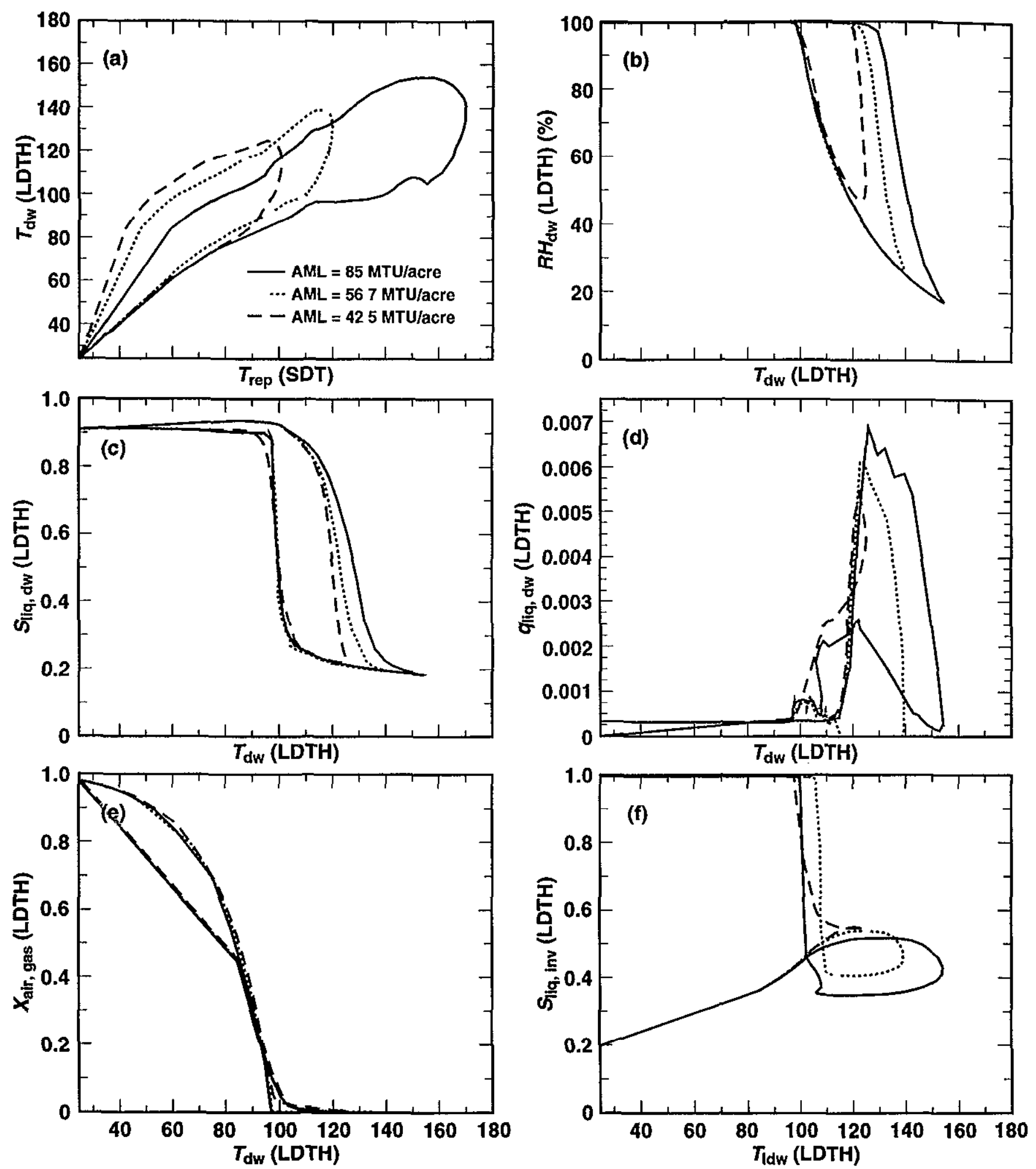

Figure 16. Functional relationships are plotted for the process-model inputs to the multi-scale T-H modeling approach, including (a) LDTH-model-predicted drift-wall temperature $T_{\mathrm{d} w}(\mathrm{LDTH})$ versus SDT-model-predicted repository host-rock temperature Trep(SDT), (b) LDTH-model-predicted drift-wall relative humidity $R H_{\mathrm{dw}}(\mathrm{LDTH})$ versus $T_{\mathrm{dw}}(\mathrm{LDTH})$, (c) LDTH-model-predicted drift-wall liquid-phase saturation $S_{\text {liq,dw }}(\mathrm{LDTH})$ versus $T_{\mathrm{dw}}$ (LDTH), (d) LDTH-model predicted liquid-phase flux $3 \mathrm{~m}$ above the drift $q_{\mathrm{liq}, \mathrm{dw}}$ (LDTH versus $T_{d w}\left(\right.$ LDTH), (e) LDTH-model-predicted gas-phase air-mass fraction in the drift $X_{\text {air,dr }}(\mathrm{LDTH})$ versus $T_{\mathrm{dw}}(\mathrm{LDTH})$, and (f) LDTH-model-predicted liquid-phase saturation in the invert $S_{\text {liq,inv }}(\mathrm{LDTH})$ versus $T_{\mathrm{dw}}(\mathrm{LDTH})$ 

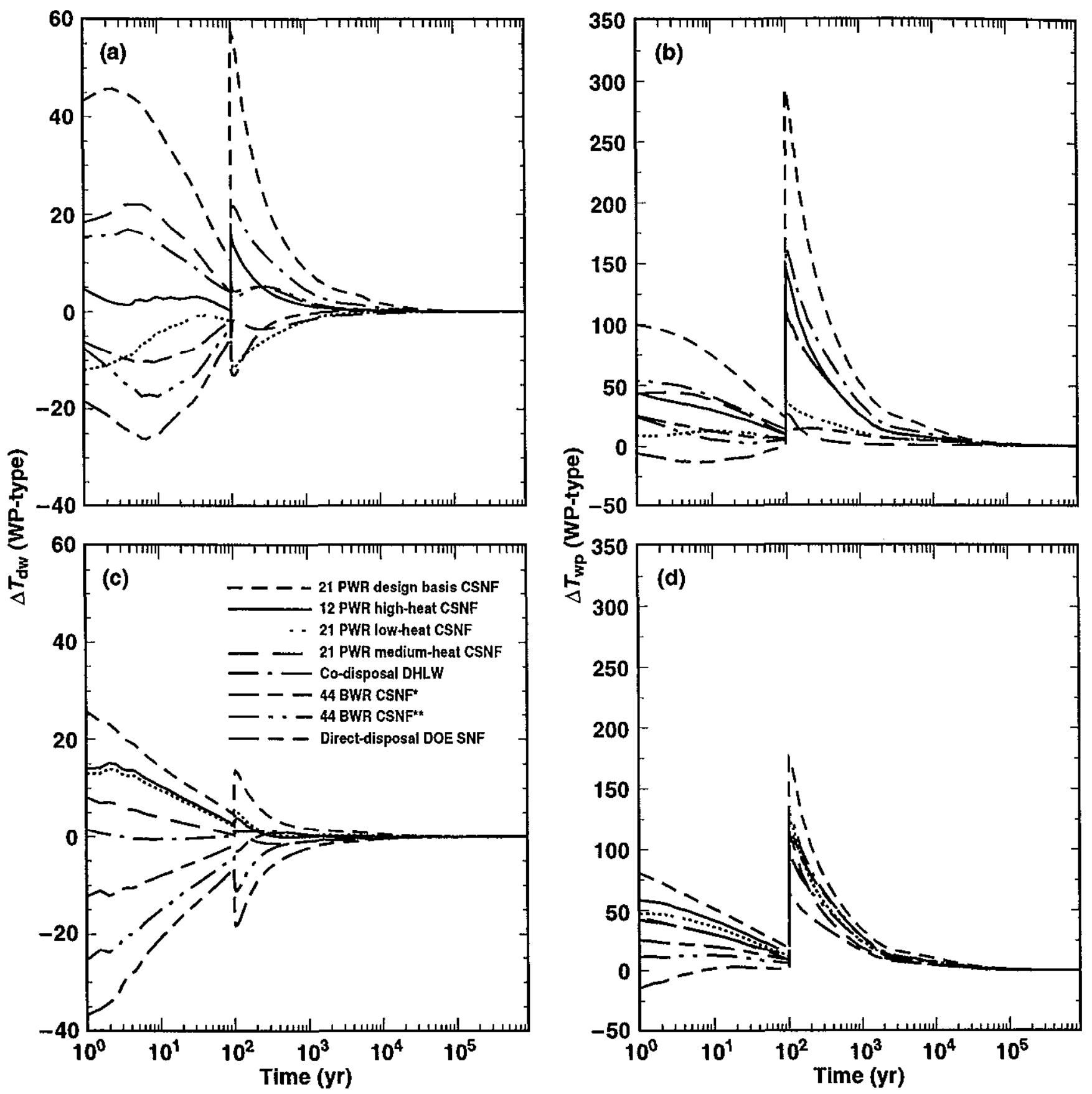

Figure 17. Functional relationships are plotted for the process-model inputs to the multi-scale T-H modeling approach as functions of time, including (a) WP-type/location-specific temperature deviations $\Delta T_{\mathrm{dw}}$ (WPtype) from the average drift-wall temperature along the drift and (b) WP-type/location-specific temperature difference $\Delta T_{\text {wp }}$ (WP-type) between the WP surface and the average drift-wall temperature along the drift for the point-load design The relationships for $\Delta T_{d w}$ (WP-type) (c) and $\Delta T_{w p}$ (WP-type) (d) are also given for the line-load design 


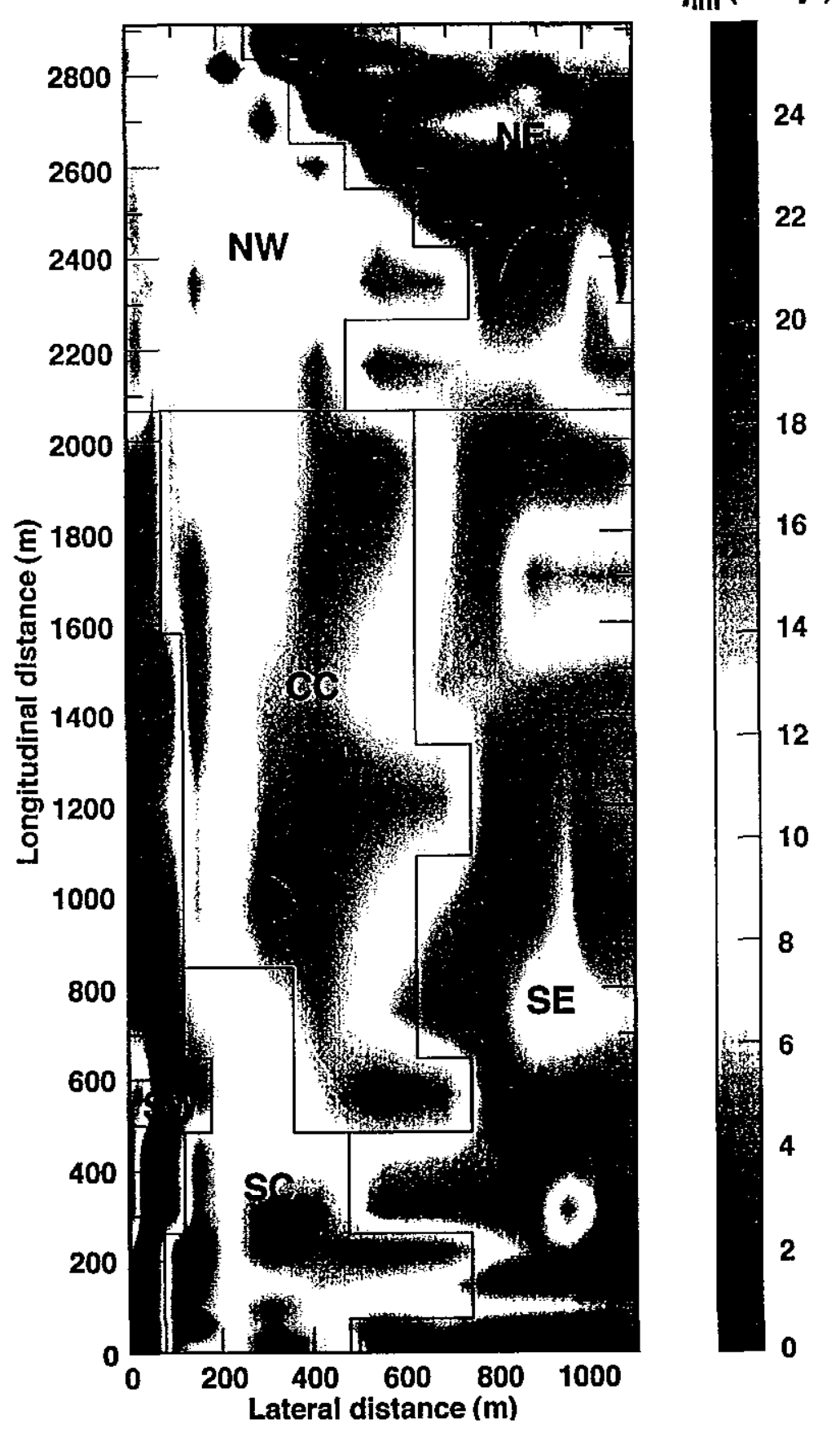

Figure 18. The six infiltration-flux subdomains and the infiltration-flux $q_{\text {inf }}$ distribution [Flint et al, 1996a] are shown for the SMT-model representation of the repository area The infiltration-flux subdomains are used to bin the WP environments for the purpose of EBS subsystem analysis for TSPA-VA In increasing order of mean $q_{\text {inf }}$ the subdomains are (1) southwest SW, (2) northeast NE, (3) southeast SE, (4) northwest NW, (5) south-central SC, and (6) central-central CC 
RE Pedigree of Thermal-Hydrological Models Level 4 deliverable document (Milestone SPLX5AM4)

This document was reviewed as part of the Near-Field Models Report

The material is the same as that which was originally reviewed as Chapter 3 of that report As a result of the technical reviews the NFMR was modified However, there were no changes of a technical or substantive nature The changes were in organization and presentation style Because this material (SPLX5AM4) had been provided as informal input to the TSPA-VA chapter prior to the reviews, this report has not been revised to be the same as the NFMR but left as is so that it properly reflects the material that has been incorporated into the draft TSPA-VA The author of the TSPA-VA chapter, Nick Francis of SNL, will make a comparison of the material in both reports and determine which he will incorporate into the final TSPAVA

Because this material has received technical review as Chapter 3 of the NFMR, no separate review has been performed Documentation of the review is contained within the NFMR package

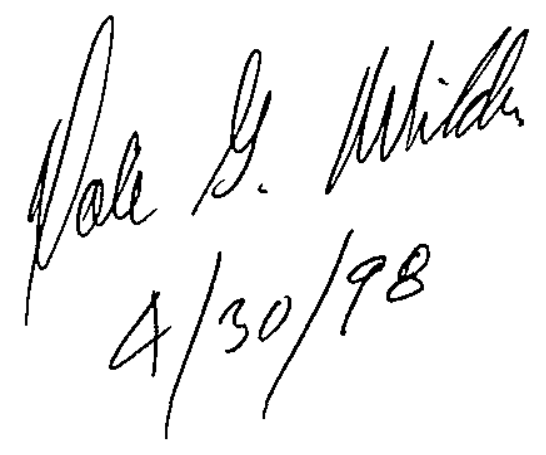


$\checkmark$ 
Number \& Title of Deliverable: SP3100M4 Near Field and Altered Zones Environments Models Report UCRL-ID-129179DR

Author(s)

Note to Reviewer.

Your review should include an examination of the deliverable's technical accuracy, adequacy, and applicability; a determination whether the data support the conclusions; and whether the description of the work in the deliverable and supporting records is sufficient to allow replication by an independent peer. Your review should also consider correctness and completeness

Comments of Reviewer: Chapters 1 and 2 and 3

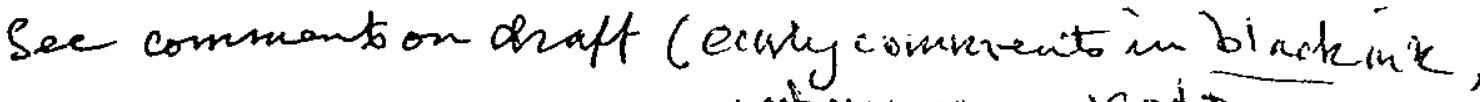

$$
\begin{aligned}
& 1 \text { coter oreas in red) }
\end{aligned}
$$

Recommendation of Reviewer (check one):

( ) Deliver as-is.

Deliver. Optional minor revisions are noted on text.

() Deliver after major revision(s) are re-reviewed by me.

() Not suitable for delivery.

Reviewer's Recommendation on Data (check one):

There are no technical data in this report.

(2) The technical data in this report were also reviewed and are technically accurate.

C.R $\$ 1348$
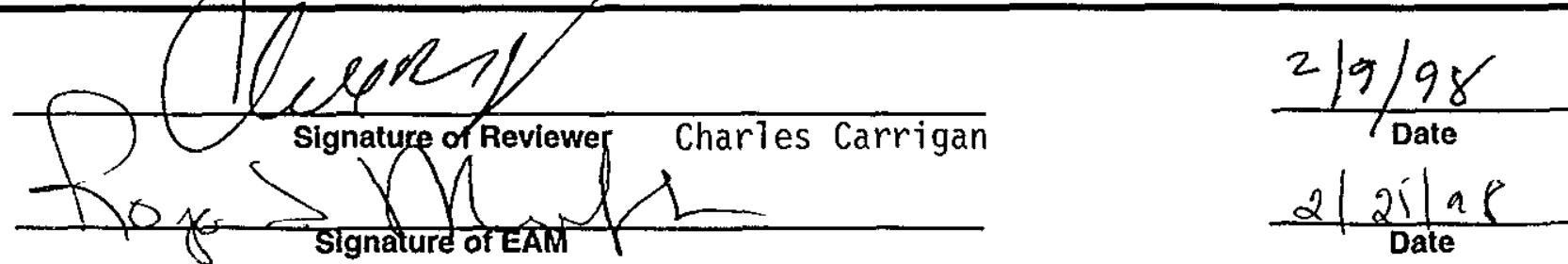

This signature on the cover letter denotes the review and approval of the Technical Area Leader 


\title{
Addendum to Milestone SPLX5AM4
}

\section{Thomas A. Buscheck}

\begin{abstract}
A multi-scale thermal-hydrological (TH) modeling approach (or methodology) has been developed that integrates the results from 1-, 2-, and 3-D drift-scale models and a 3-D mountain-scale model to provide a full description of the $\mathrm{TH}$ variables affecting the performance of the engineered barrier system (EBS) This information is required by Total Systems Performance Assessment for the Viability Assessment (TSPA-VA) to assess waste-package (WP) corrosion, waste-form dissolution, and radionuclide transport in the EBS. This methodology is a computationally efficient, flexible means of determining EBS T-H conditions that would otherwise require 60 million grid blocks if a brute-force numerical model were used, it determines EBS $\mathrm{TH}$ conditions as a function of location in the repository and WP type, including the influence of WP spacing and sequencing The EBS TH results have been provided to Performance Assessment as probability-density functions (or histograms) with respect to (1) time required to rewet to corrosive relative humidity $R H$ conditions, and (2) WP temperature when corrosive $R H$ conditions are attained This methodology captures the three key factors that influence EBS TH conditions, including (1) mountain-scale heat flow (particularly, the effect of lateral heat loss at the repository edge), (2) repository-scale variability in percolation flux, and (3) WPto-WP variability in heat output Other factors affecting EBS TH conditions are addressed, including (1) matrix imbibition diffusivity of the local host-rock unit, (2) wet and dry thermal conductivity of the local host-rock unit, and (3) repository depth (or overburden thickness)
\end{abstract}

\section{Uncertainties in the Conceptual Models and Data}

There are two classes of uncertainties for the multi-scale TH modeling approach. The first class results from key assumptions imbedded in the conceptual models for this approach that have not yet been tested. This testing should be included in the abstraction-testing phase to be conducted FY99 The second class results from uncertainties in the input data The first class of uncertainties includes

1 The local percolation flux is assumed to be equal to the local infiltration flux, thereby preserving repository-scale variability of infiltration flux in the distribution of the percolation flux Although modeling studies with the sitescale UZ flow model indicate this assumption is adequate, it would be useful to consider alternative assumptions (e $g$, the PTn spatially attenuates the distribution of percolation flux or that fault zones focus percolation flux) to assess the importance of this assumption.

2 The no-flow lateral boundary conditions in the drift-scale TH models cause $100 \%$ of the steam generation to be driven above the emplacement drifts, resulting in the maximum possible magnitude condensate drainage back to the dryout zone. This assumption is conservative with respect to dryout and rewetting and is 

effectively equivalent to assuming that buoyant gas-phase convection dominates moisture redistribution Tying the gas-phase pressure below the emplacement drifts in the drift-scale TH models to the gas-phase pressure below the repository in a mountain-scale TH model would help eliminate this artificial behavior

3 The influence of the cold-trap mechanism is not included along emplacement drifts This mechanism can transport moisture and latent heat from locations at the repository center to locations at the perimeter of the repository area.

Neglecting this influence on the temperature distribution tends to maximize the temperature variability between the repository-center and repository-edge locations of emplacement drifts

4. The influence of mountain-scale buoyant gas-phase convection is neglected.

5 The influence of repository-scale lateral migration of condensate is neglected

6. Percolation flux is assumed to be steady rather than episodic

7. Drift-scale spatial variability in percolation-flux distribution is neglected (Note that repository-scale variability of percolation flux is included.)

8. The influence of coupled THMC processes is neglected

The second class of uncertainties includes

A Matrix hydrological properties that influence the magnitude of matrix imbibition have not been calibrated using data from imbibition or thermal tests It will be very useful to include imbibition data in the matrix property calibration process

B The tortuosity factor used to calculate binary gas-phase diffusion has not been based on data obtained from relevant tests It would be useful to utilize this data as it becomes available from the laboratory-scale coupled-processes experiments.

$C$ The magnitude and distribution of fracture porosity and permeability; these property values may be particularly important in analyzing the influence of the mineral cap when coupled THC models are included in the multi-scale TH modeling approach

\section{Future Work}

Future work will be conducted, iterating between model-abstraction testing and further developments to the model-abstraction methodology and process models used in the methodology Most of the items listed in the section on uncertainties will be analyzed during model-abstraction testing The major categories of future work include

- Developing a smeared-heat-source, mountain-scale TH (SMTH) model to replace the smeared-heat-source, mountain-scale T (SMT) model used in the multi-scale TH modeling approach. This model will be useful in testing items 4 and 5 above.

- Developing an east-west hybrid mountain-drift-scale TH model to test items 2-5

- Incorporating coupled THC versions of the line-heat-source, drift-scale TH (LDTH) models used in the multi-scale TH modeling approach These models will be useful in testing item 8 . 

- Developing more detailed drift-scale models to test items 6 and 7.

- Parameter sensitivity analysis of repository-scale percolation-flux distribution to test item 1

- Parameter sensitivity analysis of matrix and fracture hydrological parameters to test items A-C 



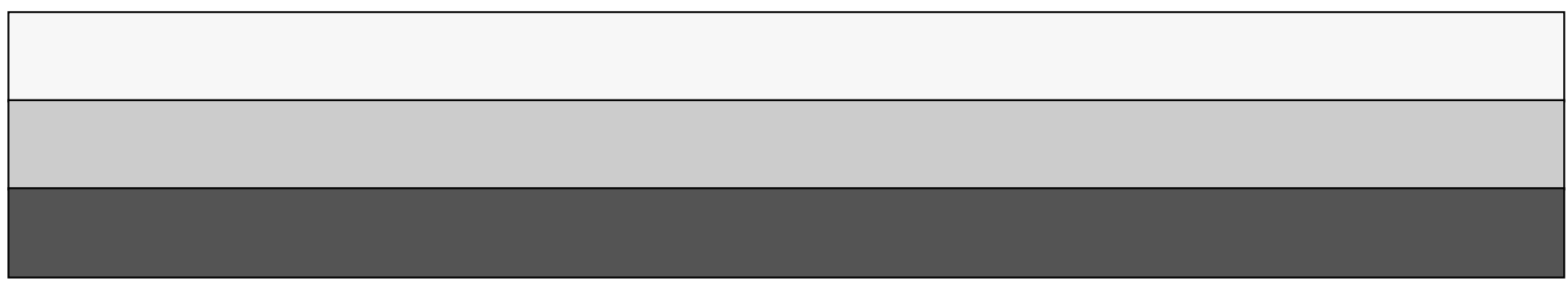

